\title{
1 Host genomic influence on bacterial composition in the switchgrass rhizosphere
}

2 Jeremy Sutherland [1,2], Terrence Bell [1,2,3], Ryan V. Trexler [3,4], John E. Carlson [2,4], Jesse R. Lasky [5]*

31 - Department of Plant Pathology and Environmental Microbiology, The Pennsylvania State University, University

4 Park, PA, USA

52 - Intercollege Graduate Degree Program in Bioinformatics and Genomics, The Pennsylvania State University,

6 University Park, PA, USA

73 - Intercollege Graduate Degree Program in Ecology, The Pennsylvania State University, University Park, PA,

8 USA

94 - Department of Ecosystem Science and Management, The Pennsylvania State University, University Park, PA,

10 USA

115 - Department of Biology, The Pennsylvania State University, University Park, PA, USA

12

13

14 *Corresponding author contact: 1-814-863-5318; jr135@psu.edu

15

16

17

18

19

20

21

22

23

24

25

26

27

28 Keywords: switchgrass, rhizosphere, microbiome, host genomic influence, heritability 
Abstract

31 Host genetic variation can shape the diversity and composition of associated microbiomes, which may reciprocally

32 influence host traits and performance. While the genetic basis of phenotypic diversity of plant populations in nature

33 has been studied, comparatively little research has investigated the genetics of host effects on their associated

34 microbiomes. Switchgrass (Panicum virgatum) is a highly outcrossing, perennial, grass species with substantial

35 locally adaptive diversity across its native North American range. Here, we compared 383 switchgrass accessions in

36 a common garden to determine the host genotypic influence on rhizosphere bacterial composition. We hypothesized

37 that the composition and diversity of rhizosphere bacterial assemblages would differentiate due to genotypic

38 differences between hosts (potentially due to root phenotypes and associated life history variation). We observed

39 higher alpha diversity of bacteria associated with upland ecotypes and tetraploids, compared to lowland ecotypes

40 and octoploids, respectively. Alpha diversity correlated negatively with flowering time and plant height, indicating

41 that bacterial composition varies along switchgrass life history axes. Narrow-sense heritability $\left(h^{2}\right)$ of the relative

42 abundance of twenty-one core bacterial families was observed. Overall compositional differences among tetraploids,

43 due to genetic variation, supports wide-spread genotypic influence on the rhizosphere microbiome. Lastly, a

44 genome-wide association study identified 1,861 single-nucleotide polymorphisms associated with 110 families and

45 genes containing them related to potential regulatory functions. Our findings suggest that switchgrass genomic and

46 life-history variation influences bacterial composition in the rhizosphere, potentially due to host adaptation to local

47 environments.

\section{Introduction}

Macroscopic organisms host diverse microbiomes, which often differ substantially among individuals

51 (Smith et al., 2015; Trivedi et al., 2020; Wilson et al., 2020). Some of the proximate causes of this variation in

52 microbiome composition arise from differences between host environments and traits, the latter of which can be

53 divided into genetic and plastic components. Host genetic differences can affect a wide range of traits that influence

54 associated microbiome composition, including traits that determine the supply of resources used by microbes or

55 traits that control environmental variables affecting microbial fitness in other ways (e.g. pH) (Lebeis et al., 2015;

56 Sasse et al., 2018). These host genetic influences on microbiomes may arise from different evolutionary processes. 
57 For example, host traits that affect microbiome composition may evolve neutrally or in response to non-microbial

58 components of the local environment (Zeng et al., 2015). Alternatively, host trait variation could have evolved as a

59 direct response to beneficial interactions with microbes in the environment (Gould et al., 2018). In the latter case,

60 hosts could either influence the abundance of microbes that are simply present in the environment, and functionally

61 important to the host, or hosts could form species or strain-specific symbiotic relationships where the host depends

62 on and influences the abundance of those taxa for reproductive success (Parker et al., 2006).

63 Because of environmental and dispersal limitations, the same microbes may not be present across the entire

64 range of a host, although functionally similar ones might be. It has been shown that reciprocal interactions between

65 host immune systems and host-associated microorganisms can lead to preferential recruitment of beneficial

66 microbial types and repel pathogenic types, to varying degrees (Hacquard et al., 2017; Jones et al., 2019). This

67 suggests that hosts might (directly or indirectly) select for functional microbial traits from certain lineages. Several

68 studies have observed the presence of 'core microbiota' - persistent members of the microbiome that appear across a

69 large portion of a host's population or species (Risely, 2020), but it is often unclear whether these microorganisms

70 are functionally important or commensal to the host. Yet, because microbial traits are often phylogenetically

71 conserved and host selection of microbes can occur in related microbial lineages (Lemanceau et al., 2017; Martiny et

72 al., 2015), a core microbiome might be preserved for higher taxonomic levels but undetectable for lower ones, at the

73 same occupancy frequency threshold. The study of diverse host genotypes and phenotypes in common environments

74 could reveal the genetic and host physiological drivers of variation in associated microbiomes and, potentially, types

75 of microbes that are functionally important to the host.

76 The demonstrated influence of host trait variation on microbial assemblages (Hestrin et al., 2021; Jones et

77 al., 2019; Wagner et al., 2016) suggests that microbiome composition can be treated as an extension of host

78 phenotype, one that may be under selective pressure by both the host and the environment (Bordenstein \& Theis,

79 2015; Hunter, 2018; Moran \& Sloan, 2015; Wagner et al., 2016; Whitham et al., 2003). Genome-wide association

80 studies (GWAS) have shown that the relationship between hosts and specific microbial taxa can be linked to single-

81 nucleotide polymorphisms (SNPs) (Beilsmith et al., 2019). However, at the microbiome level, it becomes

82 challenging to directly link host genotype and microbial composition, due to the high diversity and dimensionality of

83 microbiomes (Wray et al., 2013). Common garden experiments and genetic mapping offer a window into host 
84 genetic impacts on host-associated microbial composition. The resolution of association mapping can be improved

85 by exploiting high levels of genomic diversity within and between populations (Holland, 2007). Switchgrass (Panicum virgatum) is a C4 perennial grass species that has been extensively studied as a

87 bioenergy crop since 2005 (Bouton, 2007; McLaughlin \& Kszos, 2005; Parrish \& Fike, 2005; Sanderson et al.,

88 2006). Unlike first generation biofuels, switchgrass can be grown on marginal land with minimal inputs while also

89 providing ecological services (e.g. wildlife habitat and soil erosion mitigation) (Werling et al., 2014). In addition to

90 its ecological and agricultural value, switchgrass provides an ideal system for studying the influence of host

91 genotypic diversity on rhizosphere bacterial composition (i.e., bacteria living on or in close proximity to the root

92 system of the plant) because of the high degree of genotypic diversity in the species.

93 Switchgrass is primarily an outcrossing species with high genetic diversity within populations, showing

94 evidence of inbreeding depression, which increases heterozygosity in the genome (Sharma et al., 2012). The species

95 is comprised of two locally-adapted ecotypes, upland and lowland, based on differences in phenotype, physiology,

96 and habitat (Das et al., 2004). Separate migration events fostered by interglacial periods, in addition to gene

97 duplication through polyploidization, have also played a major role in shaping the genomic diversity of switchgrass

98 (Casler et al., 2015). Lowland switchgrass is primarily allotetraploid (4X: $n=36)$ and exhibits disomic inheritance

99 - chromosome inheritance that follows diploid association patterns. Upland accessions tend to vary in their ploidy

100 level (4X: $\mathrm{n}=36,6 \mathrm{X}: \mathrm{n}=54,8 \mathrm{X}: \mathrm{n}=72)$ and exhibit widespread aneuploidy between and within localized

101 populations (Costich et al., 2010). Additionally, populations of switchgrass are adapted to local climate conditions

102 and linkage mapping suggests a polygenic basis to this local adaptation (Lowry et al., 2019). Here, we studied

103 genotypes largely from the geographically Northeastern, upper Southern, and Midwestern United States that can be

104 genetically clustered into five groups (roughly North, South, East, West, and Northeast, with some geographic

105 overlap) (Supplemental Figure 1) (Lu et al., 2013). Genetic variation in switchgrass has been linked to measures of

106 plant fitness and performance, including biomass production (Lowry et al., 2019) and soil carbon inputs (Adkins et

107 al., 2016; Stewart et al., 2017). While substantial research has explored the switchgrass microbiome, key gaps

108 remain, including the functional role of non-fungal microorganisms and host mechanisms that underly switchgrass-

109 microbiome interactions (Hestrin et al., 2021).

110 Vascular plants influence microbes in the rhizosphere through rhizodeposits (Dennis et al., 2010) and

111 carbon-based root exudates (Compant et al., 2010; Hu et al., 2018; Yu \& Hochholdinger, 2018). Root exudates 
112 provide signaling and substrate compounds for beneficial microbial recruitment (Carvalhais et al., 2013;

113 Lakshmanan et al., 2012), and antibiotic compounds that defensively modulate the microbiome composition against

114 pathogenic taxa (Baetz \& Martinoia, 2014; Lebeis et al., 2015). When available, root exudates potentially represent

115 a larger portion of carbon in the soil compared to other carbon inputs from the environment (e.g. leaf litter)

116 (Heijboer et al., 2018). Switchgrass can benefit from a range of microbes that are influenced by root exudates

117 (Hestrin et al., 2021).

118 In this study, we analyzed bacterial 16S rRNA gene sequences from total DNA extracted from rhizosphere

119 soil samples for 383 switchgrass accessions from 63 local populations planted within a common garden in Ithaca,

120 NY, USA. Our aim was to better understand the influence of switchgrass genotype on the composition of bacteria in

121 the rhizosphere. We hypothesized that overall bacterial composition and diversity within the growing site would

122 differentiate due to host genetic variation along the three dimensions of switchgrass genetic diversity (ecotype,

123 ploidy level, and genetic cluster), as is true for multiple fitness-related traits (Lovell et al., 2021). Separately,

124 bacteria experience higher rates of gene loss, horizontal gene transfer, and shorter generation times compared to

125 their hosts. So, microbial specialization on a given host can be evolutionarily fast compared to changes in the plant

126 community (Bever et al., 2012). Given that the evolutionary response rate is mismatched between switchgrass

127 genotypes and their microbiomes, we sought to determine the lowest taxonomic level for which a potential host

128 influence could be detected. We show that switchgrass genotype influences bacteria in the rhizosphere at, at least,

129 the family level. Our findings demonstrate how plant host genotype can influence host-associated microbiomes, the

130 taxonomic level at which the microbiome is influenced, and the host genetic architecture involved.

132 Materials and Methods

\section{Switchgrass Germplasm Data}

Previously, exome capture sequencing was used to characterize variation in the genic regions of the

135 genome from the Northern Switchgrass Association Panel used in this study $(n=537)$ (Evans et al., 2018). For this

136 study, the HapMapv2 matrix was obtained from the Dryad Digital Repository (10.5061/dryad.mp6cp) in 2019.

137 Several modifications were made to the original dataset. The dataset was modified in python (G. Van Rossum \&

138 Drake, 2009) to reflect heterozygote positions more conservatively than the original, unfiltered, dataset, such that

139 heterozygote positions with read count ratios greater than 0.75 or less than 0.25 were called homozygous relative to 
the appropriate allele (e.g. $\mathrm{A}(20) / \mathrm{T}(1)=\mathrm{A})$. SNPs with a minor-allele frequency (MAF) below 0.05 were excluded,

141 resulting in 103,776 SNPs for all genotypes studied here $(n=362)$ spanning eighteen chromosomes: Chr01- 09

142 (subgenomes a and b) of the v1.1 P. virgatum reference genome (www.phytozome.net) and fifteen unanchored

143 scaffolds (Evans et al., 2018). The unanchored scaffolds of Evans et al. (2018) were renamed to the corresponding

144 contig names within the v1.1 reference genome using python. Phylogenetic tree generated in Tassel v5 (Bradbury et

145 al., 2007).

146 We compared bacterial composition to published data on several important switchgrass functional and life

147 history traits, using data from 2009, 2010, and 2011 field seasons at the common garden in Ithaca, NY (genetic

148 variation in these traits is largely consistent from year to year) (Lipka et al., 2014). The 2011 measurements for

149 anthesis date and full plant height were used to identify correlations with rhizosphere alpha diversity present in

1502016.

152 Rhizosphere sampling of switchgrass accessions

153 The original switchgrass association panel consisted of 3-10 clonally propagated individuals each from 66

154 discrete switchgrass local populations grown from seed in the greenhouse of the USDA-ARS Dairy Forage Research

155 Center in Madison WI in 2007 (Lu et al., 2013). The accessions were sourced from much of the natural range of

156 switchgrass in the eastern and midwestern United States. Young plants were deposited in the common garden in

157 Ithaca, NY, USA in 2008. In 2016, plugs were collected for transplanting from 525 cloned accessions, representing

158 all but two (perished) original populations. Prior to replanting the plugs, soil samples were collected into a

159 polythene bag from each of the switchgrass accessions by vigorously shaking off soil attached to the roots. The bags

160 with soil and fine roots were initially stored at $4{ }^{\circ} \mathrm{C}$ while being processed - each soil sample was thoroughly mixed

161 into a uniform distribution and then transferred to $50 \mathrm{ml}$ conical cryogenic tubes and stored at $-80^{\circ} \mathrm{C}$ prior to soil

162 DNA extraction.

\section{Soil DNA extractions}

165 To determine the composition of bacteria established in the switchgrass rhizosphere, we selected soil 166 samples from 383 of the 525 cloned switchgrass accessions, based on a phylogenetically determined set of clones 167 from 63 of the local populations in the association panel. Total DNA was extracted from $~ 300 \mathrm{mg}$ of soil using the 
168 NucleoSpin Soil 96 kit (Macherey-Nagel, Düren, Germany). Lysis was performed using the Buffer SL with

169 Enhancer SX, and was performed on the FastPrep 24 homogenizer (MP Biomedicals, Santa Ana, CA, USA) at 4.0

$170 \mathrm{~m} / \mathrm{s}$ for $30 \mathrm{~s}$.

Amplicon Sequencing

173 Briefly, amplicons targeting the V3-V4 region of the 16S rRNA gene were generated from all 383 samples

174 using universal bacterial primers 515F (5'-GTGYCAGCMGCCGCGGTAA-3') and 806R (5'-

175 GGaCTACNVGGGTWTCTAAT-3') (Apprill, Mcnally, Parsons, \& Weber, 2015; Parada, Needham, \& Fuhrman,

176 2016) with overhangs for attaching barcodes and standard Illumina overhang adaptors in a second PCR step (full

177 protocol outlined in the supplemental methods of Trexler \& Bell (2019)). Sequencing was performed on an Illumina

178 MiSeq using the $2 \times 250$ cycle v2 kit. Raw reads are available through NCBI SRA under project number

179 PRJNA689762.

\section{Amplicon sequence analysis pipeline}

The raw 16S rRNA gene sequences were analyzed using an adapted version of the dada2 pipeline

183 (Callahan et al., 2016). dada2 was used to process the raw sequences into Amplicon Sequence Variants (ASVs).

184 Reads were truncated above 240 bp and below 160 bp. Sequences with any missing reads after truncation were

185 discarded. Reads were then truncated at the first instance of a quality score less than 2. After truncation, reads that

186 matched against the phiX Genome were discarded. Reads with higher than two "expected errors" were also

187 discarded. Expected errors are calculated from the nominal definition of the quality score: $\mathrm{EE}=\operatorname{sum}\left(10^{(-\mathrm{Q} / 10)}\right)$.

188 Filtered sequences were used to determine the error rate using the dada2 function: learnErrors(). The filtered

189 sequences were then processed with the core sample inference algorithm, dada(), incorporating the learned error

190 rates. Forward and reverse sequence reads were then merged. A sequence table was made and chimeras were

191 removed using the "consensus" method. Taxonomic assignments for the ASVs were defined against the SILVA 138

192 ribosomal RNA gene database (Quast et al., n.d.) using DECIPHER v2.14.0 (Wright, n.d.). The sequence variant

193 table and taxonomy table were exported for downstream processing in phyloseq (McMurdie \& Holmes, 2013).

In phyloseq, ASVs designated "NA" at the phylum level, non-Bacterial entries at the domain level, and

195 those associated to chloroplasts and mitochondria were removed from the taxonomy file before further processing. 
Finally, we also removed samples with no ASVs remaining after pruning. Rarefying samples has been shown to

197 effectively reduce false discovery rates when there are large differences between the average sample library size

198 (Weiss et al., 2017). Our data was characteristic of this scenario. Therefore, we rarefied samples to 1000 sequences, 199 to retain as many samples as possible while also maintaining a sufficient sampling depth to detect the most prevalent 200 taxa comprising the switchgrass core microbiome (See below).

\section{Alpha diversity analysis}

Using the rarefied ASV dataset, we generated alpha diversity metrics using phyloseq (McMurdie \&

204 Holmes, 2013). Statistical significance was calculated using the vegan 2.5.6 package (Oksanen et al., 2019), and

205 other core functions in R version 3.6.3 (Ihaka \& Gentleman, 1996). The Chao1 and Shannon diversity indices were

206 calculated using the estimate_richness() function in phyloseq and then used to test for differences in alpha diversity

207 between genotypes differing in ecotype, ploidy level, and genetic cluster groups using an analysis of variance

208 (ANOVA) (R version 3.6.3). Correlations between diversity metrics, anthesis date and full plant height were

209 generated using the Pearson correlation test.

\section{Beta diversity and core microbiome analysis}

Bacterial diversity data rarely conform to the assumptions of MANOVA-like procedures, largely due to

213 inflated zero values among rare taxa that skew the distribution, thus non-parametric methods based on permutation

214 tests are preferred (M. J. Anderson, 2001). A non-parametric, one-way analysis of variance (NPMANOVA) is also

215 tolerant of non-independent observations (e.g. microbe-microbe interactions). We therefore calculated an

216 NPMANOVA using the adonis2 function in vegan to test for significant differences between the ecotype, ploidy

217 level, and genetic cluster groups on the overall rhizosphere microbiome composition using pairwise Bray-Curtis

218 distances at the ASV level.

The 'core microbiome' can be defined as microbial taxa that associate with a host above a particular

220 occupancy frequency threshold (i.e. their prevalence). Biological justifications for such thresholds tend to be

221 subjective, often ranging between $30 \%$ and 95\% (Risely, 2020). However, core taxa prevalence within a population

222 could be a reflection of an environmental response by the host due to local adaptation, resulting in higher intergroup

223 prevalence of certain 'core taxa' relative to the whole population. Thus, we determined two core microbiomes: A 
224 high-fidelity core (prevalence $>=90 \%$ ), to determine taxa that reliably associate with the vast majority of our panel,

225 and a low-fidelity core (prevalence $>=10 \%$ ), to study host genetic variation effects on bacterial composition. Taxa

226 present within our rarefied dataset were initially agglomerated using the tax_glom() function at all taxonomic levels

227 in phyloseq. Sample counts were then transformed to relative abundances. A filter was applied to subset

228 phylogenetic groups in abundance greater than $2 \%$. Each core microbiome was determined using the microbiome

229 package in R (Lahti, Shetty, \& Blake, 2017). The core() function in the microbiome package (detection = 0,

230 prevalence $=0.9$ and 0.1 , respectively) was applied at each taxonomic level to determine the core taxa among all

231 genotypes.

\section{Heritability Estimates}

Heritability is an estimate that describes the proportion of phenotypic variance that is due to genetic

235 variance. Narrow-sense SNP-based heritability $\left(h^{2}\right)$ was estimated using the sommer package in R as: $\sigma_{A}^{2} / \sigma_{p}^{2}$, where

$236 \sigma_{A}^{2}$ is the additive variance and $\sigma_{p}^{2}$ is the total phenotypic variance (additive + dominance) (Covarrubias-Pazaran,

237 2016). The core function of the sommer package is the 'mmer' function that fits multivariate linear mixed models.

238 The modified exome capture SNP dataset, described above, was used to generate a kinship matrix used in 'mmer' to

239 estimate narrow-sense heritability for each of bacterial families' abundance. The sommer package includes a

240 tolerance parameter for the matrix inverse when singularities are encountered in the estimation procedure. Here,

241 inversion tolerance parameters were adjusted to 10 to avoid model singularity.

\section{Redundancy Analysis (RDA) and variance partitioning}

To determine how whole microbiome variation changed across host genomic variation, much of which is

due to population structure, we implemented redundancy analysis (RDA). RDA models variation in a set of

246 response variables as a function of a set of explanatory variables. We used the first 10 principal components of

247 switchgrass SNPs (Evans et al. 2014) as explanatory variables that describe population structure in switchgrass

248 (Brown, Bray, \& Pachter, 2018) and log-scaled ASV counts for each switchgrass genotype as the response variables.

249 We performed the RDA to explain the relative proportion of total genotypic variance on the overall microbiome

250 composition. The rda() function in vegan (Oksanen et al., 2019) was used to perform the RDA for the tetraploid

251 accessions. For host genomic analyses like this RDA, we focused on tetraploids; since they (1) represent both upland 
252 and lowland ecotypes, (2) exhibit disomic inheritance unlike octoploids, and (3) exhibit more inter-group alpha 253 diversity variation compared to octoploids.

254 We identified outlier ASVs with the strongest loadings, based on inter-quartile range criteria, on the first 255 two RDA canonical axes; these ASVs are those most representative of microbiome-wide turnover across 256 switchgrass hosts of different genomic background. ASVs that were labeled as outliers were then assigned 257 taxonomic rank using the phyloseq method described above and compared to families in the original ASV dataset.

To dissect how genomic variation combined with ecotype, ploidy, and phenotypes to explain bacterial compositional turnover we also implemented variance partitioning of the RDA. Variance partitioning allows one to estimate the portions of compositional turnover explained by multiple sets of factors (Peres-Neto et al., 2006), which

261 here were the first 10 principal components of SNPs, ecotype, geography-of-origin (latitude, longitude, and their squared values), and our two focal phenotypes (anthesis date and height). We implemented two versions of variance partitioning with RDA: one on ASV counts and the other on family abundances, to test whether family-level composition was differently associated with these factors than was ASV level composition.

\section{Genome-wide association study (GWAS)}

To identify specific loci in the switchgrass genome linked to variation in rhizosphere bacterial composition, a genome-wide association study (GWAS) was conducted using the statgenGWAS package in R (Rossum et al.,

269 2020). This fast single trait GWAS method was developed by Biometris, following the method described in Kang et. 270 al (2010). The modified SNP dataset, described above, was once again used for this analysis.

272 and a chromosome positional map (2) was generated from the SNP matrix (3). These three components were used to 273 construct the R object used by statgenGWAS. Initial results from the heritability estimates and RDA indicated that 274 certain core families of bacteria were influenced by switchgrass genotype. Therefore, to determine associated genes,

275 a single trait GWAS, where the trait was the abundance of each of the families, was completed using a Generalized 276 Least Squares (GLS) method for estimating the marker effects and corresponding p-values. Our GWAS included 277 random effects correlated according to the kinship matrix, which was calculated with the VanRaden method 278 (VanRaden, 2008). A p-value threshold is required for this method to minimize the False Discovery Rate (FDR) 279 following the algorithm proposed by Brzyski et al. (2017). The method limits the number of SNPs in statistical 
280 linkage with each other passing FDR control. Significant SNPs were identified using a 0.01 threshold for the false-

281 discovery rate (FDR). Linkage disequilibrium (LD) in switchgrass decays over kilobase length. Following

282 Grabowski et al. (2017), we used a window of $25 \mathrm{~kb}$ to identify genes potentially linked to significant SNPs. Thus, in

283 this study, we defined SNPs within $25 \mathrm{~kb}$ as being "within LD of significant SNPs". For each trait, statgenGWAS

284 outputs significant SNPs and SNPs within the defined cutoff. A full description of the method can be found in

285 Rossum et al. (2020).

\section{GO Enrichment Analysis}

Significant SNPs associated with bacterial family abundance and positions within $25 \mathrm{~kb}$ of significant SNPs were then used to identify associated genes and gene ontologies. Here, we focused on three families:

290 Xanthobacteraceae, Sphingomonadaceae, and Micromonosporaceae. The Xanthobacteraceae and

291 Sphingomonadaceae families were chosen because they represent the high-fidelity core microbiome.

292 Micromonosporaceae was chosen due to its high relative heritability within our panel and its importance in 293 agriculture applications (Trujillo, Hong, \& Genilloud, 2014). Phytomine was used to identify Gene IDs for each

294 family using the P. virgatum v1.1 reference genome at www.phytozome.net. Gene IDs for corresponding SNPs were 295 then used to perform a Singular Enrichment Analysis (SEA) against the gene ID (ver. 4) background for P. virgatum 296 using the agrigo v2 web program (Du, Zhou, Ling, Zhang, \& Su, 2010). Default parameters were used.

298 Results

299 Amplicon Sequence Analysis

For 383 initial rhizosphere soil samples, 96,902 amplicon sequences variants (ASVs) were obtained

301 following initial quality filtering and sequence processing in dada2 (Callahan et al., n.d.). After sample pruning 302 (removing non-bacteria from the taxonomy table) and rarefaction (1,000 sequences/sample) in phyloseq, 365 303 samples containing 31,181 ASVs remained. Counts for unique phylogenetic classifications are as follows: Domain: 304 1, Phylum: 26, Class: 59, Order: 142, Family: 268, Genus: 510. 
We detected significant differences in alpha diversity (Chao1 and Shannon Diversity) between groups. Upland ecotypes, which are adapted to regions at higher latitudes and those geographically closer to our growing site, exhibited higher rhizosphere diversity compared to lowland ecotypes (Figure 1A, Upland-Lowland: p.adj $($ Shannon $\left.)=1.58 \mathrm{e}^{-2}\right)$. Tetraploids, which are present in both upland and lowland ecotype groups, also exhibited higher diversity overall, compared to octoploids, which are exclusively upland (Figure 1B, 4X-8X: p.adj (Shannon)

$312=<0.001$ ). Finally, the North genetic cluster, primarily comprised of upland tetraploids, exhibited the highest 313 rhizosphere diversity among all of the genetic clusters and there was a significant difference between the East and 314 West genetic clusters (Figure 1C, North-East: p.adj (Shannon) $=<0.001$, North-West: p.adj $($ Shannon $)=<0.001$,

315 North-Northeast: .adj $($ Shannon $)=<0.001$, North-South: p.adj $($ Shannon $)=<0.001$, East-West: . adj $($ Shannon $)=$ $3165.92 \mathrm{e}^{-2}$ ). All diversity measurements for accessions can be found in Supplemental Table 1. 0.17, $\mathrm{p}$-value $=0.0014$; Shannon: $r=-0.18, \mathrm{p}$-value $=<0.001)$ and full plant height $($ Chao1: $r=-0.18, \mathrm{p}$-value $=$ 0.0012; Shannon: $r=-0.13$, p-value $=0.017$ ). We also considered these trait-diversity associations stratified by ecotype, ploidy, and genetic cluster (Figure 2). In general, the negative diversity association with anthesis date and height was broadly consistent, with Shannon diversity negatively correlated with plant height for Upland ecotypes $(r$ $=-0.25, \mathrm{p}$-value $=<0.001)$, octoploids $(r=-0.23, \mathrm{p}$-value $=0.0045)$, hybrids $(r=-0.73, \mathrm{p}$-value $=0.016)$, the North genetic cluster $(r=-0.27$, p-value $=0.011)$, the Northeast genetic cluster $(r=-0.22$, p-value $=0.061)$, and the West genetic cluster $(r=-0.24, \mathrm{p}$-value $=0.032)($ Figure 2A,B,C). Likewise, Shannon diversity negatively correlated with anthesis date for Upland ecotypes $(r=-0.19$, p-value $=0.002)$, tetraploids $(r=-0.23$, p-value $=0.0025)$, hybrids $(r=$

$327(n=7)$ of ecotype/ploidy/genetic cluster combinations showed positive trait correlations with Shannon diversity, but 328 these were not significant.

\section{Beta diversity analysis}

We performed separate multivariate analyses of variance on a Bray-Curtis distance matrix using the

333 0.001), ploidy levels $(p<0.001)$, and genetic clusters $(p<0.001)$, indicating differences in overall composition 334 associated with switchgrass genetics and life-history. 
Although all taxonomic levels were tested, the family level was identified as the lowest taxonomic rank with the ability to retain a high-fidelity core (Supplemental Figure 2). The high-fidelity core microbiome (>=90\% of samples) contained two families: Xanthobacteraceae and Sphingomonadaceae. The low-fidelity core microbiome (>=10\% of samples) contained 110 families (Supplemental Table 2).

Host Genomic Influence

Of the 110 families in the core microbiome, twenty-one showed narrow-sense SNP-based heritability $\left(h^{2}\right)$ and there is considerable uncertainty in the estimate overall (Furlotte, Heckerman, \& Lippert, 2014). Therefore, we consider estimates with standard errors that do not intersect zero as showing evidence of heritability (i.e. heritable). Heritability estimates for low-fidelity core taxa in the switchgrass rhizosphere ranged from 0.106 to 0.539 , with a mean of 0.241 . Heritability estimates presented here for bacterial lineages have a range similar to that of corn and sorghum (Deng et al., 2021). The heritability estimates indicate that, in part, switchgrass genotype influences the variability in the relative abundance of certain families within our growing site. Heritability estimates for all bacterial families can be found in Supplemental Table 2.

352 results indicate that genotypic variability among tetraploids (i.e. first 10 PCs of SNPs) had modest influences on

353 bacterial ASV composition $\left(R^{2}=0.063, R_{\text {adjusted }}^{2}=0.007\right)$. Switchgrass SNP PC1, which is associated with

354 separation between the North and the Northeast and South genetic clusters, loaded most strongly to the first primary

355 canonical axis (RDA1, PC1 = 0.99, the next strongest loaded PC was PC10, with a 0.097 loading). Switchgrass SNP

356 PC7, which is associated the variance in the North genetic cluster, loaded most strongly to the second canonical axis

357 (RDA2, PC7 = 0.899). The proportion of explained variance in bacterial ASV composition was fairly low along

358 these individual canonical axes (RDA1 $=0.9 \%$, RDA2 $=0.7 \%$ ), which was unsurprising given the large diversity in

359 the bacterial composition. Still, the RDA identified bacterial ASV compositional turnover in association with

360 switchgrass population structure, as shown by the turnover between the North and the Northeast and South

361 switchgrass genetic clusters (Figure 4). 
Outlier ASVs were determined for each of the first two canonical RDA axes $(n=9,215)$. These outlier ASVs are most representative of the variation in bacterial composition among the tetraploid genotypes. We then

364 identified the taxonomic ranks for the outlier ASVs. Our results show that Xanthobacteraceae and 365 Sphingomonadaceae represent the high-fidelity core for both the outlier ASV dataset and the original ASV dataset, 366 signifying host genotypic influence might be strongest on these families. When we consider the low-fidelity core (n $367=110$ families), $70.9 \%$ of families in the RDA outlier ASV core microbiome are in original core microbiome 368 (Supplemental Table 2). When we consider just the heritable families, $80.95 \%$ of heritable families in the outlier ASV core microbiome are in the original core microbiome (Supplemental Table 2).

371 explained by SNP PCs, ecotype, geographic origin (i.e. latitude and longitude coordinates), and the two phenotypes,

372 we found that the total $R_{\text {adjusted }}^{2}$ was low, approximately $\% 1$ of ASV composition. However, variance partitioning of 373 family-level turnover found these 4 factors explained a larger portion, with $R_{\text {adjusted }}^{2} 0.096$ (Figure 4). This variance 374 partitioning found that the largest portion of bacterial compositional variation was explained by the collinear portion 375 of SNP PCs, ecotype, and geographic origin $\left(\mathrm{R}_{\text {adjusted }}^{2}=0.0866\right)$, suggesting that geographic population structure 376 associated with ecotypic variation explains a large portion of turnover in bacterial family composition.

\section{Genome-wide association study}

379 A primary limitation of heritability estimates and the RDA was that we could not account for which SNPs 380 have the greatest effect on compositional variation. To overcome this, a genome-wide association study (GWAS)

381 was conducted to identify specific loci associated with the relative abundance of families in the core microbiome. In 382 total, 1,861 SNPs were found to be associated with the abundance of the 110 tested core families. 878 SNPs were 383 found to be associated with the abundance of the 21 heritable core families. Furthermore, 36 SNPs were found to be 384 associated with the abundance of the two families (Xanthobacteraceae and Sphingomonadaceae) that represent the 385 high-fidelity core microbiome (Figure 6, Supplemental Table 2).

\section{GO Enrichment Analysis}

Despite the general difficulty identifying specific molecular functions or pathways in non-model plant 389 species, resources for gene ontology (GO) still remain useful for biological inference (Tian et al., 2017). Therefore, 
we completed a GO enrichment analysis for genes harboring significant SNPs and positions within $25 \mathrm{~kb}$ of significant SNPs to determine possible cellular processes $(\mathrm{P})$, cellular components $(\mathrm{C})$, and molecular functions $(\mathrm{F})$ associated with three core family abundances (Supplemental Table 3). Primarily, we identified two types of cellular processes: metabolic and stimuli response processes. Broadly, we identified several molecular functions relating to ATPase activity, hydrolase activity, and pyrophosphatase activity (Supplemental Figure 4, Supplemental Table 3). Functions involving ATP hydrolysis as an energy source either typically catalyze a reaction or drive membrane transport against a concentration gradient (Berg, Tymoczko, \& Stryer, 2002). In the context of our GWAS, this could suggest possible root exudate activity whereby switchgrass genotypes differentially transport exudates against a lower soil compound gradient influencing core family abundances. Perturbing these regions in future studies could reveal the underlying pathways and mechanisms. Lastly, genes harboring SNPs associated with Sphingomonadaceae abundance, in particular, were enriched for GO terms associated with cellular membrane components,

401 metallopeptidase and metalloendopeptidase activity, and cellular processes that relate to metabolism and response to

402 stimuli (Supplemental Table 3). Again, given the context of our GWAS, we suspect that the genes associated with

403 these GO terms could interact with Sphingomonadaceae populations in the soil. More work involving these genes 404 could expose perturbations that more predictably affect Sphingomonadaceae abundance in switchgrass.

\section{Discussion}

Macroscopic organisms often exhibit striking variation among individuals in the microbial assemblages

408 they host, but the genetic basis and ecological relevance of this variation is often unclear. Common garden 409 experiments with diverse genotypes offer a powerful window into dissecting the ecological genomics of host

410 influences on their microbiomes. Previous studies have demonstrated that genomic differences among switchgrass

411 genotypes and populations may, in part, have led to much of the adaptive phenotypic differences observed between

412 switchgrass populations (Adkins et al., 2016; Lowry et al., 2019). We add to these observations by showing a similar

413 phenomenon within a less visible portion of the switchgrass phenotype. We found that switchgrass genotype

414 influences the rhizosphere microbiome in a variety of ways relative to bacterial alpha and beta diversity as a result of 415 variability within the switchgrass genome.

416 We demonstrated that the alpha diversity (Chao1 and Shannon diversity) of rhizosphere bacteria within a 417 common garden was significantly differentiated between switchgrass ecotypes, ploidy levels, and genetic clusters. 
418 These groupings with distinct bacterial assemblages are associated with life history variation and locally-adapted

419 traits in this species. Furthermore, alpha diversity within each group typically had no correlation with, or was

420 negatively correlated with, anthesis date and plant height (Figure 2). Flowering time is an important adaptation to

421 local growing conditions and has major fitness consequences for the plant (Grabowski et al., 2017b). In general, in

422 common garden experiments, upland ecotypes have an anthesis date 2-4 weeks earlier than lowland ecotypes

423 (Schwartz \& Amasino, 2013). As plants move through different developmental stages the diversity and availability

424 of metabolites influencing the rhizosphere microbiome shifts (Wagner, 2021). Rhizosphere sampling in this study

425 occurred in May, 2016. Therefore, it's reasonable to expect genotypes at different stages of development at the time

426 of sampling to exert different selective pressure on the microbiome composition. Future research examining

427 temporal exudate availability in the rhizosphere of switchgrass could expand on this hypothesis.

428 It is already widely hypothesized that hosts mediate their microbiomes relative to environmental

429 conditions, resource availability, and microbial function, not necessarily always a specific species or strain

430 (Lemanceau et al., 2017; Martiny et al., 2015). Thus, some basis for comparing taxa between host groupings

431 becomes important when determining the taxonomic level at which host influence is detectable. A "core"

432 microbiome can be defined in a variety of ways, and may not represent microbes that have the most important

433 functional impacts on a system (Bell \& Bell, 2021). For example, commensal microorganisms remain widespread

434 throughout host populations (Zeng et al., 2015). Still, the consistent occurrence of microbial taxa provides an

435 opportunity to assess relationships between host genetics and microbial recruitment. Here, we applied the "common

436 core" concept (Risely, 2020) to identify bacterial taxa that were consistently associated with diverse switchgrass

437 genotypes in a common garden. Given the disparity in evolutionary pace (i.e. there are many bacterial generations

438 during the lifecycle of a switchgrass plant), it is unlikely that switchgrass has mechanisms to distinguish between

439 closely related bacterial taxa unless doing so provided a substantial fitness advantage (Yin et al., 2021). Therefore,

440 the core microbiome provides both a basis for measuring bacterial abundance across multiple switchgrass genotypes

441 as well as a means to detect host genomic influence at the lowest possible taxonomic rank.

442 For example, Singer et al. (2019) observed a large core endophytic switchgrass microbiome dominated by

443 root-colonizing bacterial genera such as Streptomyces, Pseudomonas, and Bradyrhizobium, while rhizosphere

444 diversity was more variable between their two sampling sites. Likewise, Singer et al. (2019b) observed different

445 core bacterial classes associated with upland and lowland switchgrass ecotypes, with each ecotype preferentially 
enriched for Alphaproteobacteria and Actinobacteria, respectively. For our study, out of 268 families, only two

447 associated with the majority (>=90\%) of our rhizosphere samples (Xanthobacteraceae and Sphingomonadaceae) and

448 less than half $(n=110)$ associated with more than $10 \%$ of our samples. Xanthobacteraceae and Sphingomonadaceae

449 are families in the Alphaproteobacteria class. We were unable to detect any genera or species associated with our

450 genotypes at the $90 \%$ occupancy threshold. This indicates that a large swath of the switchgrass rhizosphere

451 microbiome assembly is stochastic and only certain lineages were able to consistently associate with our genotypes

452 in the common garden.

453 The abundance of twenty-one of the 110 families were determined to show evidence of heritability. After

454 reasonably establishing heritability of select core families, the RDA allowed us to identify how genome-wide

455 variation in switchgrass influenced the rhizosphere microbiome composition. RDA methods used in microbial

456 ecology typically explain the variance in microbiome composition due to environmental variables, such as

457 temperature or pH (Paliy \& Shankar, 2016). However, here, we modeled microbial compositional data as a function

458 of host genomic data. As such, the RDA in this study represents the compositional variance of the microbiome due

459 to genetic variation in the hosts. We then extended the analysis to explore outlier ASVs along each of the first two

460 RDA axes, because those ASVs represent taxa associated with host genomic influence on overall turnover in

461 bacterial composition. Once clustered at the family level, we determined that seventeen out of the 21 heritable

462 families were in the outlier ASV dataset. Additionally, the results of the variance partitioning suggest that

463 geographic population structure associated with ecotypic variation explains a larger portion of turnover in bacterial

464 family composition compared to ASV composition. Thus, we determined that genotypic variability in switchgrass

465 sampled from across its natural range influences the composition of the rhizosphere bacterial microbiome,

466 particularly for tetraploids.

467 The ecophysiology of host-microbe interactions in our study is unclear, requiring detailed investigation, but

468 there may be hints in the function of switchgrass genes that are strongly associated with core family abundances. We

469 conducted a GWAS to identify potential loci that strongly associate with core family abundances. The outcrossing

470 nature of switchgrass and its rapid decay in LD can help pinpoint causal loci with GWAS. Several considerations

471 had to be made though, in order to reliably trust the significance of the resulting QTLs. First, we considered only

472 tetraploids for the same reasons as the RDA, that they (1) represent both upland and lowland ecotypes, (2) exhibit

473 disomic inheritance unlike octoploids, increasing the effect size of additive effects, and (3) exhibit the most inter- 
474 group alpha diversity variation compared to octoploids or hybrids. We used exome capture SNPs (Evans et. al.

475 (2018), which are more effective than genotype-by-sequencing (GBS) in their ability to tag causal polymorphisms,

476 compared to GBS SNPs that are often far from any genes (Kaur et al., 2014). The identification of genes containing

477 significant SNPs could provide insights into potential host-microbe interaction pathways. To explore this

478 relationship further, we chose to focus on three core families: Xanthobacteraceae, Sphingomonadaceae, and

479 Micromonosporaceae.

We identified hundreds of switchgrass genes containing SNPs (including those within $25 \mathrm{~kb}$ of significant SNPs) associated with Micromonosporaceae $(\mathrm{n}=315)$, Xanthobacteraceae $(\mathrm{n}=578)$, and Sphingomonadaceae $(\mathrm{n}=$

482 718) abundance in the rhizosphere. Many species within the Micromonosporaceae family degrade chitin, cellulose,

483 lignin, and pectin, and play an important role in the turnover of organic plant material. Moreover, many strains

484 produce useful secondary metabolites and enzymes used by plants (Trujillo et al., 2014). Members of

485 Xanthobacteraceae have been experimentally identified as nitrate reducers (C. R. Anderson et al., 2011) and

486 therefore their regulation could be important to host metabolic activity. Our GO enrichment analysis indicates that

487 genes associated with Micromonosporaceae and Xanthobacteraceae abundance are involved in hydrolase,

488 pyrophosphatase, and ATPase activity suggesting that the enrichment for this set of genes plays an important role in

489 overall plant fitness. Members of the Sphingomonadaceae family are known to be antagonistic against plant

490 pathogens and induce plant growth promotion (Glaeser \& Kämpfer, 2014). GO terms for genes associated with this

491 family are enriched for metallopeptidase and metalloendopeptidase activity, membrane cellular components, and

492 processes involved in stimuli response. Altogether, this suggests that the activity of these genes is linked to

493 environmental stimuli, possibly initiated by Sphingomonadaceae, and interacting with plant cell membranes. Future

494 work examining these families could make these connections to plant function more robust.

495 In conclusion, bacterial composition in the switchgrass rhizosphere is influenced by host genotypic

496 variability. Rhizosphere diversity shows major differences among switchgrass ecotypes, ploidy levels, genetic

497 clusters, and life-history axes. In particular, the North switchgrass genetic cluster was most distinct at our common

498 garden site. Two high-fidelity core families, Xanthobacteraceae and Sphingomonadaceae, were observed across the 499 majority of our switchgrass genotypes. Twenty-one bacterial families were found to exhibit evidence for heritability.

500 Though the explained variance was low, a redundancy analysis revealed widespread genotypic influence on the 501 composition of the rhizosphere bacterial microbiome and outlier ASVs along each primary axis belonged largely to 
our defined core microbiome. Finally, we identified 1,861 SNPs associated with the abundance of core microbiome families and discussed potential pathway mechanisms that could influence a subset of those families that we expected could influence host fitness. A GO enrichment analysis determined several functional and cellular processes for which host genotypic influence could be expressed, notably by hydrolase activity. This study should function as a foundation on which further exploration can be achieved investigating the relationship between switchgrass genotype and its associated rhizosphere microbiome in different environmental contexts or under artificial genetic perturbation.

\section{Acknowledgements}

We thank Wanyan Wang for assistance in collecting and cataloging the soil samples from the GWAS panel and selecting samples for metagenome analysis. We thank Maureen Mailander for conducting the initial rhizosphere soil DNA extractions. We are also grateful to our entire project team (investigators Marvin Hall, Stacy Bonos, Julie Hanson, Don Viands, and their students and staff for the collection of the GWAS family plants from the common garden site at Ithaca, NY). We greatly appreciate the opportunity provided by Dr. Michael Casler for allowing us to collect samples of all of the genotypes in this range-wide collection of switchgrass genotypes and check cultivars at of Cornell University for this project. This research was supported by the National Institute of Food and

519 Agriculture, U.S. Department of Agriculture, under award number 2019-67009-29006 to JEC, TBH, and JRL. Seed

520 support was provided by the Northeast Woody/warm-season BIOmass consortium, funded by USDA-AFRI Grant 521 \#2012-68005-19703. Program support to JEC was provided through the USDA National Institute of Food and

522 Agriculture Federal Appropriations under Project PEN04532 and Accession number 1000326. JRL was also 523 supported by NIH award 1R35GM138300-01.

\section{References}

Adkins, J., Jastrow, J. D., Morris, G. P., Six, J., \& de Graaff, M. A. (2016). Effects of switchgrass cultivars and intraspecific differences in root structure on soil carbon inputs and accumulation. Geoderma, 262, 147-154. doi: 10.1016/j.geoderma.2015.08.019

Anderson, C. R., Condron, L. M., Clough, T. J., Fiers, M., Stewart, A., Hill, R. A., \& Sherlock, R. R. (2011). Biochar induced soil microbial community change: Implications for biogeochemical cycling of carbon, nitrogen and phosphorus. Pedobiologia, 54(5-6), 309-320. doi: 10.1016/j.pedobi.2011.07.005

Anderson, M. J. (2001). A new method for non-parametric multivariate analysis of variance. Austral Ecology, 26(1), 32-46. doi: 10.1111/j.1442-9993.2001.01070.pp.x 

primer greatly increases detection of SAR11 bacterioplankton. Aquatic Microbial Ecology. doi: 10.3354/ame01753

Baetz, U., \& Martinoia, E. (2014, February 1). Root exudates: The hidden part of plant defense. Trends in Plant Science, Vol. 19, pp. 90-98. doi: 10.1016/j.tplants.2013.11.006

Beilsmith, K., Thoen, M. P. M., Brachi, B., Gloss, A. D., Khan, M. H., \& Bergelson, J. (2019). Genome-wide association studies on the phyllosphere microbiome: Embracing complexity in host-microbe interactions. The Plant Journal, 97(1), 164-181. doi: 10.1111/tpj.14170

Bell, T. H., \& Bell, T. (2021). Many roads to bacterial generalism. FEMS Microbiology Ecology. doi: $10.1093 / \mathrm{femsec} / \mathrm{fiaa} 240$

Berg, J. M., Tymoczko, J. L., \& Stryer, L. (2002). A Family of Membrane Proteins Uses ATP Hydrolysis to Pump Ions Across Membranes. Retrieved from https://www.ncbi.nlm.nih.gov/books/NBK22464/

Bever, J. D., Platt, T. G., \& Morton, E. R. (2012). Microbial population and community dynamics on plant roots and their feedbacks on plant communities. Annual Review of Microbiology, 66, 265-283. doi: 10.1146/annurevmicro-092611-150107

Bordenstein, S. R., \& Theis, K. R. (2015). Host biology in light of the microbiome: Ten principles of holobionts and hologenomes. PLoS Biology, 13(8). doi: 10.1371/journal.pbio.1002226

Bouton, J. H. (2007, December 1). Molecular breeding of switchgrass for use as a biofuel crop. Current Opinion in Genetics and Development, Vol. 17, pp. 553-558. doi: 10.1016/j.gde.2007.08.012

Bradbury, P. J., Zhang, Z., Kroon, D. E., Casstevens, T. M., Ramdoss, Y., \& Buckler, E. S. (2007). TASSEL: software for association mapping of complex traits in diverse samples. Bioinformatics, 23(19), 2633-2635. doi: 10.1093/BIOINFORMATICS/BTM308

Brown, B. C., Bray, N. L., \& Pachter, L. (2018). Expression reflects population structure. PLoS Genetics, 14(12), e1007841. doi: 10.1371/journal.pgen.1007841

Brzyski, D., Peterson, C. B., Sobczyk, P., Candès, E. J., Bogdan, M., \& Sabatti, C. (2017). Controlling the rate of GWAS false discoveries. Genetics. doi: 10.1534/genetics.116.193987

Callahan, B. J., Mcmurdie, P. J., Rosen, M. J., Han, A. W., Johnson, A. J. A., \& Holmes, S. P. (n.d.). DADA2: High resolution sample inference from Illumina amplicon data. doi: 10.1038/nmeth.3869

Callahan, B. J., McMurdie, P. J., Rosen, M. J., Han, A. W., Johnson, A. J. A., \& Holmes, S. P. (2016). DADA2: High-resolution sample inference from Illumina amplicon data. Nature Methods, 13(7), 581-583. doi: 10.1038/nmeth.3869

Carvalhais, L. C., Dennis, P. G., Fan, B., Fedoseyenko, D., Kierul, K., Becker, A., ... Borriss, R. (2013). Linking Plant Nutritional Status to Plant-Microbe Interactions. PLOS ONE, 8(7). doi: 10.1371/journal.pone.0068555

Casler, M. D., Vogel, K. P., \& Harrison, M. (2015). Switchgrass Germplasm Resources. Crop Science, 55(6), $2463-$ 2478. doi: $10.2135 /$ cropsci2015.02.0076

Compant, S., Clément, C., \& Sessitsch, A. (2010, May 1). Plant growth-promoting bacteria in the rhizo- and endosphere of plants: Their role, colonization, mechanisms involved and prospects for utilization. Soil Biology and Biochemistry, Vol. 42, pp. 669-678. doi: 10.1016/j.soilbio.2009.11.024

Costich, D. E., Friebe, B., Sheehan, M. J., Casler, M. D., \& Buckler, E. S. (2010). Genome-size Variation in Switchgrass ( Panicum virgatum ): Flow Cytometry and Cytology Reveal Rampant Aneuploidy. The Plant Genome, 3(3), 130-141. doi: 10.3835/plantgenome2010.04.0010

Covarrubias-Pazaran, G. (2016). Genome-Assisted prediction of quantitative traits using the r package sommer. PLOS ONE. doi: 10.1371/journal.pone.0156744

Das, M. K., Fuentes, R. G., \& Taliaferro, C. M. (2004). Genetic Variability and Trait Relationships in Switchgrass. Crop Science, 44(2), 443-448. doi: 10.2135/cropsci2004.4430

Deng, S., Caddell, D. F., Xu, G., Dahlen, L., Washington, L., Yang, J., \& Coleman-Derr, D. (2021). Genome wide association study reveals plant loci controlling heritability of the rhizosphere microbiome. ISME Journal, 114. doi: 10.1038/s41396-021-00993-Z

Dennis, P. G., Miller, A. J., \& Hirsch, P. R. (2010). Are root exudates more important than other sources of rhizodeposits in structuring rhizosphere bacterial communities? FEMS Microbiology Ecology. doi: 10.1111/j.1574-6941.2010.00860.x

Du, Z., Zhou, X., Ling, Y., Zhang, Z., \& Su, Z. (2010). agriGO: A GO analysis toolkit for the agricultural community. Nucleic Acids Research. doi: 10.1093/nar/gkq310

Evans, J., Sanciangco, M. D., Lau, K. H., Crisovan, E., Barry, K., Daum, C., ... Buell, C. R. (2018). Extensive Genetic Diversity is Present within North American Switchgrass Germplasm. The Plant Genome, 11(1), 1-16. doi: 10.3835/plantgenome2017.06.0055 
Furlotte, N. A., Heckerman, D., \& Lippert, C. (2014). Quantifying the uncertainty in heritability. Journal of Human Genetics. doi: 10.1038/jhg.2014.15

Glaeser, S. P., \& Kämpfer, P. (2014). The family Sphingomonadaceae. In The Prokaryotes: Alphaproteobacteria and Betaproteobacteria (Vol. 9783642301971, pp. 641-707). doi: 10.1007/978-3-642-30197-1_302

Gould, A. L., Zhang, V., Lamberti, L., Jones, E. W., Obadia, B., Korasidis, N., ... Ludington, W. B. (2018). Microbiome interactions shape host fitness. Proceedings of the National Academy of Sciences of the United States of America, 115(51), E11951-E11960. doi: 10.1073/pnas.1809349115

Grabowski, P. P., Evans, J., Daum, C., Deshpande, S., Barry, K. W., Kennedy, M., ... Casler, M. D. (2017a). Genome-wide associations with flowering time in switchgrass using exome-capture sequencing data. New Phytologist, 213(1), 154-169. doi: 10.1111/nph.14101

Grabowski, P. P., Evans, J., Daum, C., Deshpande, S., Barry, K. W., Kennedy, M., ... Casler, M. D. (2017b). Genome-wide associations with flowering time in switchgrass using exome-capture sequencing data. New Phytologist. doi: 10.1111/nph.14101

Hacquard, S., Spaepen, S., Garrido-Oter, R., \& Schulze-Lefert, P. (2017). Interplay between Innate Immunity and the Plant Microbiota. Annual Review of Phytopathology, 55, 565-589. doi: 10.1146/annurev-phyto-080516035623

Heijboer, A., de Ruiter, P. C., Bodelier, P. L. E., \& Kowalchuk, G. A. (2018). Modulation of Litter Decomposition by the Soil Microbial Food Web Under Influence of Land Use Change. Frontiers in Microbiology, 9(NOV), 2860. doi: $10.3389 /$ fmicb.2018.02860

Hestrin, R., Lee, M. R., Whitaker, B. K., \& Pett-Ridge, J. (2021). The switchgrass microbiome: A review of structure, function, and taxonomic distribution. Phytobiomes Journal. doi: 10.1094/pbiomes-04-20-0029-fi

Holland, J. B. (2007, April 1). Genetic architecture of complex traits in plants. Current Opinion in Plant Biology, Vol. 10, pp. 156-161. doi: 10.1016/j.pbi.2007.01.003

Hu, L., Robert, C. A. M., Cadot, S., Zhang, X., Ye, M., Li, B., ... Erb, M. (2018). Root exudate metabolites drive plant-soil feedbacks on growth and defense by shaping the rhizosphere microbiota. Nature Communications, 9(1), 1-13. doi: 10.1038/s41467-018-05122-7

Hunter, P. (2018). The revival of the extended phenotype. EMBO Reports, 19(7). doi: 10.15252/embr.201846477

Ihaka, R., \& Gentleman, R. (1996). R: A Language for Data Analysis and Graphics. Journal of Computational and Graphical Statistics, 5(3), 299-314. doi: 10.1080/10618600.1996.10474713

Jones, P., Garcia, B. J., Furches, A., Tuskan, G. A., \& Jacobson, D. (2019, May 31). Plant host-associated mechanisms for microbial selection. Frontiers in Plant Science, Vol. 10, p. 862. doi: 10.3389/fpls.2019.00862

Kang, H. M., Sul, J. H., Service, S. K., Zaitlen, N. A., Kong, S. Y., Freimer, N. B., ... Eskin, E. (2010). Variance component model to account for sample structure in genome-wide association studies. Nature Genetics, 42(4), 348-354. doi: 10.1038/ng.548

Kaur, P., \& Gaikwad, K. (2017). From genomes to gene-omes: Exome sequencing concept and applications in crop improvement. Frontiers in Plant Science. doi: 10.3389/fpls.2017.02164

Lahti, L., Shetty, S., \& Blake, T. (2017). Tools for microbiome analysis in R. Microbiome Package Version 0.99.

Lakshmanan, V., Kitto, S. L., Caplan, J. L., Hsueh, Y. H., Kearns, D. B., Wu, Y. S., \& Bais, H. P. (2012). Microbeassociated molecular patterns-triggered root responses mediate beneficial Rhizobacterial recruitment in Arabidopsis. Plant Physiology, 160(3), 1642-1661. doi: 10.1104/pp.112.200386

Lebeis, S. L., Paredes, S. H., Lundberg, D. S., Breakfield, N., Gehring, J., McDonald, M., ... Dangl, J. L. (2015). Salicylic acid modulates colonization of the root microbiome by specific bacterial taxa. Science, 349(6250), 860-864. doi: 10.1126/science.aaa8764

Lemanceau, P., Blouin, M., Muller, D., \& Moënne-Loccoz, Y. (2017). Let the Core Microbiota Be Functional. Trends in Plant Science. doi: 10.1016/j.tplants.2017.04.008

Lipka, A. E., Lu, F., Cherney, J. H., Buckler, E. S., Casler, M. D., \& Costich, D. E. (2014). Accelerating the Switchgrass (Panicum virgatum L.) Breeding Cycle Using Genomic Selection Approaches. PLoS ONE, 9(11), e112227. doi: 10.1371/journal.pone.0112227

Lovell, J. T., MacQueen, A. H., Mamidi, S., Bonnette, J., Jenkins, J., Napier, J. D., ... Schmutz, J. (2021). Genomic mechanisms of climate adaptation in polyploid bioenergy switchgrass. Nature, 590(7846), 438-444. doi: 10.1038/s41586-020-03127-1

Lowry, D. B., Lovell, J. T., Zhang, L., Bonnette, J., Fay, P. A., Mitchell, R. B., ... Juenger, T. E. (2019). QTL × environment interactions underlie adaptive divergence in switchgrass across a large latitudinal gradient. Proceedings of the National Academy of Sciences of the United States of America. doi: 10.1073/pnas.1821543116

Lu, F., Lipka, A. E., Glaubitz, J., Elshire, R., Cherney, J. H., Casler, M. D., .. Costich, D. E. (2013). Switchgrass 
Genomic Diversity, Ploidy, and Evolution: Novel Insights from a Network-Based SNP Discovery Protocol. PLoS Genetics. doi: 10.1371/journal.pgen.1003215

Martiny, J. B. H., Jones, S. E., Lennon, J. T., \& Martiny, A. C. (2015, November 6). Microbiomes in light of traits: A phylogenetic perspective. Science, Vol. 350. doi: 10.1126/science.aac9323

McLaughlin, S. B., \& Kszos, L. A. (2005). Development of switchgrass (Panicum virgatum) as a bioenergy feedstock in the United States. Biomass and Bioenergy, 28(6), 515-535. doi: 10.1016/j.biombioe.2004.05.006

McMurdie, P. J., \& Holmes, S. (2013). phyloseq: An R Package for Reproducible Interactive Analysis and Graphics of Microbiome Census Data. PLoS ONE, 8(4), e61217. doi: 10.1371/journal.pone.0061217

Moran, N. A., \& Sloan, D. B. (2015). The Hologenome Concept: Helpful or Hollow? PLoS Biology, 13(12). doi: 10.1371/journal.pbio.1002311

Oksanen, J., Blanchet, F. G., Friendly, M., Kindt, R., Legendre, P., Mcglinn, D., ... Maintainer, H. W. (2019). vegan: Community Ecology Package. R package version 2.5-5. https://CRAN.R-project.org/package=vegan. Community Ecology Package.

Palazzo, A. F., \& Gregory, T. R. (2014). The Case for Junk DNA. PLoS Genetics. doi: 10.1371/journal.pgen.1004351

Paliy, O., \& Shankar, V. (2016). Application of multivariate statistical techniques in microbial ecology. Molecular Ecology. doi: $10.1111 / \mathrm{mec} .13536$

Parada, A. E., Needham, D. M., \& Fuhrman, J. A. (2016). Every base matters: Assessing small subunit rRNA primers for marine microbiomes with mock communities, time series and global field samples. Environmental Microbiology. doi: 10.1111/1462-2920.13023

Parker, M. A., Malek, W., \& Parker, I. M. (2006). Growth of an invasive legume is symbiont limited in newly occupied habitats. Diversity <html_ent Glyph="@amp;" Ascii="\&amp;"/> Distributions, 12(5), 563-571. doi: $10.1111 / \mathrm{j} .1366-9516.2006 .00255 . x$

Parrish, D. J., \& Fike, J. H. (2005, September). The biology and agronomy of switchgrass for biofuels. Critical Reviews in Plant Sciences, Vol. 24, pp. 423-459. doi: 10.1080/07352680500316433

Peres-Neto, P. R., Legendre, P., Dray, P., \& Borcard, D. (2006). VARIATION PARTITIONING OF SPECIES DATA MATRICES: ESTIMATION AND COMPARISON OF FRACTIONS. Ecology, 87(10), 2614-2625. doi: 10.1890/0012-9658

Quast, C., Pruesse, E., Yilmaz, P., Gerken, J., Schweer, T., Yarza, P., ... Glö Ckner, F. O. (n.d.). The SILVA ribosomal RNA gene database project: improved data processing and web-based tools. doi: 10.1093/nar/gks1219

Risely, A. (2020). Applying the core microbiome to understand host-microbe systems. Journal of Animal Ecology. doi: 10.1111/1365-2656.13229

Rossum, B. van, Kruijer, W., Eeuwijk, F. van, \& Boer, M. (2020). Package "statgenGWAS" Title Genome Wide Association Studies. doi: 10.1038/ng.548

Sanderson, M. A., Adler, P. R., Boateng, A. A., Casler, M. D., \& Sarath, G. (2006). Switchgrass as a biofuels feedstock in the USA. Canadian Journal of Plant Science, 86(5), 1315-1325. doi: 10.4141/p06-136

Sasse, J., Martinoia, E., \& Northen, T. (2018, January 1). Feed Your Friends: Do Plant Exudates Shape the Root Microbiome? Trends in Plant Science, Vol. 23, pp. 25-41. doi: 10.1016/j.tplants.2017.09.003

Schwartz, C., \& Amasino, R. (2013). Nitrogen Recycling and Flowering Time in Perennial Bioenergy Crops. Frontiers in Plant Science, O(APR), 76. doi: 10.3389/FPLS.2013.00076

Sharma, M. K., Sharma, R., Cao, P., Jenkins, J., Bartley, L. E., Qualls, M., ... Ronald, P. C. (2012). A GenomeWide Survey of Switchgrass Genome Structure and Organization. PLoS ONE, 7(4), e33892. doi: 10.1371/journal.pone.0033892

Singer, E., Bonnette, J., Kenaley, S. C., Woyke, T., \& Juenger, T. E. (2019). Plant compartment and genetic variation drive microbiome composition in switchgrass roots. Environmental Microbiology Reports, 11(2), 185. doi: 10.1111/1758-2229.12727

Singer, E., Bonnette, J., Woyke, T., \& Juenger, T. E. (2019). Conservation of Endophyte Bacterial Community Structure Across Two Panicum Grass Species. Frontiers in Microbiology, 10(SEP), 2181. doi: 10.3389/FMICB.2019.02181

Smith, C. C. R., Snowberg, L. K., Gregory Caporaso, J., Knight, R., \& Bolnick, D. I. (2015). Dietary input of microbes and host genetic variation shape among-population differences in stickleback gut microbiota. ISME Journal, 9(11), 2515-2526. doi: 10.1038/ismej.2015.64

Stewart, C. E., Roosendaal, D., Denef, K., Pruessner, E., Comas, L. H., Sarath, G., ... Soundararajan, M. (2017). Seasonal switchgrass ecotype contributions to soil organic carbon, deep soil microbial community composition and rhizodeposit uptake during an extreme drought. Soil Biology and Biochemistry, 112, 191- 
Tian, T., Liu, Y., Yan, H., You, Q., Yi, X., Du, Z., .. Su, Z. (2017). AgriGO v2.0: A GO analysis toolkit for the agricultural community, 2017 update. Nucleic Acids Research. doi: 10.1093/nar/gkx382

Trexler, R. V., \& Bell, T. H. (2019). Testing sustained soil-to-soil contact as an approach for limiting the abiotic influence of source soils during experimental microbiome transfer. FEMS Microbiology Letters. doi: 10.1093/femsle/fnz228

Trivedi, P., Leach, J. E., Tringe, S. G., Sa, T., \& Singh, B. K. (2020, November 1). Plant-microbiome interactions: from community assembly to plant health. Nature Reviews Microbiology, Vol. 18, pp. 607-621. doi: 10.1038/s41579-020-0412-1

Trujillo, M. E., Hong, K., \& Genilloud, O. (2014). The family Micromonosporaceae. In The Prokaryotes: Actinobacteria (pp. 499-569). doi: 10.1007/978-3-642-30138-4_196

Van Rossum, G., \& Drake, F. L. (2009). Python 3 Reference Manual. Scotts Valley, CA: CreateSpace.

VanRaden, P. M. (2008). Efficient methods to compute genomic predictions. Journal of Dairy Science, 91(11), 4414-4423. doi: 10.3168/jds.2007-0980

Wagner, M. R. (2021). Prioritizing host phenotype to understand microbiome heritability in plants. New Phytologist. doi: 10.1111/NPH.17622

Wagner, M. R., Lundberg, D. S., Del Rio, T. G., Tringe, S. G., Dangl, J. L., \& Mitchell-Olds, T. (2016). Host genotype and age shape the leaf and root microbiomes of a wild perennial plant. Nature Communications, 7. doi: $10.1038 /$ ncomms12151

Weiss, S., Xu, Z. Z., Peddada, S., Amir, A., Bittinger, K., Gonzalez, A., ... Knight, R. (2017). Normalization and microbial differential abundance strategies depend upon data characteristics. Microbiome, 5(1), 27. doi: 10.1186/s40168-017-0237-y

Werling, B. P., Dickson, T. L., Isaacs, R., Gaines, H., Gratton, C., Gross, K. L., .. Landis, D. A. (2014). Perennial grasslands enhance biodiversity and multiple ecosystem services in bioenergy landscapes. Proceedings of the National Academy of Sciences of the United States of America, 111(4), 1652-1657. doi: 10.1073/pnas.1309492111

Whitham, T. G., Young, W. P., Martinsen, G. D., Gehring, C. A., Schweitzer, J. A., Shuster, S. M., ... Kuske, C. R. (2003, March 1). Community and ecosystem genetics: A consequence of the extended phenotype. Ecology, Vol. 84, pp. 559-573. doi: 10.1890/0012-9658(2003)084[0559:CAEGAC]2.0.CO;2

Wilson, A. S., Koller, K. R., Ramaboli, M. C., Nesengani, L. T., Ocvirk, S., Chen, C., ... O'Keefe, S. J. D. (2020, March 1). Diet and the Human Gut Microbiome: An International Review. Digestive Diseases and Sciences, Vol. 65, pp. 723-740. doi: 10.1007/s10620-020-06112-w

Wray, N. R., Yang, J., Hayes, B. J., Price, A. L., Goddard, M. E., \& Visscher, P. M. (2013, July). Pitfalls of predicting complex traits from SNPs. Nature Reviews Genetics, Vol. 14, pp. 507-515. doi: 10.1038/nrg3457

Wright, E. S. (n.d.). Using DECIPHER v2.0 to Analyze Big Biological Sequence Data in R.

Yin, C., Casa Vargas, J. M., Schlatter, D. C., Hagerty, C. H., Hulbert, S. H., \& Paulitz, T. C. (2021). Rhizosphere community selection reveals bacteria associated with reduced root disease. Microbiome 2021 9:1, 9(1), 1-18. doi: 10.1186/S40168-020-00997-5

Yu, P., \& Hochholdinger, F. (2018). The role of host genetic signatures on root-microbe interactions in the rhizosphere and endosphere. Frontiers in Plant Science, Vol. 871. doi: 10.3389/fpls.2018.01896

Zeng, Q., Sukumaran, J., Wu, S., \& Rodrigo, A. (2015). Neutral Models of Microbiome Evolution. PLOS Computational Biology, 11(7), e1004365. doi: 10.1371/journal.pcbi.1004365 


\section{A}
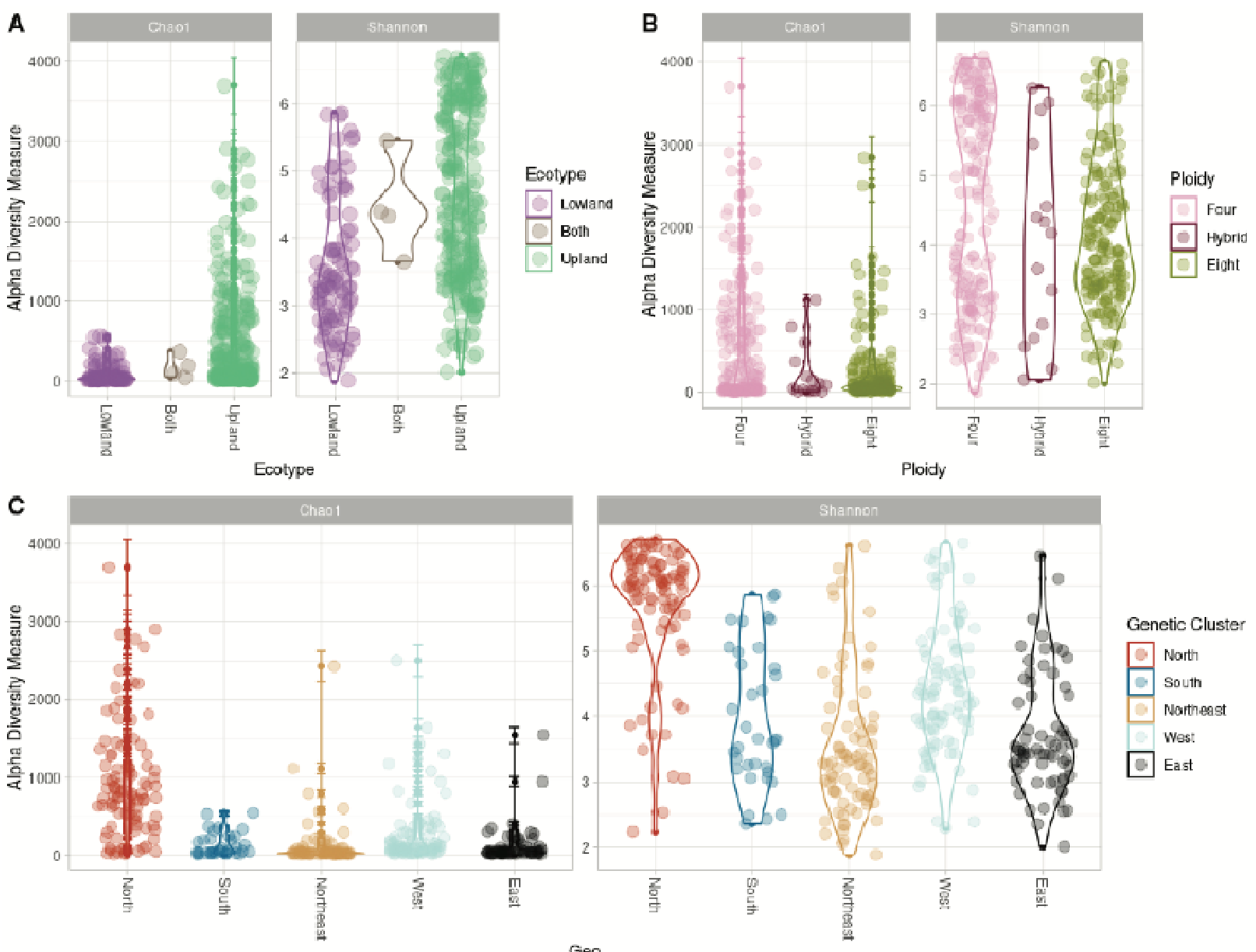

Geo

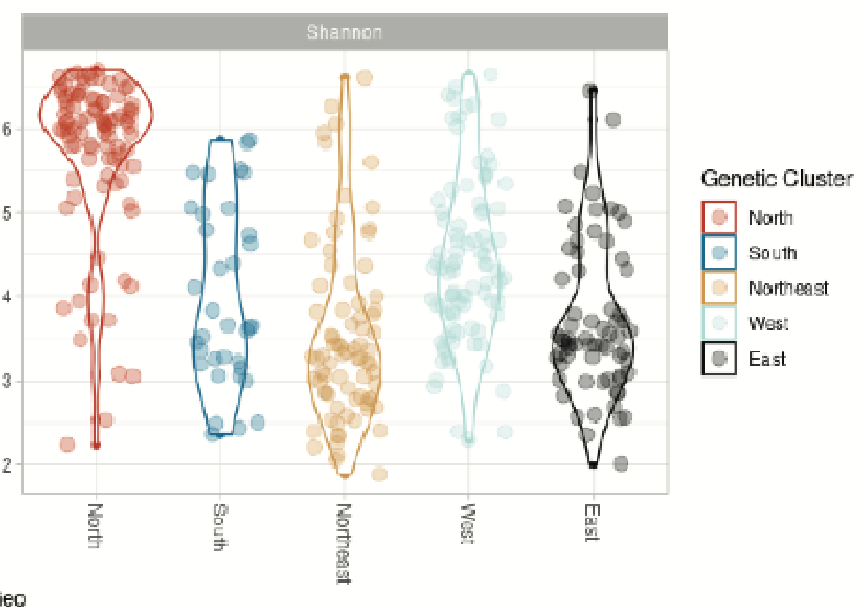

Figure 1:

A: Alpha diversity by Ecotype. Alpha-diversity, measured by Chao1 and Shannon diversity Index, plotted for switchgrass ecotypes with Lowland (purple), Both (brown), and Upland (green). B: Alpha diversity by Ploidy. Alpha-diversity, measured by Chao1 and Shannon diversity Index, plotted for switchgrass ploidy levels with Tetraploid - Four (pink), Hybrid (maroon), and Octoploid - Eight (olive). C: Alpha diversity by Genetic cluster. Alpha-diversity, measured by Chao1 and Shannon diversity Index, plotted for switchgrass genetic clusters with North (red), South (dark blue), Northeast (beige), West (light blue), and East (black). 

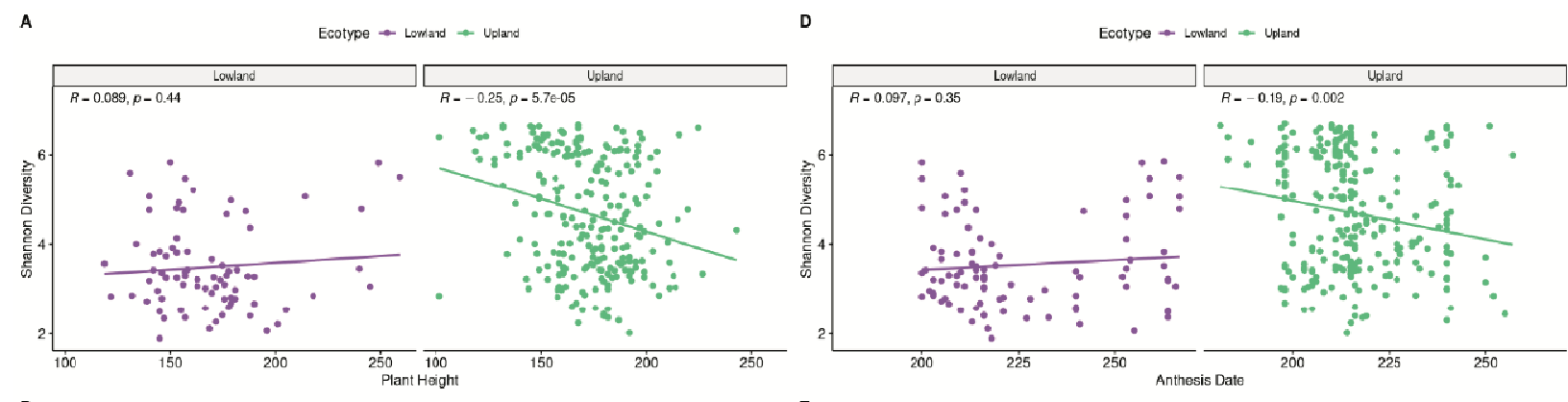

B

Ploidy $=$ Four $\rightarrow$ Hybrid - Eght

E
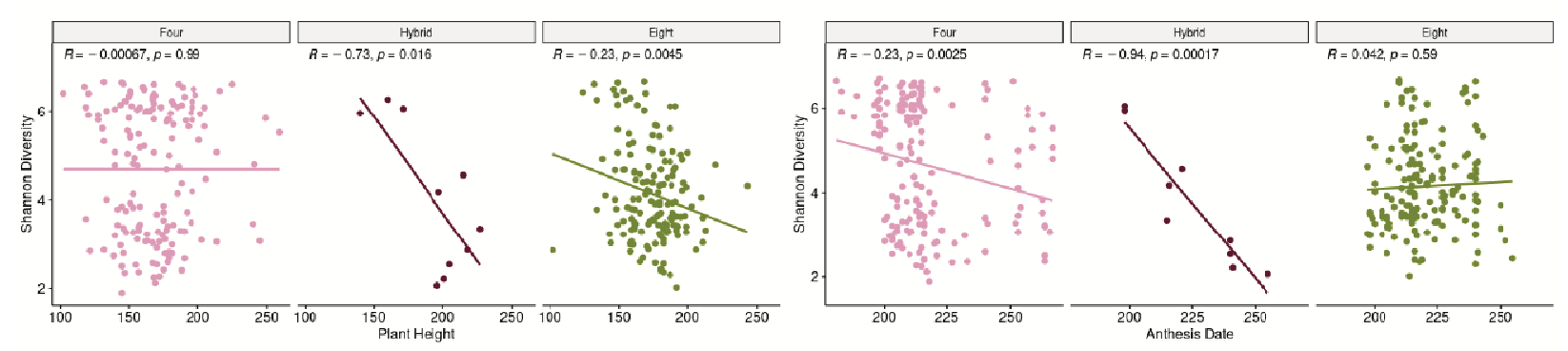

c

Geo $\rightarrow$ Noth $\rightarrow$ South $\rightarrow$ Northeast - West - East

$\mathbf{F}$
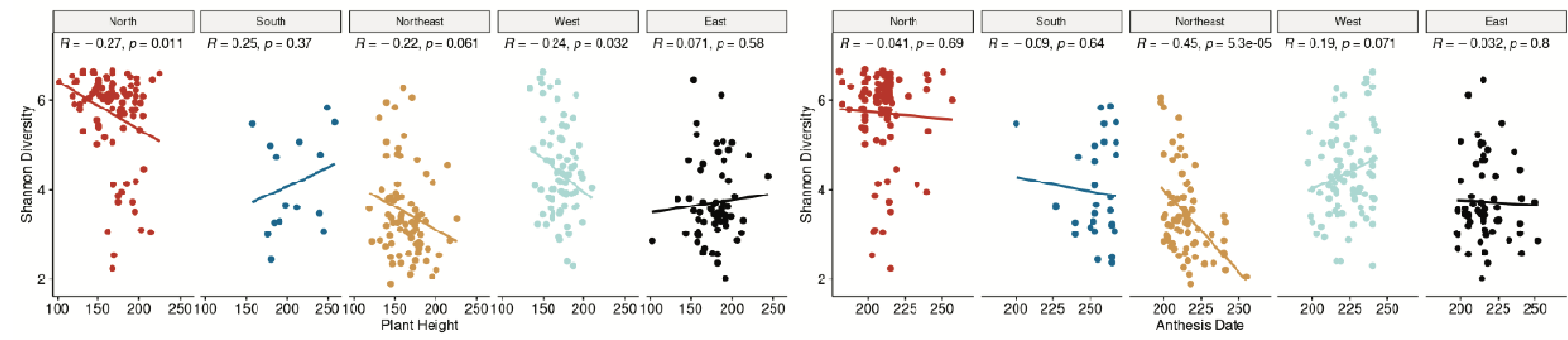

Figure 2:

Relationships between Shannon diversity and plant height. A: Ecotype: plotted for switchgrass ecotypes with

Lowland (purple), Both (brown), and Upland (green). B: Ploidy: plotted for switchgrass ploidy levels with

Tetraploid - Four (pink), Hybrid (maroon), and Octoploid - Eight (olive). C: Genetic cluster. plotted for switchgrass genetic clusters with North (red), South (dark blue), Northeast (beige), West (light blue), and East (black). Relationships between Shannon diversity and anthesis date. D: Ecotype: plotted for switchgrass ecotypes with Lowland (purple), Both (brown), and Upland (green). E: Ploidy: plotted for switchgrass ploidy levels with genetic clusters with North (red), South (dark blue), Northeast (beige), West (light blue), and East (black). 
bioRxiv preprint doi: https://doi org/10.1101/2021.09.01.458593; this version posted September 2, 2021. The copyright holder for this preprint (which was not certified by peer review) is the author/funder, who has granted bioRxiv a license to display the preprint in perpetuity. It is made available under aCC-BY-NC-ND 4.0 International license.

Heritable Core Families

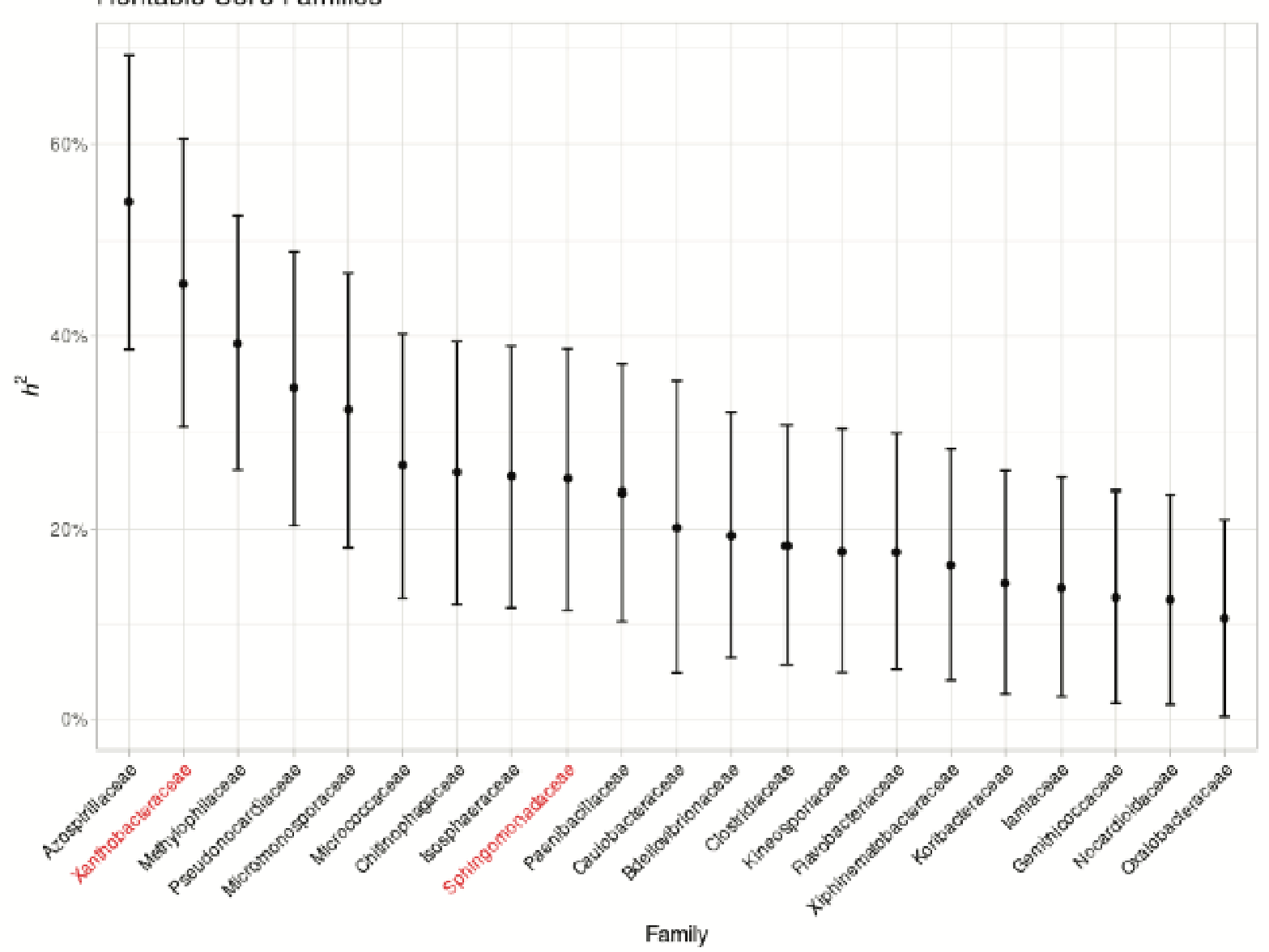

Figure 3:

Heritability estimates for bacterial families in the switchgrass rhizosphere. For 110 bacterial families that were observed in more than $10 \%$ of switchgrass samples, narrow-sense heritability $\left(h^{2}\right)$ was calculated using a mixed linear model. 21 families had heritability estimates with standard error greater than zero. Families observed in more than $90 \%$ of our samples are represented in red. 


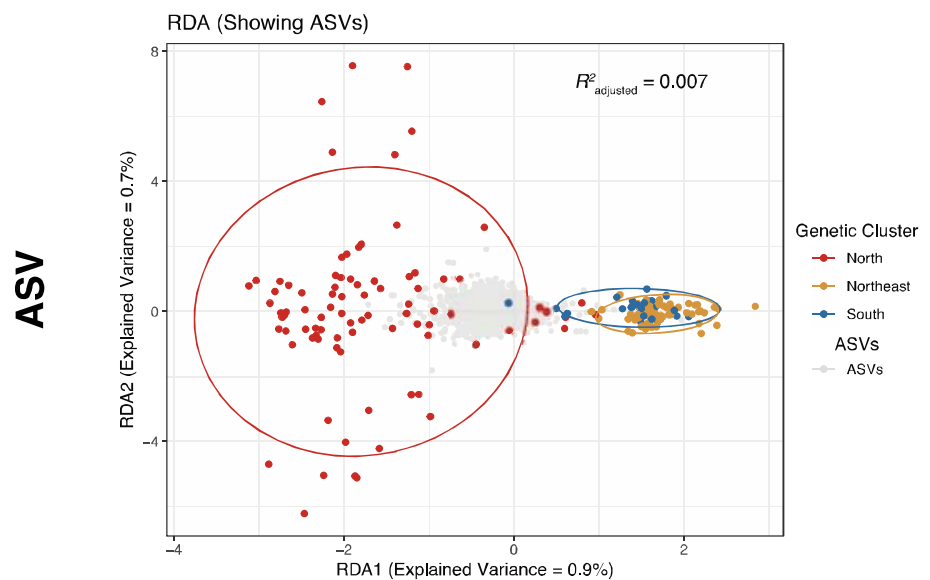

Total $R^{2}=0.008$
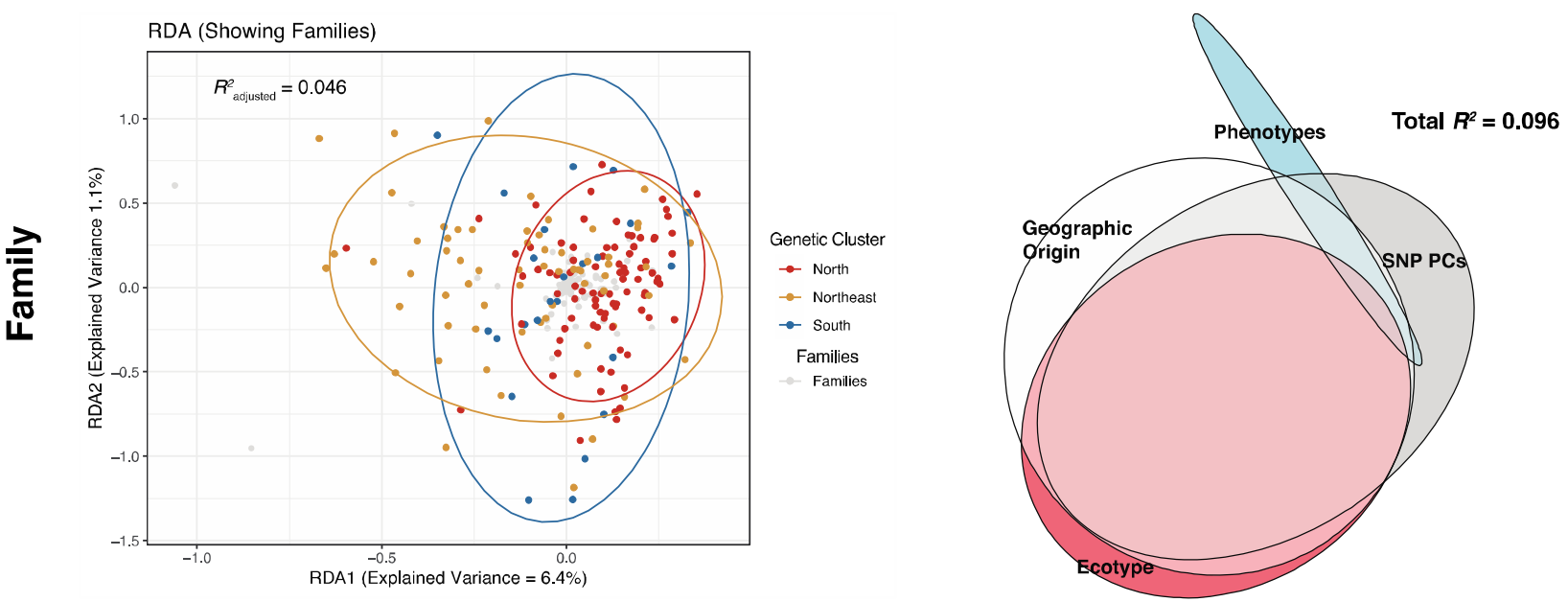

Figure 4:

Redundancy Analyses and Variance Partitioning. A: Results of RDA analysis presenting amplicon sequence variants (Grey) and the North (Red), Northeast (Beige), and South (Blue) genetic clusters. B: Results of variance partitioning analysis for ASVs presenting Ecotype (Red), SNP PCs (Grey), Phenotypes (Blue), and Geographic Origin (White). C: Results of RDA analysis presenting rhizosphere bacterial families (Grey) and the North (Red), Northeast (Beige), and South (Blue) genetic clusters. D: Results of variance partitioning analysis for rhizosphere bacterial families presenting Ecotype (Red), SNP PCs (Grey), Phenotypes (Blue), and Geographic Origin (White). 
bioRxiv preprint doi: https://doi.org/10.1101/2021.09.01.458593; this version posted September 2, 2021. The copyright holder for this preprint (which was not certified by peer review) is the author/funder, who has granted bioRxiv a license to display the preprint in perpetuity. It is made available under aCC-BY-NC-ND 4.0 International license.

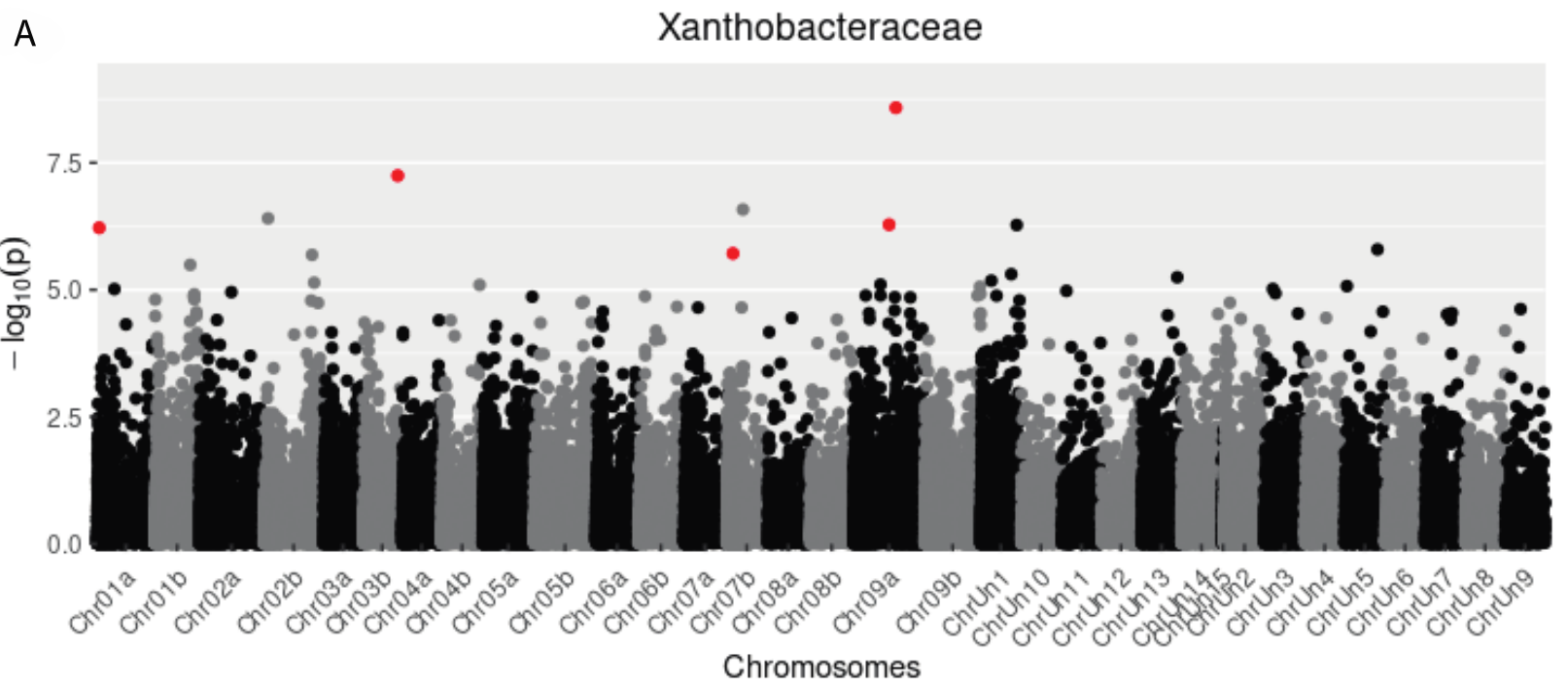

B Sphingomonadaceae

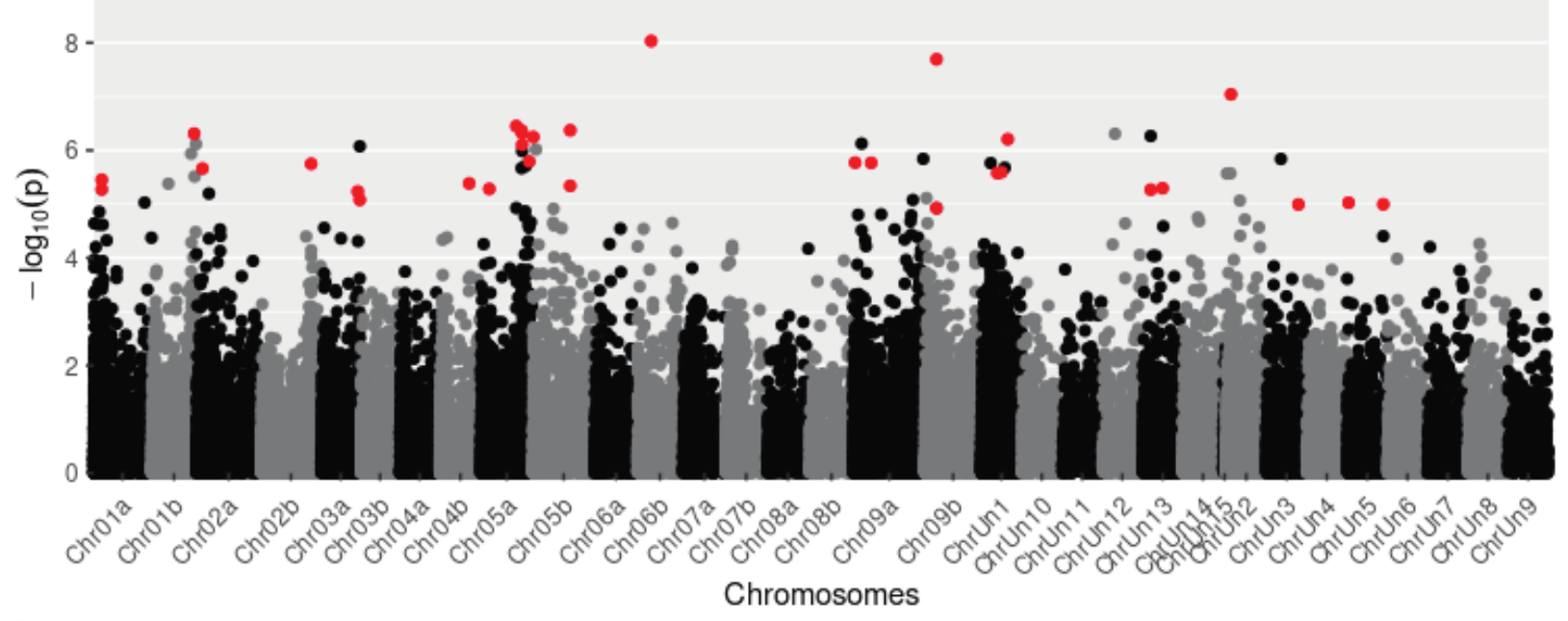

C

Micromonosporaceae

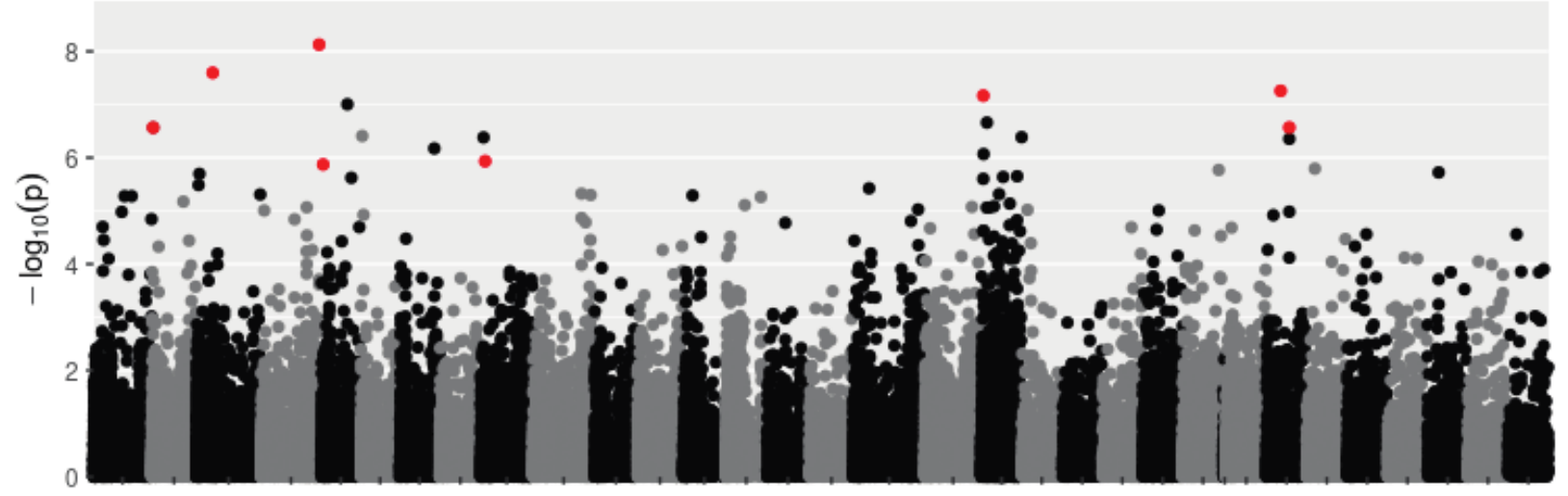

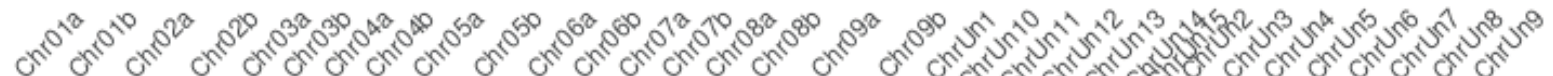

Figure 5:

\section{Chromosomes}


bioRxiv preprint doi: https://doi. org/101101/2021.09.01.458593; this version posted September 2, 2021. The copyright holder for this preprint (which was not certified by peer review) is the author/funder, who has granted bioRxiv a license to display the preprint in perpetuity. It is made available under aCC-BY-NC-ND 4.0 International license.

Genome-wide association study (GWAS): A: Manhattan plot presenting significant SNPs (Red) associated with Xanthobacteraceae rhizosphere abundance. B: Manhattan plot presenting significant SNPs (Red) associated with Sphingomonadaceae rhizosphere abundance. $\boldsymbol{C}$ : Manhattan plot presenting significant SNPs (Red) associated with

Supplemental Figures:

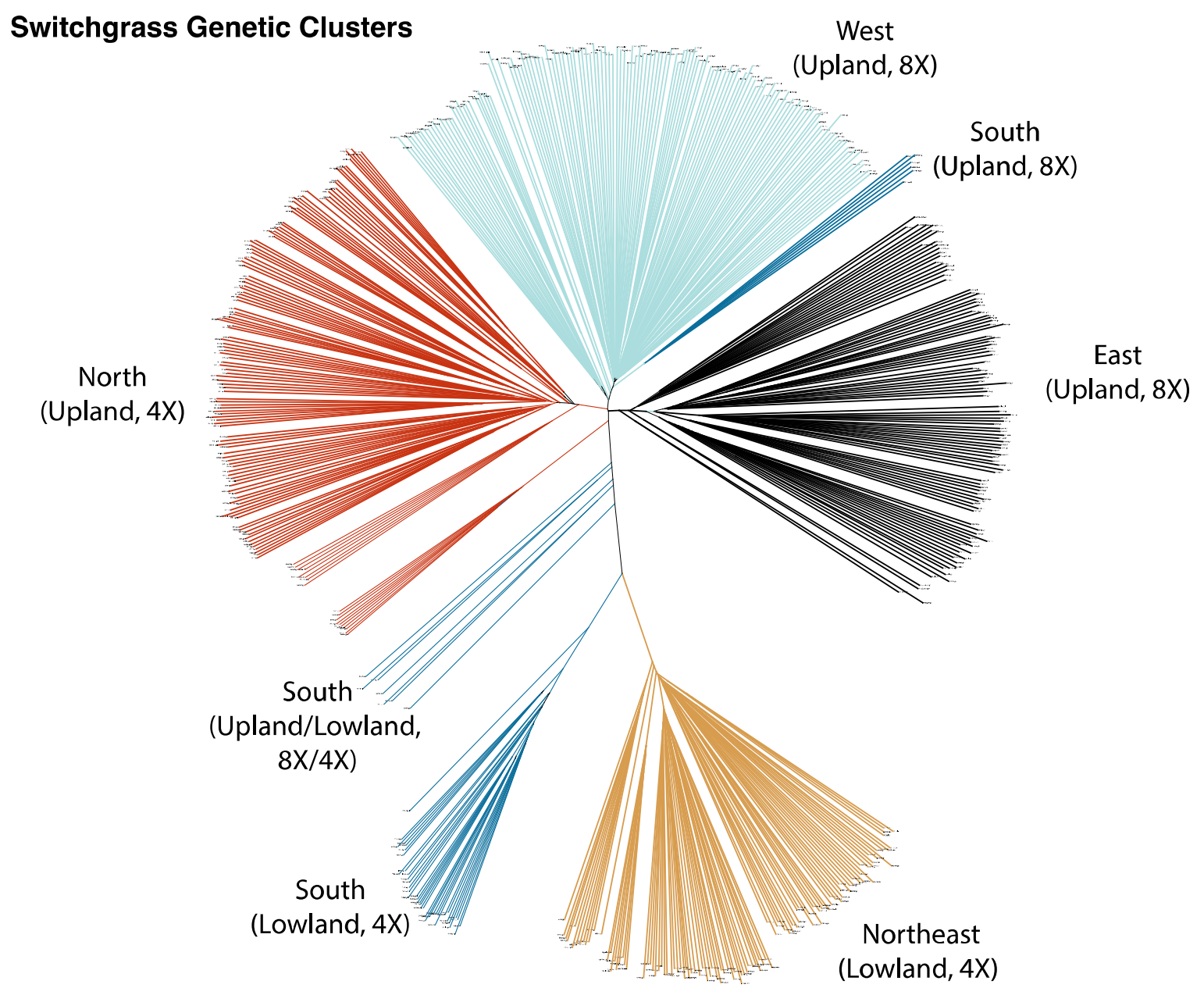

Supplemental Figure 1:

Phylogenetic analysis: Results of phylogenetic analysis based on exome capture dataset from Evans et al. 2018 with (black). 
bioRxiv preprint doi: https://doi org/101101/2021.09 01.458593. this version posted September 2, 2021. The copyright holder for this preprint (which was not certified by peer review) is the author/funder, who has granted bioRxiv a license to display the preprint in perpetuity. It is made available under aCC-BY-NC-ND 4.0 International license.
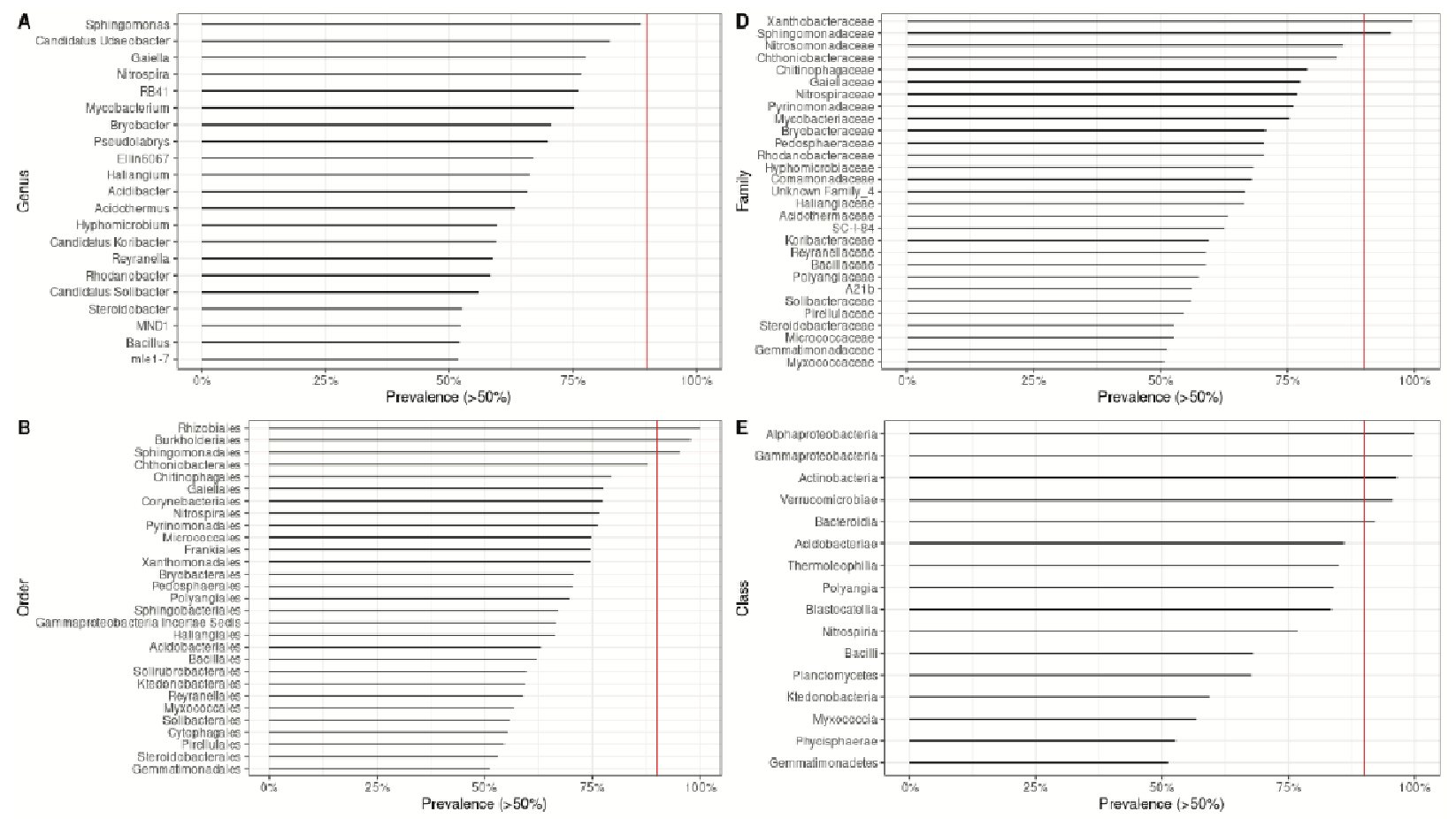

C

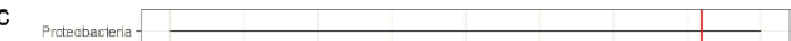

Prevalence of rhizosphere bacterial taxa: The prevalence of rhizosphere bacterial taxa in greater than $50 \%$ of switchgrass samples shown for $\boldsymbol{A}$ : Genus, B: Family, $\boldsymbol{C}$ : Order, D: Class, and $\boldsymbol{E}$ : Phylum. The $90 \%$ occupancy threshold for each group is indicated by a vertical red line. 
RDA (Showing SNP PCs)

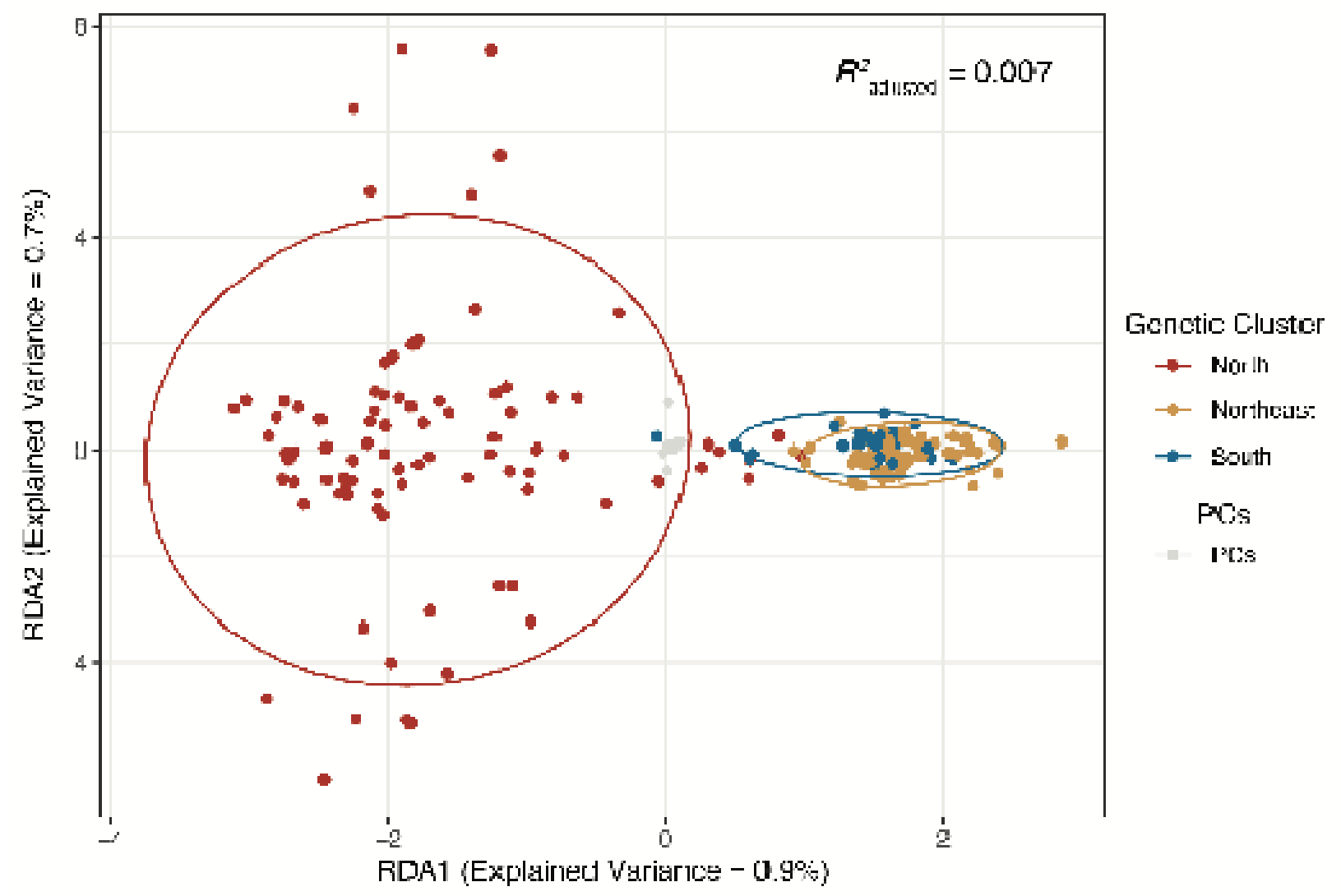

Supplemental Figure 3:

Redundancy Analyses (PCs): Results of RDA analysis presenting SNP PCs (grey) and the North (red), Northeast 813 (beige), and South (dark blue) genetic clusters. 
bioRxiv preprint doi: https://doi.org/10.1101/2021.09.01.458593; this version posted September 2, 2021. The copyright holder for this preprint (which was not certified by peer review) is the author/funder, who has granted bioRxiv a license to display the preprint in perpetuity. It is made available under aCC-BY-NC-ND 4.0 International license.

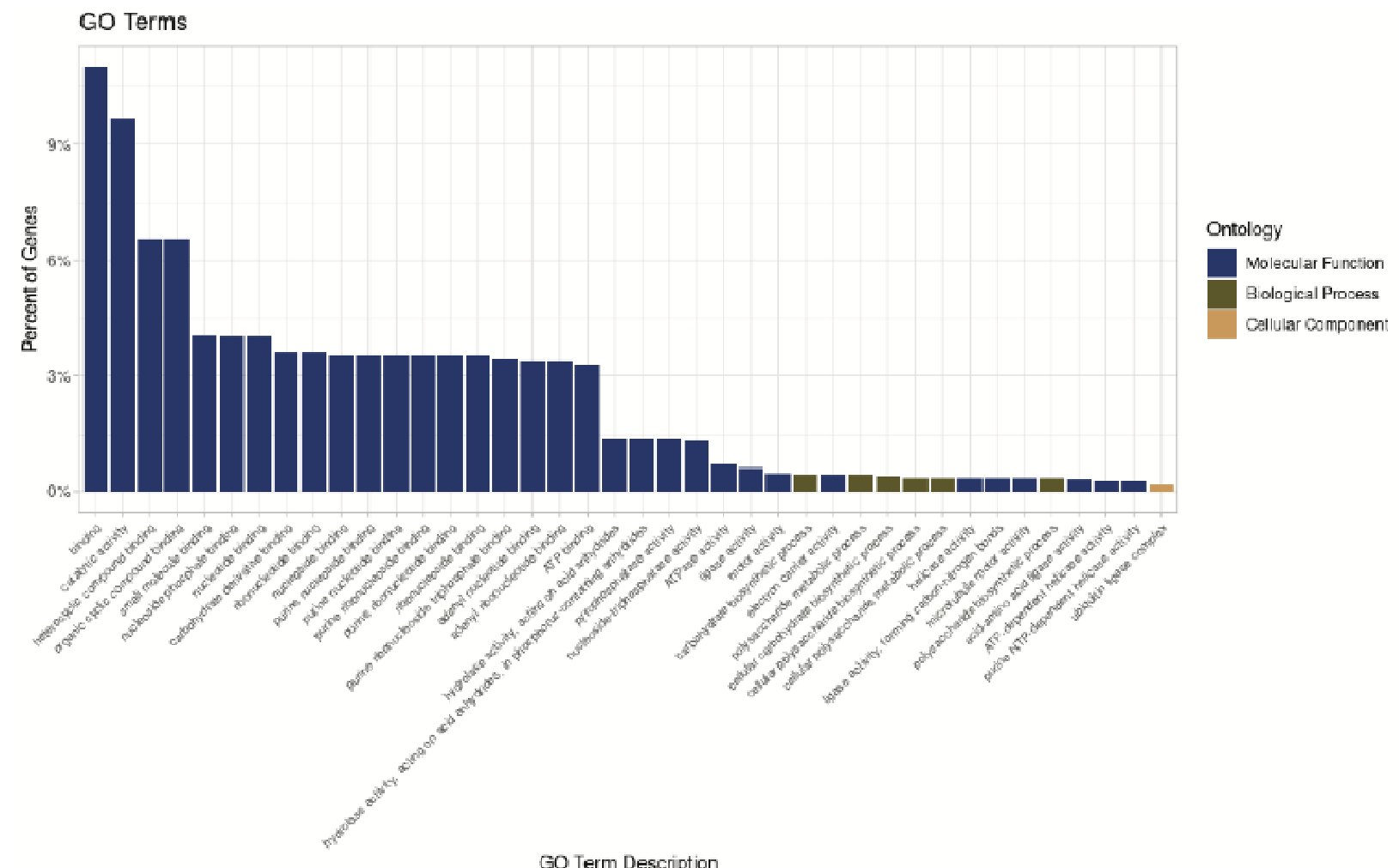

Supplemental Figure 4:

GO Terms: Percent of enriched GO terms related to Molecular Function (dark blue), Biological Process (olive), and 
bioRxiv preprint doi: $h t t p s: / / d o i . o r g / 10.1101 / 2021.09 .01 .458593 \cdot$ this version posted September 2, 2021. The copyright holder for this preprint (which was not certified by peer review) is the author/funder, who has granted bioRxiv a license to display the preprint in perpetuity. It is made available under aCC-BY-NC-ND 4.0 International license.

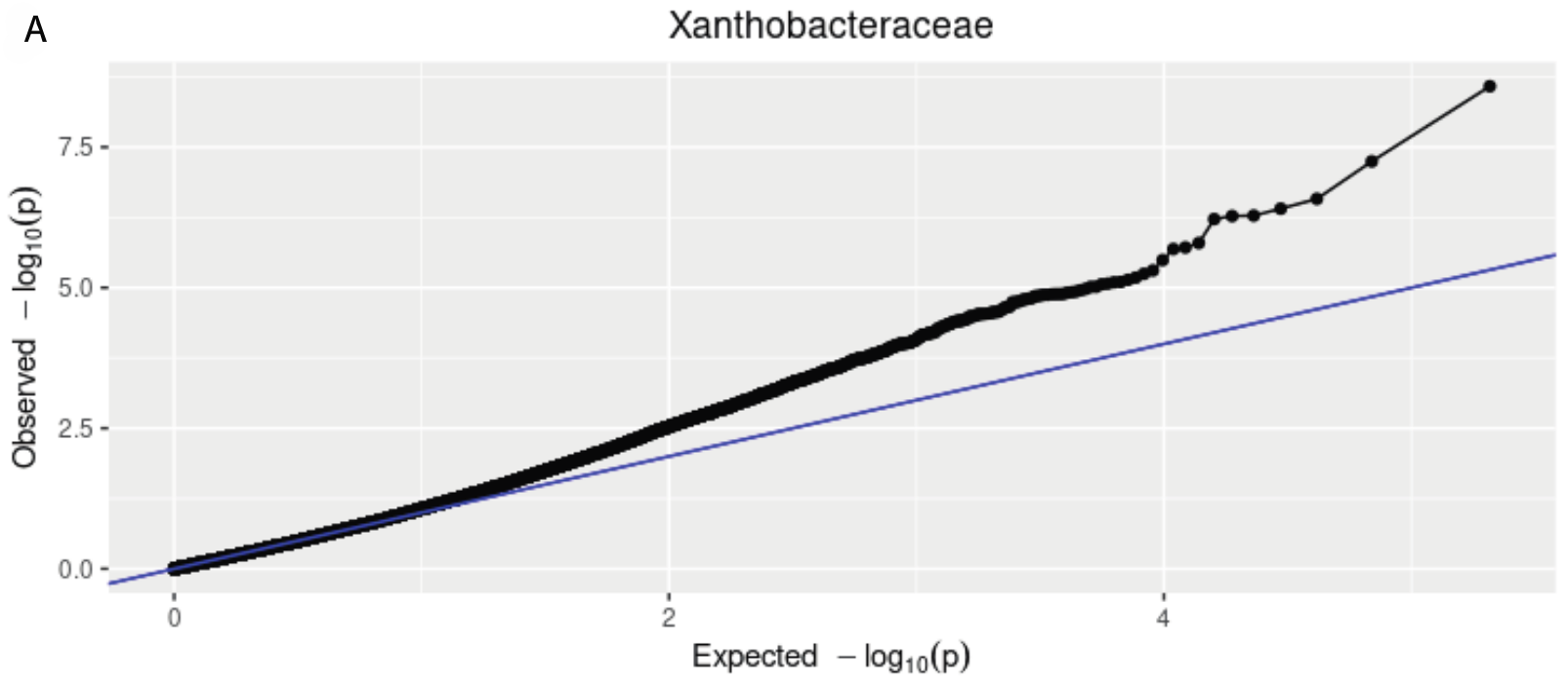

B

\section{Sphingomonadaceae}

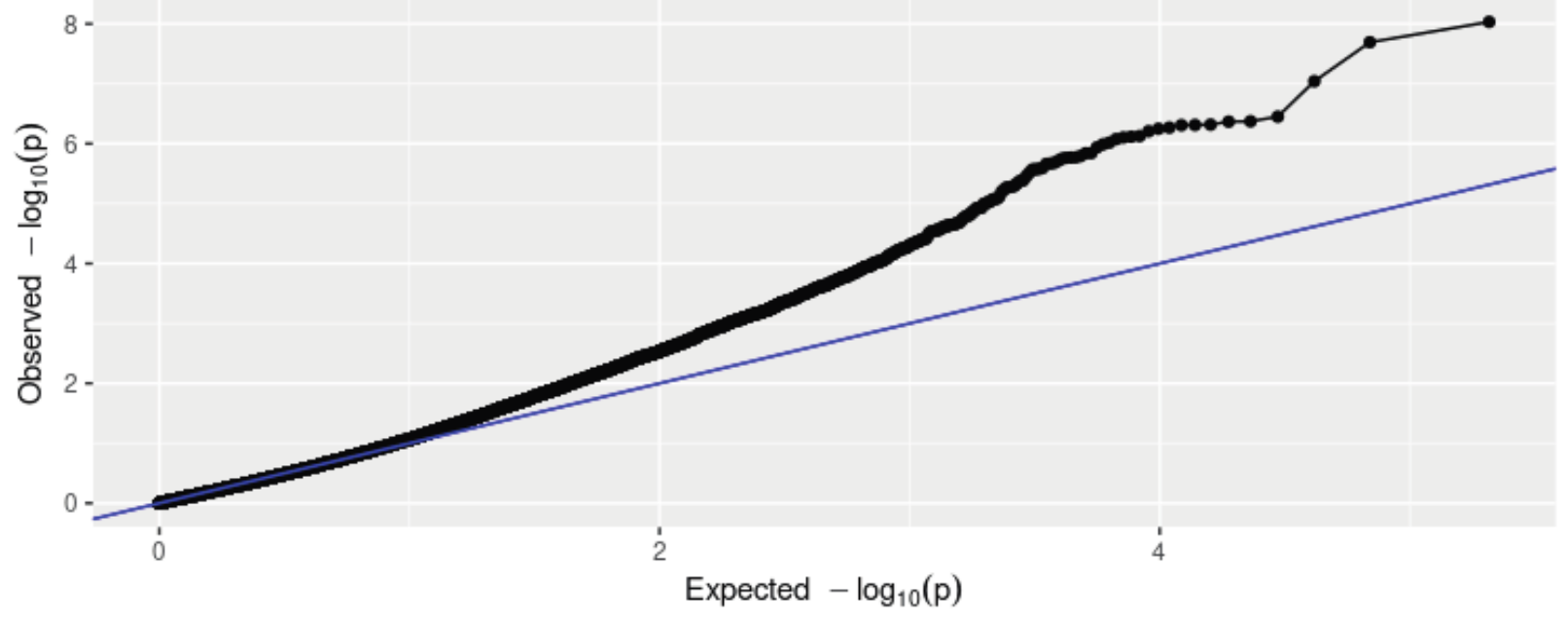

C

\section{Micromonosporaceae}

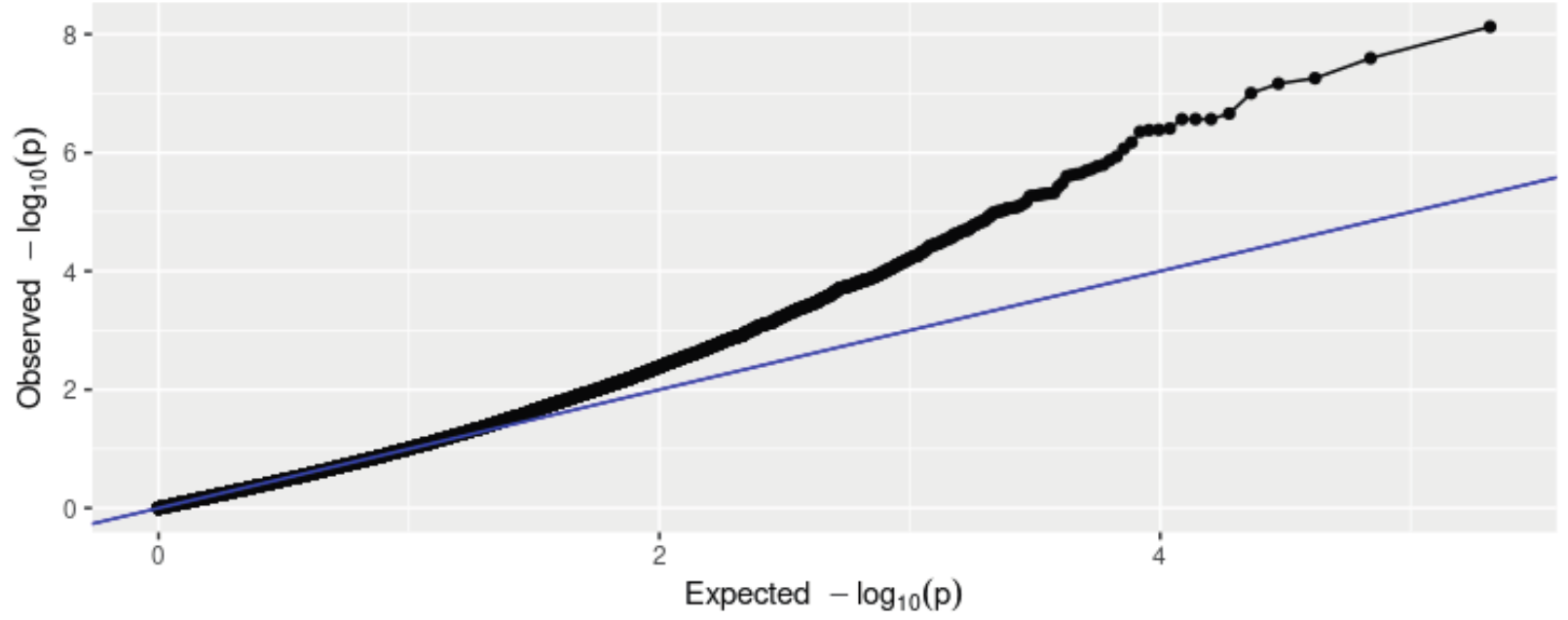


821 Genome-wide association study (GWAS): A: QQ plot presenting significant SNPs (red) associated with

822 Xanthobacteraceae rhizosphere abundance. B: QQ plot presenting significant SNPs (red) associated with

823 Sphingomonadaceae rhizosphere abundance. $C$ : QQ plot presenting significant SNPs (red) associated with

824 Micromonosporaceae rhizosphere abundance.

825

826

Supplemental Tables:

827

Observ

Accession
Blackwell.01

.2

Blackwell.01

Blackwell.02

Blackwell.03

Blackwell.04

Blackwell.05

Blackwell.06

Carthage.01

.2

Carthage.01

Carthage.02

Carthage.03

Carthage.04

Carthage.05

Carthage.06

CaveinRock.

01

CaveinRock.

03

CaveinRock.

04

CaveinRock.

06

CaveinRock.

07

CaveinRock.

08

Dacotah.02

Dacotah.03

\section{ed}

\section{4}

82

82.75

157.090

132

909

128.111

122

111

196.576

$175 \quad 923$

13

203

655

35

33

33

47

25

15

46

179

46

241.217

391

34

34

11

51

11

51.75

19

19

19

468

676

25

19

756.309

278

1277.42

424 se.chao1 23.394779

ACE

354.272

918

82.8502

1.4225048

13.659610

641

145.800

369

4.9758218

125.653

226

$9.7584752 \quad 194.578$

467

13

0
12.043015

13
226.089

895

35

34.6522

222

33.4661

103

47.1796

516

5

0.4898979

26.12

16.12

0.2472676

46.3328

042

22.700631

225.941

994

34

NA

1.4216995

52.5269

868

$$
19
$$

19

50.450369

725.718

703

1308.02

044
Se.ACE

8.002603

4.475540

56

5.671623

4.950851

1

5.869440

07

0.960768

92

5.819401

91

2.229670

06

2.343733

1.792922

1.792922
95

3.028009

26

1.147710

2

0.966091

78

2.872233

76

7.275428

77

2.222875

72

NA

3.487480

35

1.589438

83

2.026144

77.663680

14.55862
4.215349
4.5370031

0.983254

0.986778

4.5327523

0.986856

4.8451448

0.990238

2.3923152

0.899676

5.0021228

0.991456

3.3590414

0.960402

3.1504598

0.94669

3.2537473

0.95452

3.6323294

0.969314

2.9982538

0.941572

2.4329510

0.900104

3.5933987

4.7746719

0.967658

0.988734

3.3010188

0.957934

2.0135421

0.816972

3.5505624

0.964654

2.5947938

0.906036

2.3547577

0.872682

5.9079517

0.996468

6.3979261

0.998092

InvSimpson

5.46364491

28.2917445
17.00212

02
8
162.179695

59.715753

75.6315232

76.0803408

102.438025

9.96770464

117.041199

25.2538007

18.7582067

21.9876869

32.588151

17.1150818

10.0104108

30.9195473

88.7626487

23.7721676

11.361576

3.3283031

10.642373

3.3283031

7.85434895

283.125708

Fisher

132.26882

21.150173

40.732534

36.441366

61.407364

2.1091676

76.920499

7.0549535

6.5554321

6.5554321

10.234894

4.6508688

2.5030219

9.9583175

6.8040632

3

1.7290385

1

342.72404

524.109015
63.520861

916.05373 


\begin{tabular}{|c|c|c|c|c|c|c|c|c|c|}
\hline & & 624.741 & 38.926336 & 620.717 & 13.96987 & 5.7900730 & & & 276.56328 \\
\hline \multirow[t]{2}{*}{ Dacotah.04 } & 423 & 573 & 4 & 968 & 77 & 9 & 0.99604 & 252.525253 & 7 \\
\hline & & 674.666 & 37.119183 & 708.293 & 15.52590 & 5.9068336 & & & 337.92165 \\
\hline \multirow[t]{2}{*}{ Dacotah.05 } & 465 & 667 & 8 & 812 & 06 & 3 & 0.996498 & 285.551114 & 5 \\
\hline & & 1104.38 & 65.879614 & 1139.99 & 17.53679 & 6.2936985 & & & 713.14069 \\
\hline \multirow[t]{2}{*}{ Dacotah.07 } & 625 & 71 & 1 & 626 & 3 & 4 & 0.997828 & 460.405157 & 8 \\
\hline & & & 221.95544 & 2679.47 & 13.78880 & 6.6552991 & & & 2260.3525 \\
\hline \multirow[t]{2}{*}{ Dacotah.08 } & 828 & 2680.32 & 6 & 419 & 54 & 8 & 0.9986 & 714.285714 & 9 \\
\hline & & & & & 2.304418 & 3.0658291 & & & 5.5839911 \\
\hline \multirow[t]{2}{*}{ ECS.1.05 } & 29 & 29 & 0 & 29 & 54 & 5 & 0.942692 & 17.4495707 & 2 \\
\hline & & & 2.2998855 & 20.5890 & 1.683910 & & & & 3.1175139 \\
\hline \multirow[t]{2}{*}{ ECS.1.06 } & 18 & 19 & 8 & 909 & 07 & 2.5683886 & 0.914612 & 11.7112475 & 4 \\
\hline & & & & & 2.788866 & 3.6244770 & & & 9.6838002 \\
\hline \multirow[t]{2}{*}{ ECS.12.01 } & 45 & 45 & 0 & 45 & 76 & 8 & 0.969748 & 33.0556657 & 4 \\
\hline & & 183.769 & 17.238614 & 165.971 & 5.763388 & 4.6236123 & & & \\
\hline \multirow[t]{2}{*}{ ECS.12.02 } & 148 & 231 & 5 & 715 & 15 & 2 & 0.987436 & 79.5924865 & 47.997644 \\
\hline & & & & 92.3956 & 4.726708 & & & & \\
\hline \multirow[t]{2}{*}{ ECS.12.03 } & 92 & 92.2 & 0.6211081 & 644 & 63 & 4.2780631 & 0.983272 & 59.7800096 & 24.694105 \\
\hline & & 135.312 & 1.6025110 & 136.017 & 4.915418 & 4.6706732 & & & 41.613637 \\
\hline \multirow[t]{2}{*}{ ECS.12.05 } & 134 & 5 & 7 & 432 & 19 & 1 & 0.988754 & 88.9205051 & 9 \\
\hline & & & 0.6211025 & 91.4664 & 4.756108 & 4.3463872 & & & 24.331359 \\
\hline \multirow[t]{2}{*}{ ECS.12.07 } & 91 & 91.2 & 9 & 354 & 06 & 3 & 0.985614 & 69.5120256 & 3 \\
\hline & & 126.583 & 5.4482389 & 125.221 & 5.179940 & 4.4153944 & & & 35.190936 \\
\hline \multirow[t]{2}{*}{ ECS.2.02 } & 119 & 333 & 4 & 544 & 28 & 3 & 0.984792 & 65.7548659 & 6 \\
\hline & & 290.454 & & 272.205 & 6.573931 & 5.1440032 & & & \\
\hline \multirow[t]{2}{*}{ ECS.2.03 } & 235 & 546 & 18.730274 & 486 & 01 & 3 & 0.992416 & 131.85654 & 96.81155 \\
\hline & & & 0.7360481 & 81.5651 & 4.487695 & 4.1634070 & & & 20.806009 \\
\hline \multirow[t]{2}{*}{ ECS.2.04 } & 81 & 81.25 & 2 & 007 & 33 & 4 & 0.981912 & 55.285272 & 8 \\
\hline & & & 0.3817603 & 76.5797 & 4.342524 & & & & 19.113207 \\
\hline \multirow[t]{2}{*}{ ECS.2.06 } & 76 & 76.1 & 9 & 785 & 45 & 4.0168183 & 0.977958 & 45.3679339 & 7 \\
\hline & & & 2.3326329 & 67.2962 & 3.995960 & 4.0140341 & & & 16.184541 \\
\hline \multirow[t]{2}{*}{ ECS.2.07 } & 67 & 68 & 5 & 963 & 89 & 7 & 0.979062 & 47.7600535 & 4 \\
\hline & & & 0.2472066 & 45.3072 & 2.933789 & 3.5627293 & & & 9.6838002 \\
\hline \multirow[t]{2}{*}{ ECS.10.01 } & 45 & 45 & 2 & 902 & 86 & 5 & 0.967504 & 30.7730182 & 4 \\
\hline & & & & & 1.624807 & 2.9845207 & & & 4.6508688 \\
\hline \multirow[t]{2}{*}{ ECS.10.03 } & 25 & 25 & 0 & 25 & 68 & 5 & 0.940842 & 16.9038845 & 2 \\
\hline & & & 4.5993925 & 32.8037 & 2.514591 & 3.0079953 & & & \\
\hline ECS.10.07 & 31 & 34 & 4 & 5 & 17 & 2 & 0.937756 & 16.0658055 & 6.0650427 \\
\hline & & & 0.4909902 & 28.2733 & 2.356810 & 3.0237944 & & & 5.3470387 \\
\hline ECS.10.08 & 28 & 28 & 5 & 113 & 57 & 5 & 0.943754 & 17.7790421 & 8 \\
\hline & & & & & 3.089571 & 3.5389183 & & & 9.4113548 \\
\hline ECS.10.09 & 44 & 44 & 0 & 44 & 9 & 4 & 0.966258 & 29.6366546 & 7 \\
\hline & & & 2.3232382 & 39.4975 & 2.415816 & 3.3910601 & & & 7.8209646 \\
\hline ECS.10.10 & 38 & 39 & 4 & 37 & 29 & 4 & 0.961654 & 26.0783393 & 9 \\
\hline & & 117.833 & 1.2604964 & 118.395 & 4.950770 & 4.5256214 & & & 34.366727 \\
\hline ECS.11.01 & 117 & 333 & 7 & 017 & 42 & 5 & 0.987064 & 77.3036487 & 8 \\
\hline & & & 0.0988571 & 44.4333 & 2.851068 & 3.5181090 & & & 9.4113548 \\
\hline ECS.11.02 & 44 & 44 & 1 & 048 & 81 & 1 & 0.96517 & 28.7108814 & 7 \\
\hline & & & & & 2.053959 & 3.2729350 & & & 6.3090836 \\
\hline ECS.11.04 & 32 & 32 & 0 & 32 & 59 & 9 & 0.957414 & 23.4818955 & 3 \\
\hline & & & & & 1.337712 & 2.6862938 & & & 3.3283031 \\
\hline ECS.11.05 & 19 & 19 & 0 & 19 & 11 & 4 & 0.92127 & 12.7016385 & 1 \\
\hline
\end{tabular}




\begin{tabular}{|c|c|c|c|c|c|c|c|c|c|}
\hline & & & 25.182649 & 196.417 & 6.860286 & 4.5762160 & & & 52.304464 \\
\hline \multirow[t]{2}{*}{ ECS.11.07 } & 157 & 218.875 & 8 & 512 & 26 & 5 & 0.986162 & 72.2647782 & 6 \\
\hline & & & & & & 2.2086196 & & & \\
\hline \multirow[t]{2}{*}{ HighTide.02 } & 11 & 11 & 0 & NA & NA & 1 & 0.86129 & 7.20928556 & 1.7290385 \\
\hline & & & & & 1.345185 & 2.8546305 & & & 3.7583769 \\
\hline \multirow[t]{2}{*}{ HighTide.03 } & 21 & 21 & 0 & 21 & 42 & 9 & 0.9339 & 15.128593 & 1 \\
\hline & & & & & 1.788854 & 2.6534529 & & & 3.5419457 \\
\hline \multirow[t]{2}{*}{ HighTide.05 } & 20 & 20 & 0 & 20 & 38 & 5 & 0.913368 & 11.5430788 & 8 \\
\hline & & & & & 0.953462 & 2.0604604 & & & \\
\hline \multirow[t]{2}{*}{ HighTide.09 } & 11 & 11 & 0 & 11 & 59 & 1 & 0.848558 & 6.60318802 & 1.7290385 \\
\hline & & & & & 0.968245 & 2.5352006 & & & 2.7047898 \\
\hline \multirow[t]{2}{*}{ HighTide.10 } & 16 & 16 & 0 & 16 & 84 & 8 & 0.909588 & 11.0604787 & 6 \\
\hline & & & 5.7942620 & 136.481 & 5.060855 & 4.6272811 & & & 40.732534 \\
\hline \multirow[t]{2}{*}{ Kanlow.01 } & 132 & 139.8 & 5 & 022 & 93 & 3 & 0.988286 & 85.3679358 & 1 \\
\hline & & & & 59.2239 & 3.562309 & 3.8346694 & & & 13.710755 \\
\hline \multirow[t]{2}{*}{ Kanlow.02 } & 59 & 59 & 0.1652482 & 335 & 36 & 8 & 0.974376 & 39.0259132 & 8 \\
\hline & & & 2.3277386 & 48.5768 & 3.106327 & 3.6482240 & & & 10.513519 \\
\hline \multirow[t]{2}{*}{ Kanlow.03 } & 48 & 49 & 8 & 655 & 2 & 8 & 0.970032 & 33.3689269 & 9 \\
\hline & & & & & 2.034190 & 3.0615609 & & & 5.5839911 \\
\hline \multirow[t]{2}{*}{ Kanlow.04 } & 29 & 29 & 0 & 29 & 51 & 8 & 0.943474 & 17.6909741 & 2 \\
\hline & & 197.676 & 8.8938170 & 202.486 & 6.234049 & 4.7330135 & & & 62.459927 \\
\hline \multirow[t]{2}{*}{ Kanlow.05 } & 177 & 471 & 5 & 714 & 7 & 2 & 0.987688 & 81.2215725 & 9 \\
\hline & & & & & 2.304418 & 3.0572103 & & & 5.5839911 \\
\hline \multirow[t]{2}{*}{ Kanlow.06 } & 29 & 29 & 0 & 29 & 54 & 4 & 0.944458 & 18.0043931 & 2 \\
\hline & & & & & 3.016620 & 3.2779203 & & & 8.3425609 \\
\hline \multirow[t]{2}{*}{ Kanlow.08 } & 40 & 40 & 0 & 40 & 63 & 6 & 0.950638 & 20.2584984 & 6 \\
\hline & & & & & 1.951800 & 2.4982881 & & & 3.7583769 \\
\hline \multirow[t]{2}{*}{ Kanlow.10 } & 21 & 21 & 0 & 21 & 15 & 9 & 0.87997 & 8.33125052 & 1 \\
\hline & & & & & 2.236067 & 3.3007340 & & & 7.3080809 \\
\hline \multirow[t]{2}{*}{ KY1625.01 } & 36 & 36 & 0 & 36 & 98 & 1 & 0.955154 & 22.2985328 & 3 \\
\hline & & & & & 1.609630 & 2.8223172 & & & \\
\hline \multirow[t]{2}{*}{ KY1625.02 } & 22 & 22 & 0 & 22 & 11 & 1 & 0.930418 & 14.3715329 & 3.9775371 \\
\hline & & & 0.4885042 & 22.5871 & 1.832393 & & & & \\
\hline \multirow[t]{2}{*}{ KY1625.03 } & 22 & 22 & 1 & 936 & 2 & 2.8498394 & 0.93646 & 15.7381177 & 3.9775371 \\
\hline & & & 2.3145502 & 28.1911 & 2.095781 & 3.0126158 & & & 5.1125109 \\
\hline \multirow[t]{2}{*}{ KY1625.04 } & 27 & 28 & 5 & 385 & 78 & 9 & 0.944648 & 18.0661945 & 2 \\
\hline & & & 0.4952605 & 53.1403 & 3.309600 & 3.7910374 & & & 11.936998 \\
\hline KY1625.06 & 53 & 53 & 6 & 509 & 16 & 2 & 0.974256 & 38.8440025 & 1 \\
\hline & & & 0.2465033 & 36.3734 & 2.316959 & & & & 7.3080809 \\
\hline KY1625.07 & 36 & 36 & 2 & 074 & 53 & 3.323476 & 0.957368 & 23.4565585 & 3 \\
\hline Pathfinder.0 & & & 0.4894725 & 25.1111 & 1.066883 & & & & 4.4238312 \\
\hline 1 & 24 & 24 & 1 & 111 & 2 & 2.8738709 & 0.931104 & 14.5146308 & 1 \\
\hline Pathfinder.0 & & & 0.4918693 & 31.3805 & 1.810100 & 3.2172318 & & & \\
\hline 2 & 31 & 31 & 8 & 41 & 82 & 1 & 0.952968 & 21.2621194 & 6.0650427 \\
\hline Pathfinder.0 & & & 0.4960158 & 63.1347 & 3.615392 & 4.0034066 & & & 14.932265 \\
\hline 3 & 63 & 63 & 7 & 518 & 81 & 9 & 0.979342 & 48.4073967 & 5 \\
\hline Pathfinder.0 & & & 0.1653594 & 64.1680 & 3.910412 & 3.9565316 & & & 15.242462 \\
\hline 4 & 64 & 64 & 6 & 336 & 95 & 2 & 0.97814 & 45.7456542 & 8 \\
\hline Pathfinder.0 & & 497.149 & 32.223917 & 481.942 & 10.68062 & 5.5926925 & & & 195.49644 \\
\hline 5 & 354 & 254 & 2 & 64 & 65 & 1 & 0.995268 & 211.327134 & 5 \\
\hline Pathfinder.0 & & & 0.0992619 & 68.3272 & 4.026175 & 3.9687013 & & & 16.502381 \\
\hline 6 & 68 & 68 & 8 & 39 & 65 & 1 & 0.977834 & 45.1141388 & 4 \\
\hline
\end{tabular}




\begin{tabular}{|c|c|c|c|c|c|c|c|c|c|}
\hline & & 266.675 & & 262.922 & 6.869075 & & & & 88.440004 \\
\hline \multirow[t]{2}{*}{ Shelter.01 } & 222 & 676 & 15.401994 & 522 & 03 & 5.0768225 & 0.992116 & 126.839168 & 9 \\
\hline & & 148.157 & 4.7464328 & 147.604 & 5.125929 & 4.6565174 & & & 44.758093 \\
\hline \multirow[t]{2}{*}{ Shelter.04 } & 141 & 895 & 2 & 547 & 49 & 1 & 0.988222 & 84.9040584 & 5 \\
\hline & & 107.111 & 4.9755659 & 105.959 & 5.042556 & 4.3239777 & & & 28.042367 \\
\hline \multirow[t]{2}{*}{ Shelter.05 } & 101 & 111 & 3 & 064 & 18 & 8 & 0.984116 & 62.9564342 & 7 \\
\hline & & & & & 2.620767 & 3.4252775 & & & 7.8209646 \\
\hline \multirow[t]{2}{*}{ Shelter.06 } & 38 & 38 & 0 & 38 & 26 & 8 & 0.962992 & 27.0211846 & 9 \\
\hline & & & & 41.3370 & 2.594245 & 3.4853419 & & & 8.6065827 \\
\hline \multirow[t]{2}{*}{ Shelter.07 } & 41 & 41 & 0.1646216 & 185 & 3 & 4 & 0.964894 & 28.4851592 & 4 \\
\hline & & & & & 2.247805 & 3.4858016 & & & 7.8209646 \\
\hline \multirow[t]{2}{*}{ Shelter.08 } & 38 & 38 & 0 & 38 & 95 & 3 & 0.965726 & 29.1766354 & 9 \\
\hline & & & & & 0.980580 & 3.1696484 & & & 4.8804419 \\
\hline \multirow[t]{2}{*}{ Sunburst.01 } & 26 & 26 & 0 & 26 & 68 & 6 & 0.955562 & 22.503263 & 6 \\
\hline & & & & & 1.615145 & 2.9328576 & & & 4.1993718 \\
\hline \multirow[t]{2}{*}{ Sunburst.02 } & 23 & 23 & 0 & 23 & 71 & 3 & 0.94052 & 16.8123739 & 9 \\
\hline & & & 0.4890096 & 24.0864 & 1.483973 & 3.0044659 & & & 4.1993718 \\
\hline \multirow[t]{2}{*}{ Sunburst.04 } & 23 & 23 & 5 & 198 & 93 & 3 & 0.946512 & 18.6957822 & 9 \\
\hline & & 61.3333 & 0.9245561 & 61.5347 & 3.627977 & 3.9264577 & & & 14.317643 \\
\hline \multirow[t]{2}{*}{ Sunburst.05 } & 61 & 333 & 5 & 21 & 36 & 1 & 0.977988 & 45.4297656 & 8 \\
\hline & & 231.823 & & 231.577 & 6.244902 & 4.9978561 & & & 77.506253 \\
\hline \multirow[t]{2}{*}{ Sunburst.06 } & 204 & 529 & 11.04251 & 917 & 37 & 5 & 0.99154 & 118.20331 & 5 \\
\hline & & & 0.4923659 & 33.3279 & 2.307691 & 3.2662388 & & & 6.5554321 \\
\hline \multirow[t]{2}{*}{ Sunburst.07 } & 33 & 33 & 6 & 766 & 93 & 2 & 0.956992 & 23.2514881 & 1 \\
\hline & & 1300.36 & 84.349896 & 1313.73 & 17.21792 & & & & 849.79393 \\
\hline \multirow[t]{2}{*}{ SW102.01 } & 661 & 913 & 8 & 961 & 41 & 6.3621531 & 0.997996 & 499.001996 & 8 \\
\hline & & 2380.54 & 191.69492 & 2405.20 & 15.69208 & 6.6029326 & & & \\
\hline \multirow[t]{2}{*}{ SW102.02 } & 798 & 688 & 1 & 226 & 59 & 9 & 0.998492 & 663.129974 & 1832.3246 \\
\hline & & 758.794 & 47.138486 & 755.958 & 15.62673 & 5.9716331 & & & 369.39039 \\
\hline \multirow[t]{2}{*}{ SW102.03 } & 484 & 393 & 3 & 608 & 43 & 7 & 0.99687 & 319.488818 & 3 \\
\hline & & 793.045 & 43.863284 & 800.693 & 15.20757 & & & & \\
\hline \multirow[t]{2}{*}{ SW102.04 } & 522 & 455 & 9 & 061 & 04 & 6.0783177 & 0.997264 & 365.497076 & 440.66336 \\
\hline & & 1037.39 & 72.873095 & 1011.43 & 17.55745 & 6.1260082 & & & 518.14414 \\
\hline \multirow[t]{2}{*}{ SW102.05 } & 557 & 823 & 3 & 725 & 61 & 5 & 0.997286 & 368.459838 & 6 \\
\hline & & 545.011 & 31.403449 & 565.668 & 12.82308 & 5.6877861 & & & 236.27209 \\
\hline \multirow[t]{2}{*}{ SW102.06 } & 391 & 111 & 6 & 334 & 41 & 8 & 0.995596 & 227.066303 & 9 \\
\hline & & & 2.2303578 & 77.2480 & 4.314111 & 4.0450301 & & & 19.113207 \\
\hline SW109.01 & 76 & 77.5 & 1 & 166 & 34 & 7 & 0.97858 & 46.6853408 & 7 \\
\hline & & & & 41.2737 & 2.709759 & & & & 8.6065827 \\
\hline SW109.02 & 41 & 41 & 0.2469324 & 255 & 07 & 3.4328486 & 0.961836 & 26.2027041 & 4 \\
\hline & & & 60.039323 & 973.887 & 18.10678 & 6.1203808 & & & 503.93733 \\
\hline SW109.03 & 551 & 946 & 6 & 63 & 14 & 5 & 0.997308 & 371.471025 & 8 \\
\hline & & 107.857 & 6.3350402 & 104.429 & 4.952243 & 4.3188250 & & & 27.662922 \\
\hline SW109.04 & 100 & 143 & 3 & 098 & 42 & 3 & 0.984176 & 63.1951466 & 1 \\
\hline & & 144.807 & 1.1265561 & 146.463 & 5.203400 & & & & 46.134760 \\
\hline SW109.05 & 144 & 692 & 4 & 757 & 52 & 4.7150251 & 0.989222 & 92.7815921 & 6 \\
\hline & & & 2.3261795 & 44.7873 & 2.485914 & 3.5940011 & & & 9.4113548 \\
\hline SW109.06 & 44 & 45 & 1 & 431 & 29 & 9 & 0.968868 & 32.12129 & 7 \\
\hline & & 458.222 & 33.945054 & 435.872 & 9.938721 & 5.4450033 & & & 160.03554 \\
\hline SW109.07 & 317 & 222 & 8 & 385 & 04 & 3 & 0.994486 & 181.356547 & 6 \\
\hline & & 82.8571 & 1.3946665 & 83.3088 & 4.499746 & 4.1874380 & & & 21.150173 \\
\hline SW110.01 & 82 & 429 & 3 & 896 & 92 & 5 & 0.982186 & 56.1356237 & 3 \\
\hline
\end{tabular}




\begin{tabular}{|c|c|c|c|c|c|c|c|c|c|}
\hline & & 825.411 & 48.780317 & 772.572 & 14.60961 & 6.1071805 & & & 450.97506 \\
\hline \multirow[t]{2}{*}{ SW110.02 } & 527 & 765 & 8 & 416 & 38 & 1 & 0.997406 & 385.505012 & 8 \\
\hline & & 798.962 & 39.216606 & 830.401 & 15.60662 & 6.1457769 & & & 496.98551 \\
\hline \multirow[t]{2}{*}{ SW110.03 } & 548 & 264 & 9 & 116 & 49 & 6 & 0.997474 & 395.882819 & 9 \\
\hline & & & & & 3.603239 & & & & 14.013230 \\
\hline \multirow[t]{2}{*}{ SW110.04 } & 60 & 60 & 0 & 60 & 28 & 3.8856459 & 0.97624 & 42.0875421 & 2 \\
\hline & & 102.333 & 0.7585402 & 102.712 & 4.970449 & 4.3883292 & & & 28.423670 \\
\hline \multirow[t]{2}{*}{ SW110.05 } & 102 & 333 & 2 & 117 & 37 & 4 & 0.98537 & 68.3526999 & 5 \\
\hline & & & 18.055641 & 293.765 & 7.543141 & 5.1113165 & & & 99.470471 \\
\hline \multirow[t]{2}{*}{ SW110.06 } & 239 & 296.5 & 1 & 997 & 39 & 5 & 0.992004 & 125.062531 & 7 \\
\hline & & & & & 2.247805 & 3.4529103 & & & 7.8209646 \\
\hline \multirow[t]{2}{*}{ SW112.01 } & 38 & 38 & 0 & 38 & 95 & 5 & 0.963954 & 27.7423293 & 9 \\
\hline & & & 0.4933771 & 38.2777 & 1.942205 & 3.4570502 & & & 7.8209646 \\
\hline \multirow[t]{2}{*}{ SW112.03 } & 38 & 38 & 9 & 778 & 17 & 9 & 0.964716 & 28.3414579 & 9 \\
\hline & & & 1.2952673 & 57.4978 & 3.514503 & 3.7856122 & & & 13.111649 \\
\hline \multirow[t]{2}{*}{ SW112.04 } & 57 & 57.5 & 1 & 983 & 42 & 5 & 0.972816 & 36.7863449 & 3 \\
\hline & & 350.258 & & 346.502 & 7.517912 & 5.4187040 & & & 139.50889 \\
\hline \multirow[t]{2}{*}{ SW112.05 } & 293 & 621 & 16.574448 & 027 & 2 & 1 & 0.994522 & 182.548375 & 4 \\
\hline & & 96.6666 & & 96.1614 & 4.781793 & 4.3380314 & & & 25.793473 \\
\hline \multirow[t]{2}{*}{ SW112.06 } & 95 & 667 & 2.2045363 & 415 & 98 & 2 & 0.9846 & 64.9350649 & 8 \\
\hline & & & & & 2.065116 & 3.3471525 & & & 6.8040632 \\
\hline \multirow[t]{2}{*}{ SW112.07 } & 34 & 34 & 0 & 34 & 43 & 7 & 0.960178 & 25.1117473 & 3 \\
\hline & & 998.937 & 55.867297 & 1045.23 & 17.58806 & 6.2536799 & & & 645.37092 \\
\hline \multirow[t]{2}{*}{ SW114.01 } & 604 & 5 & 2 & 435 & 44 & 5 & 0.997728 & 440.140845 & 7 \\
\hline & & 386.571 & 17.559381 & 375.829 & 7.422961 & 5.5696491 & & & 165.45875 \\
\hline \multirow[t]{2}{*}{ SW114.02 } & 323 & 429 & 7 & 321 & 37 & 5 & 0.99548 & 221.238938 & 9 \\
\hline & & 785.269 & 38.483632 & 812.478 & 15.36338 & 6.1335031 & & & \\
\hline \multirow[t]{2}{*}{ SW114.03 } & 542 & 231 & 2 & 316 & 57 & 9 & 0.997442 & 390.930414 & 483.37524 \\
\hline & & 2838.97 & 254.66957 & 2870.12 & 16.33949 & 6.6092716 & & & 1946.6333 \\
\hline \multirow[t]{2}{*}{ SW114.04 } & 807 & 222 & 4 & 007 & 29 & 9 & 0.998482 & 658.761528 & 9 \\
\hline & & 495.142 & 29.713622 & 473.017 & 10.17081 & 5.6495506 & & & 205.95653 \\
\hline \multirow[t]{2}{*}{ SW114.05 } & 364 & 857 & 5 & 313 & 75 & 8 & 0.995624 & 228.519196 & 8 \\
\hline & & 88.6666 & 4.4908603 & 87.4215 & 4.615603 & 4.1227654 & & & 21.844089 \\
\hline \multirow[t]{2}{*}{ SW114.07 } & 84 & 667 & 8 & 719 & 31 & 6 & 0.98023 & 50.5816894 & 3 \\
\hline & & & 0.0992509 & 67.2028 & 4.068502 & 3.9451636 & & & 16.184541 \\
\hline \multirow[t]{2}{*}{ SW114.08 } & 67 & 67 & 3 & 536 & 12 & 1 & 0.976966 & 43.4140835 & 4 \\
\hline & & & 9.6567964 & 311.412 & 5.471092 & 5.4390300 & & & 132.26882 \\
\hline SW115.01 & 284 & 311.55 & 4 & 824 & 91 & 6 & 0.994722 & 189.465707 & 2 \\
\hline & & 2898.46 & & 2884.04 & 13.35152 & 6.6685517 & & & 2419.7627 \\
\hline SW115.02 & 837 & 61 & 249.31555 & 551 & 03 & 5 & 0.998622 & 725.689405 & 8 \\
\hline & & 1466.80 & & 1517.40 & 18.08361 & 6.4207845 & & & 1004.4280 \\
\hline SW115.03 & 694 & 667 & 98.459852 & 599 & 24 & 8 & 0.998112 & 529.661017 & 4 \\
\hline & & 822.007 & 44.036882 & 824.114 & 15.88440 & 6.1353856 & & & 485.61692 \\
\hline SW115.04 & 543 & 092 & 6 & 014 & 11 & 3 & 0.997444 & 391.236307 & 7 \\
\hline & & & 20.348782 & 328.695 & 8.397857 & 5.1688365 & & & \\
\hline SW115.06 & 262 & 333.4 & 6 & 018 & 74 & 4 & 0.992 & 125 & 115.55145 \\
\hline & & & 126.47829 & 1753.29 & 17.03139 & 6.4819939 & & & \\
\hline SW116.02 & 728 & 1740.7 & 5 & 48 & 67 & 9 & 0.99825 & 571.428571 & 1204.2124 \\
\hline & & 2207.68 & 167.39303 & 2281.26 & 15.23266 & 6.6061864 & & & \\
\hline SW116.03 & 798 & 085 & 3 & 827 & 02 & 1 & 0.998506 & 669.344043 & 1832.3246 \\
\hline & & 1813.15 & 134.05897 & 1866.32 & 17.50813 & 6.4907478 & & & 1251.8622 \\
\hline SW116.05 & 735 & 217 & 7 & 534 & 57 & 8 & 0.998256 & 573.394495 & 8 \\
\hline
\end{tabular}




\begin{tabular}{|c|c|c|c|c|c|c|c|c|c|}
\hline & & & 59.339305 & 999.748 & 19.75033 & 6.0799997 & & & \\
\hline \multirow[t]{2}{*}{ SW116.07 } & 542 & 930.128 & 5 & 134 & 77 & 7 & 0.997072 & 341.530055 & 483.37524 \\
\hline & & 1447.09 & 92.913821 & 1475.47 & 16.84388 & 6.4515826 & & & 1069.5348 \\
\hline \multirow[t]{2}{*}{ SW116.08 } & 706 & 317 & 4 & 377 & 07 & 4 & 0.998206 & 557.413601 & 7 \\
\hline & & 713.439 & 38.111760 & 787.171 & 16.89353 & 5.9544505 & & & 374.59615 \\
\hline \multirow[t]{2}{*}{ SW116.09 } & 487 & 394 & 3 & 713 & 21 & 1 & 0.996664 & 299.760192 & 7 \\
\hline & & 366.428 & 21.837920 & 368.981 & 8.768288 & 5.3205579 & & & 133.06144 \\
\hline \multirow[t]{2}{*}{ SW122.01 } & 285 & 571 & 2 & 817 & 86 & 9 & 0.99364 & 157.232704 & 7 \\
\hline & & & 2.5842331 & 69.2796 & 4.071990 & & & & 16.184541 \\
\hline \multirow[t]{2}{*}{ SW122.02 } & 67 & 69 & 3 & 504 & 03 & 3.8993284 & 0.975504 & 40.8229915 & 4 \\
\hline & & 413.838 & 15.307925 & 421.873 & 8.208279 & & & & 195.49644 \\
\hline \multirow[t]{2}{*}{ SW122.03 } & 354 & 71 & 4 & 189 & 85 & 5.6665673 & 0.995926 & 245.459008 & 5 \\
\hline & & 131.666 & 8.0006549 & 126.221 & 5.170465 & 4.4950221 & & & 35.605862 \\
\hline \multirow[t]{2}{*}{ SW122.05 } & 120 & 667 & 2 & 269 & 05 & 9 & 0.986472 & 73.920757 & 2 \\
\hline & & 105.333 & 4.1251151 & 103.015 & 4.694652 & 4.4101508 & & & 28.423670 \\
\hline \multirow[t]{2}{*}{ SW122.06 } & 102 & 333 & 3 & 706 & 7 & 5 & 0.985426 & 68.6153424 & 5 \\
\hline & & & 0.6206871 & 50.8760 & 3.353897 & 3.6167772 & & & 11.076870 \\
\hline \multirow[t]{2}{*}{ SW123.01 } & 50 & 50.2 & 9 & 602 & 4 & 8 & 0.968186 & 31.4327026 & 8 \\
\hline & & & 0.4890096 & 23.5247 & & 2.8611842 & & & 4.1993718 \\
\hline \multirow[t]{2}{*}{ SW123.02 } & 23 & 23 & 5 & 303 & 1.7591 & 2 & 0.933426 & 15.020879 & 9 \\
\hline & & 74.1111 & & 75.6248 & 4.313761 & 3.8457485 & & & 17.467286 \\
\hline \multirow[t]{2}{*}{ SW123.04 } & 71 & 111 & 3.1006765 & 977 & 74 & 6 & 0.972622 & 36.5256776 & 6 \\
\hline & & 347.837 & 30.158536 & 331.011 & 8.837619 & 5.0507301 & & & 101.49086 \\
\hline \multirow[t]{2}{*}{ SW123.05 } & 242 & 838 & 5 & 052 & 16 & 8 & 0.991038 & 111.582236 & 4 \\
\hline & & & & & 1.371988 & 3.3944481 & & & 6.8040632 \\
\hline \multirow[t]{2}{*}{ SW123.06 } & 34 & 34 & 0 & 34 & 68 & 7 & 0.96294 & 26.9832704 & 3 \\
\hline & & & 4.3392619 & 100.045 & 4.810379 & 4.3102378 & & & 26.909539 \\
\hline \multirow[t]{2}{*}{ SW123.08 } & 98 & 102.2 & 8 & 873 & 46 & 8 & 0.98365 & 61.1620795 & 2 \\
\hline & & & & & 2.701351 & 3.3406406 & & & 7.5634245 \\
\hline \multirow[t]{2}{*}{ SW123.09 } & 37 & 37 & 0 & 37 & 01 & 8 & 0.958218 & 23.9337514 & 5 \\
\hline & & & 41.605091 & 761.943 & 15.29225 & 5.9929967 & & & 385.21207 \\
\hline \multirow[t]{2}{*}{ SW124.01 } & 493 & 740 & 3 & 89 & 28 & 9 & 0.996924 & 325.097529 & 7 \\
\hline & & 1292.58 & 81.263119 & 1335.18 & 17.82383 & 6.3785069 & & & 884.35986 \\
\hline \multirow[t]{2}{*}{ SW124.02 } & 669 & 599 & 2 & 265 & 77 & 6 & 0.998028 & 507.099392 & 2 \\
\hline & & & 32.108803 & 498.286 & 10.69483 & 5.6405265 & & & 209.17261 \\
\hline \multirow[t]{2}{*}{ SW124.03 } & 367 & 514 & 5 & 973 & 89 & 3 & 0.99553 & 223.713647 & 1 \\
\hline & & 896.641 & & 927.474 & 18.04594 & 6.0501102 & & & 448.89384 \\
\hline SW124.04 & 526 & 026 & 58.341897 & 031 & 61 & 2 & 0.99703 & 336.700337 & 2 \\
\hline & & 864.282 & 53.513328 & 924.436 & 18.47727 & 6.0417601 & & & 444.75983 \\
\hline SW124.05 & 524 & 258 & 7 & 656 & 51 & 1 & 0.996972 & 330.250991 & 4 \\
\hline & & 894.063 & 47.921104 & 960.870 & 18.78322 & 6.1707030 & & & 552.94865 \\
\hline SW124.06 & 571 & 694 & 1 & 215 & 19 & 1 & 0.9974 & 384.615385 & 2 \\
\hline & & 667.657 & 30.555908 & 697.271 & 14.53763 & 6.0207062 & & & 385.21207 \\
\hline SW127.01 & 493 & 343 & 3 & 655 & 25 & 1 & 0.99709 & 343.642612 & 7 \\
\hline & & 78.6666 & 2.2042773 & 78.9334 & 4.343880 & 4.0427247 & & & 19.448027 \\
\hline SW127.03 & 77 & 667 & 9 & 648 & 99 & 9 & 0.978958 & 47.5239996 & 4 \\
\hline & & & & & 2.641022 & 3.5083058 & & & 8.3425609 \\
\hline SW127.04 & 40 & 40 & 0 & 40 & 53 & 8 & 0.965962 & 29.3789294 & 6 \\
\hline & & 196.111 & 7.8214233 & 194.488 & 5.495054 & 4.9072919 & & & 64.054480 \\
\hline SW127.05 & 180 & 111 & 9 & 214 & 92 & 7 & 0.990942 & 110.399647 & 1 \\
\hline & & & 1.0591134 & 100.137 & 4.847002 & 4.3011674 & & & 27.285333 \\
\hline SW127.06 & 99 & 99.6 & 4 & 629 & 36 & 3 & 0.982466 & 57.032052 & 1 \\
\hline
\end{tabular}




\begin{tabular}{|c|c|c|c|c|c|c|c|c|c|}
\hline & & & & & 2.770274 & 3.5758062 & & & 9.1409943 \\
\hline \multirow[t]{2}{*}{ SW127.07 } & 43 & 43 & 0 & 43 & 1 & 3 & 0.968068 & 31.3165477 & 4 \\
\hline & & 392.484 & 20.896337 & 394.986 & 8.967902 & 5.4558879 & & & 155.60752 \\
\hline \multirow[t]{2}{*}{ SW128.01 } & 312 & 375 & 4 & 534 & 23 & 1 & 0.99458 & 184.501845 & 3 \\
\hline & & 150.076 & & 154.143 & 5.565713 & 4.3789688 & & & 45.673925 \\
\hline \multirow[t]{2}{*}{ SW128.02 } & 143 & 923 & 4.1280238 & 344 & 67 & 5 & 0.982148 & 56.0161327 & 4 \\
\hline & & & 0.4866642 & 19.3706 & 2.048086 & 2.3949373 & & & 3.3283031 \\
\hline \multirow[t]{2}{*}{ SW128.03 } & 19 & 19 & 6 & 19 & 57 & 6 & 0.881198 & 8.41736671 & 1 \\
\hline & & & & & 3.903123 & & & & 15.242462 \\
\hline \multirow[t]{2}{*}{ SW128.04 } & 64 & 64 & 0 & 64 & 75 & 3.9237705 & 0.975576 & 40.9433344 & 8 \\
\hline & & & & & 2.215646 & 3.2258587 & & & 6.5554321 \\
\hline \multirow[t]{2}{*}{ SW128.05 } & 33 & 33 & 0 & 33 & 84 & 1 & 0.952642 & 21.1157566 & 1 \\
\hline & & & & & 1.309307 & 2.2966286 & & & 2.3044443 \\
\hline \multirow[t]{2}{*}{ SW128.06 } & 14 & 14 & 0 & 14 & 34 & 3 & 0.875366 & 8.02349279 & 1 \\
\hline & & 861.389 & 53.433810 & 830.197 & 15.52612 & 6.0907763 & & & 453.06585 \\
\hline \multirow[t]{2}{*}{ SW129.01 } & 528 & 831 & 7 & 982 & 43 & 3 & 0.997306 & 371.195249 & 4 \\
\hline & & 538.780 & 29.045800 & 537.935 & 11.50814 & 5.7503007 & & & \\
\hline \multirow[t]{2}{*}{ SW129.02 } & 399 & 22 & 4 & 175 & 23 & 1 & 0.996034 & 252.143217 & 245.87671 \\
\hline & & 828.436 & 49.952721 & 802.482 & 15.18090 & & & & 438.62905 \\
\hline \multirow[t]{2}{*}{ SW129.03 } & 521 & 975 & 2 & 816 & 18 & 6.0772823 & 0.997272 & 366.568915 & 3 \\
\hline & & 911.059 & 54.945604 & 970.392 & 18.66920 & 6.1061963 & & & \\
\hline \multirow[t]{2}{*}{ SW129.04 } & 549 & 702 & 2 & 393 & 72 & 6 & 0.997182 & 354.861604 & 499.29176 \\
\hline & & & 42.080110 & 641.626 & 14.17244 & 5.7986501 & & & 279.25447 \\
\hline \multirow[t]{2}{*}{ SW129.05 } & 425 & 646.625 & 5 & 598 & 85 & 5 & 0.996154 & 260.0104 & 9 \\
\hline & & 1142.28 & 78.015661 & 1180.96 & 19.09270 & 6.2106376 & & & 621.49858 \\
\hline \multirow[t]{2}{*}{ SW129.06 } & 596 & 347 & 3 & 226 & 1 & 2 & 0.997542 & 406.834825 & 1 \\
\hline & & & & & 2.190890 & & & & 5.8233357 \\
\hline \multirow[t]{2}{*}{ SW31.01 } & 30 & 30 & 0 & 30 & 23 & 3.0852854 & 0.945866 & 18.4726789 & 9 \\
\hline & & & & & 0.963624 & 2.2390348 & & & 2.3044443 \\
\hline \multirow[t]{2}{*}{ SW31.03 } & 14 & 14 & 0 & 14 & 11 & 1 & 0.858202 & 7.05228565 & 1 \\
\hline & & & & & 1.839732 & & & & 4.8804419 \\
\hline \multirow[t]{2}{*}{ SW31.04 } & 26 & 26 & 0 & 26 & 42 & 3.0493745 & 0.946344 & 18.6372447 & 6 \\
\hline & & 79.3333 & 0.9249512 & 79.4706 & 4.431733 & 4.1405708 & & & 20.123282 \\
\hline \multirow[t]{2}{*}{ SW31.05 } & 79 & 333 & 5 & 263 & 96 & 2 & 0.98132 & 53.5331906 & 8 \\
\hline & & & & & 1.322875 & 2.5340035 & & & 2.7047898 \\
\hline \multirow[t]{2}{*}{ SW31.06 } & 16 & 16 & 0 & 16 & 66 & 6 & 0.911206 & 11.2620222 & 6 \\
\hline & & & 0.4937104 & 40.1868 & 2.684726 & 3.4847579 & & & 8.3425609 \\
\hline SW31.07 & 40 & 40 & 4 & 67 & 94 & 6 & 0.96575 & 29.1970803 & 6 \\
\hline & & 1083.81 & & 1081.42 & 16.80824 & 6.2911341 & & & 696.29238 \\
\hline SW33.01 & 620 & 579 & 64.532596 & 018 & 14 & 2 & 0.997848 & 464.684015 & 7 \\
\hline & & 362.205 & 12.554748 & 362.792 & 6.639766 & & & & 162.73204 \\
\hline SW33.02 & 320 & 48 & 6 & 142 & 2 & 5.5708467 & 0.995528 & 223.613596 & 9 \\
\hline & & 1428.79 & 98.343364 & 1366.97 & 16.58372 & 6.3986478 & & & 925.37053 \\
\hline SW33.03 & 678 & 286 & 1 & 366 & 52 & 9 & 0.998096 & 525.210084 & 6 \\
\hline & & 1639.92 & 112.71225 & 1628.25 & 16.21770 & 6.4920891 & & & \\
\hline SW33.04 & 729 & 715 & 2 & 185 & 83 & 6 & 0.998294 & 586.166471 & 1210.8657 \\
\hline & & 2501.04 & 199.10825 & 2617.03 & & 6.6425969 & & & 2147.5297 \\
\hline SW33.05 & 821 & 511 & 3 & 967 & 14.67729 & 6 & 0.99857 & 699.300699 & 2 \\
\hline & & 1303.60 & 84.013939 & 1349.35 & 18.81321 & 6.3653057 & & & 862.55656 \\
\hline SW33.06 & 664 & 265 & 2 & 139 & 05 & 1 & 0.997982 & 495.540139 & 8 \\
\hline & & 1177.84 & 79.315215 & 1203.65 & 18.52369 & 6.2509562 & & & 670.28051 \\
\hline SW38.03 & 612 & 091 & 4 & 042 & 44 & 9 & 0.997674 & 429.922614 & 5 \\
\hline
\end{tabular}




\begin{tabular}{|c|c|c|c|c|c|c|c|c|c|}
\hline & & 128.230 & 3.5599718 & 127.799 & 4.976695 & 4.5357387 & & & 37.284421 \\
\hline \multirow[t]{2}{*}{ SW38.05 } & 124 & 769 & 1 & 801 & 05 & 8 & 0.986764 & 75.5515261 & 1 \\
\hline & & 183.230 & 10.632199 & 186.067 & 6.446704 & 4.6670977 & & & 53.283425 \\
\hline \multirow[t]{2}{*}{ SW38.08 } & 159 & 769 & 7 & 433 & 68 & 2 & 0.987926 & 82.822594 & 2 \\
\hline & & & 11.643834 & 86.0334 & 4.512650 & 3.8596990 & & & 19.784719 \\
\hline \multirow[t]{2}{*}{ SW40.01 } & 78 & 93.6 & 3 & 614 & 94 & 8 & 0.97251 & 36.3768643 & 8 \\
\hline & & & 1.5802298 & 87.1796 & 4.619396 & 4.1893661 & & & 22.545448 \\
\hline \multirow[t]{2}{*}{ SW40.03 } & 86 & 87 & 7 & 919 & 96 & 4 & 0.981636 & 54.4543672 & 7 \\
\hline & & & 3.4443596 & 116.662 & 5.085906 & 4.4602852 & & & 33.144492 \\
\hline \multirow[t]{2}{*}{ SW40.05 } & 114 & 117.5 & 9 & 351 & 97 & 1 & 0.985974 & 71.2961643 & 1 \\
\hline & & & & & 3.010186 & 3.7165490 & & & 10.794182 \\
\hline \multirow[t]{2}{*}{ SW40.07 } & 49 & 49 & 0 & 49 & 79 & 6 & 0.97272 & 36.6568915 & 1 \\
\hline & & & 0.4947642 & 48.1610 & 2.873662 & 3.7158136 & & & 10.513519 \\
\hline \multirow[t]{2}{*}{ SW40.08 } & 48 & 48 & 5 & 024 & 47 & 3 & 0.97287 & 36.8595651 & 9 \\
\hline & & 664.853 & 34.724433 & 702.893 & 14.94659 & 5.9359553 & & & 344.33832 \\
\hline \multirow[t]{2}{*}{ SW40.09 } & 469 & 659 & 1 & 196 & 72 & 2 & 0.99674 & 306.748466 & 1 \\
\hline & & & 172.75986 & 2170.37 & 17.03852 & 6.5359544 & & & 1462.4471 \\
\hline \multirow[t]{2}{*}{ SW43.04 } & 762 & 2152.04 & 4 & 263 & 82 & 4 & 0.998346 & 604.594921 & 6 \\
\hline & & 446.181 & 26.003820 & 434.897 & 9.737036 & 5.5506106 & & & 179.55857 \\
\hline \multirow[t]{2}{*}{ SW43.05 } & 338 & 818 & 6 & 751 & 3 & 6 & 0.99503 & 201.207244 & 6 \\
\hline & & 209.972 & 5.5984958 & 212.743 & 5.474219 & 5.0187191 & & & 74.599851 \\
\hline \multirow[t]{2}{*}{ SW43.06 } & 199 & 973 & 7 & 621 & 28 & 1 & 0.991912 & 123.63996 & 3 \\
\hline & & 763.266 & 41.327118 & 817.411 & 16.79084 & & & & 416.84738 \\
\hline \multirow[t]{2}{*}{ SW43.07 } & 510 & 667 & 6 & 937 & 3 & 6.0271439 & 0.996988 & 332.005312 & 1 \\
\hline & & 1757.07 & 125.32180 & 1871.02 & 18.99345 & & & & 1273.0791 \\
\hline \multirow[t]{2}{*}{ SW43.08 } & 738 & 534 & 9 & 408 & 74 & 6.4967984 & 0.99826 & 574.712644 & 4 \\
\hline & & 633.294 & 38.729967 & 644.634 & 13.91327 & 5.8080659 & & & 283.33186 \\
\hline \multirow[t]{2}{*}{ SW43.09 } & 428 & 737 & 4 & 653 & 25 & 5 & 0.996198 & 263.019463 & 7 \\
\hline & & 1410.72 & 94.611359 & 1451.75 & 18.50389 & & & & \\
\hline \multirow[t]{2}{*}{ SW46.01 } & 680 & 109 & 1 & 494 & 5 & 6.3937451 & 0.998046 & 511.770727 & 934.8075 \\
\hline & & 715.722 & 38.512163 & 733.864 & 14.59347 & 5.9981188 & & & 379.86965 \\
\hline \multirow[t]{2}{*}{ SW46.02 } & 490 & 222 & 3 & 85 & 81 & 8 & 0.997004 & 333.778371 & 9 \\
\hline & & 382.166 & 21.991383 & 382.836 & 8.730470 & 5.3930006 & & & 143.63640 \\
\hline \multirow[t]{2}{*}{ SW46.04 } & 298 & 667 & 6 & 675 & 75 & 6 & 0.994236 & 173.490632 & 8 \\
\hline & & 1852.18 & 131.96638 & 1875.62 & 16.01166 & 6.5442029 & & & 1445.1947 \\
\hline \multirow[t]{2}{*}{ SW46.05 } & 760 & 121 & 9 & 984 & 99 & 8 & 0.998392 & 621.890547 & 1 \\
\hline & & 1363.33 & 93.472807 & 1397.52 & 18.65401 & 6.3482679 & & & 841.41469 \\
\hline SW46.06 & 659 & 813 & 9 & 822 & 17 & 6 & 0.997928 & 482.625483 & 2 \\
\hline & & 1147.76 & 69.956191 & 1162.16 & 17.26003 & 6.3141691 & & & 744.68150 \\
\hline SW49.01 & 634 & 471 & 6 & 993 & 7 & 6 & 0.99789 & 473.933649 & 1 \\
\hline & & 959.281 & 57.225214 & 1041.20 & 19.01996 & 6.1591322 & & & 550.38240 \\
\hline SW49.03 & 570 & 69 & 4 & 129 & 96 & 8 & 0.997394 & 383.729854 & 8 \\
\hline & & 225.028 & 8.3254188 & 225.001 & 5.352650 & 5.0574989 & & & 78.684440 \\
\hline SW49.04 & 206 & 571 & 3 & 183 & 5 & 5 & 0.992248 & 128.998968 & 2 \\
\hline & & & 9.1880682 & 215.042 & 4.734906 & 5.1035270 & & & 76.920499 \\
\hline SW49.05 & 203 & 222.375 & 9 & 156 & 71 & 6 & 0.992956 & 141.964793 & 8 \\
\hline & & 3696.56 & 356.66937 & 3821.17 & 13.28291 & 6.7004636 & & & 2946.5009 \\
\hline SW49.07 & 861 & 122 & 6 & 219 & 27 & 2 & 0.998662 & 747.384156 & 9 \\
\hline & & 160.687 & 6.5400071 & 157.389 & 4.955924 & 4.7395828 & & & 48.940833 \\
\hline SW50.01 & 150 & 5 & 8 & 41 & 38 & 5 & 0.989294 & 93.405567 & 4 \\
\hline & & & 0.4930066 & 36.3805 & 1.828162 & 3.3943770 & & & 7.3080809 \\
\hline SW50.02 & 36 & 36 & 5 & 41 & 46 & 2 & 0.961728 & 26.1287625 & 3 \\
\hline
\end{tabular}




\begin{tabular}{|c|c|c|c|c|c|c|c|c|c|}
\hline & & & 0.4967426 & 77.1556 & 4.371533 & 4.1016497 & & & 19.448027 \\
\hline \multirow[t]{2}{*}{ SW50.04 } & 77 & 77 & 4 & 42 & 25 & 3 & 0.978962 & 47.5330355 & 4 \\
\hline & & 270.634 & 14.994995 & 273.208 & 7.329285 & 5.0486945 & & & 90.972487 \\
\hline \multirow[t]{2}{*}{ SW50.05 } & 226 & 146 & 6 & 032 & 65 & 4 & 0.99152 & 117.924528 & 5 \\
\hline & & & 14.347272 & 274.058 & 7.230033 & 5.0337627 & & & 90.972487 \\
\hline \multirow[t]{2}{*}{ SW50.06 } & 226 & 269.4 & 6 & 509 & 75 & 1 & 0.991252 & 114.311843 & 5 \\
\hline & & 421.245 & 32.003419 & 422.220 & 10.58460 & 5.2786440 & & & 137.87913 \\
\hline \multirow[t]{2}{*}{ SW51.04 } & 291 & 283 & 8 & 328 & 53 & 6 & 0.993042 & 143.71946 & 6 \\
\hline & & & 0.0990867 & 55.3411 & 3.295062 & 3.7914025 & & & 12.520377 \\
\hline \multirow[t]{2}{*}{ SW51.05 } & 55 & 55 & 4 & 99 & 38 & 6 & 0.97375 & 38.0952381 & 3 \\
\hline & & & 5.3706097 & 78.9042 & 4.324772 & 4.0147670 & & & 19.113207 \\
\hline \multirow[t]{2}{*}{ SW51.06 } & 76 & 81.25 & 9 & 093 & 9 & 9 & 0.97785 & 45.1467269 & 7 \\
\hline & & 150.769 & 7.3624733 & 146.966 & 5.283612 & 4.6034867 & & & 43.850023 \\
\hline \multirow[t]{2}{*}{ SW51.08 } & 139 & 231 & 9 & 957 & 92 & 6 & 0.987286 & 78.6534529 & 6 \\
\hline & & & 0.1234276 & 40.3710 & 2.809075 & 3.4342469 & & & 8.3425609 \\
\hline \multirow[t]{2}{*}{ SW51.09 } & 40 & 40 & 1 & 482 & 33 & 6 & 0.963066 & 27.0753236 & 6 \\
\hline & & 162.437 & 8.1461593 & 159.136 & 5.737042 & 4.6733323 & & & \\
\hline \multirow[t]{2}{*}{ SW58.01 } & 148 & 5 & 8 & 152 & 13 & 3 & 0.98829 & 85.3970965 & 47.997644 \\
\hline & & & 27.463211 & 173.401 & 6.877900 & 4.3815745 & & & 39.425196 \\
\hline \multirow[t]{2}{*}{ SW58.02 } & 129 & 190.75 & 4 & 199 & 91 & 9 & 0.984006 & 62.5234463 & 8 \\
\hline & & & 3.9161574 & 81.2211 & 4.368121 & & & & 19.113207 \\
\hline \multirow[t]{2}{*}{ SW58.03 } & 76 & 80.5 & 1 & 229 & 71 & 3.8240742 & 0.971712 & 35.3506787 & 7 \\
\hline & & & 1.2954545 & 60.5070 & 3.621399 & 3.9010984 & & & 14.013230 \\
\hline \multirow[t]{2}{*}{ SW58.06 } & 60 & 60.5 & 5 & 73 & 39 & 5 & 0.97694 & 43.3651344 & 2 \\
\hline & & & & & 3.198557 & 3.7778140 & & & 11.648288 \\
\hline \multirow[t]{2}{*}{ SW58.07 } & 52 & 52 & 0 & 52 & 37 & 1 & 0.973852 & 38.2438427 & 1 \\
\hline & & & & & 3.135249 & 3.6251846 & & & 10.234894 \\
\hline \multirow[t]{2}{*}{ SW58.09 } & 47 & 47 & 0 & 47 & 15 & 6 & 0.9697 & 33.0033003 & 7 \\
\hline & & 2218.63 & 168.30984 & 2254.01 & 14.65760 & 6.6111904 & & & 1856.8282 \\
\hline \multirow[t]{2}{*}{ SW63.02 } & 800 & 83 & 8 & 11 & 05 & 3 & 0.998522 & 676.589987 & 8 \\
\hline & & & 55.708170 & 1015.40 & 18.56500 & 6.2140248 & & & 595.80752 \\
\hline \multirow[t]{2}{*}{ SW63.03 } & 587 & 971.2 & 2 & 894 & 61 & 8 & 0.997602 & 417.014179 & 1 \\
\hline & & 1402.29 & & 1394.20 & 18.30181 & 6.3834456 & & & 902.29902 \\
\hline \multirow[t]{2}{*}{ SW63.04 } & 673 & 787 & 95.766148 & 466 & 41 & 8 & 0.998032 & 508.130081 & 9 \\
\hline & & 1151.76 & 70.944254 & 1149.66 & 17.10747 & 6.3137867 & & & 741.09718 \\
\hline \multirow[t]{2}{*}{ SW63.05 } & 633 & 667 & 4 & 334 & 1 & 6 & 0.997894 & 474.833808 & 4 \\
\hline & & 1122.24 & 65.186885 & 1154.21 & 17.85312 & & & & 766.62362 \\
\hline SW63.06 & 640 & 54 & 4 & 806 & 42 & 6.329736 & 0.997926 & 482.160077 & 5 \\
\hline & & 516.944 & 23.458376 & 539.202 & 11.40023 & 5.7776168 & & & 253.27906 \\
\hline SW63.07 & 405 & 444 & 7 & 793 & 07 & 9 & 0.996194 & 262.743037 & 7 \\
\hline & & & 0.4947642 & 48.1944 & 2.971564 & 3.7002456 & & & 10.513519 \\
\hline SW64.01 & 48 & 48 & 5 & 849 & 78 & 5 & 0.972234 & 36.0152705 & 9 \\
\hline & & & 0.2462960 & 34.4562 & 2.009731 & 3.2804634 & & & 6.8040632 \\
\hline SW64.02 & 34 & 34 & 9 & 359 & 91 & 4 & 0.955036 & 22.2400142 & 3 \\
\hline & & 52.3333 & 0.9242565 & 52.7819 & 3.208699 & 3.6578331 & & & 11.648288 \\
\hline SW64.03 & 52 & 333 & 8 & 731 & 85 & 7 & 0.968262 & 31.5079715 & 1 \\
\hline & & & 0.4435179 & 63.7052 & 3.955878 & & & & 14.932265 \\
\hline SW64.04 & 63 & 63.125 & 9 & 147 & 82 & 3.6988139 & 0.968618 & 31.8654006 & 5 \\
\hline & & & & 41.2576 & 2.803450 & 3.4153709 & & & 8.6065827 \\
\hline SW64.06 & 41 & 41 & 0.2469324 & 295 & 83 & 2 & 0.95907 & 24.431957 & 4 \\
\hline & & & 0.4918693 & 31.3759 & 2.176306 & 3.1894652 & & & \\
\hline SW64.07 & 31 & 31 & 8 & 414 & 75 & 3 & 0.953168 & 21.3529211 & 6.0650427 \\
\hline
\end{tabular}




\begin{tabular}{|c|c|c|c|c|c|c|c|c|c|}
\hline & & 646.802 & 29.564399 & 665.689 & 13.94684 & 5.9994619 & & & 365.95694 \\
\hline \multirow[t]{2}{*}{ SW787.05 } & 482 & 92 & 1 & 818 & 58 & 6 & 0.997048 & 338.753388 & 7 \\
\hline & & 297.396 & 11.386718 & 297.021 & 6.246260 & 5.3102846 & & & 117.01568 \\
\hline \multirow[t]{2}{*}{ SW787.06 } & 264 & 226 & 2 & 915 & 36 & 6 & 0.993794 & 161.134386 & 1 \\
\hline & & & & & 3.783842 & 4.0028546 & & & 14.932265 \\
\hline \multirow[t]{2}{*}{ SW788.01 } & 63 & 63 & 0 & 63 & 01 & 7 & 0.979754 & 49.3924726 & 5 \\
\hline & & & & & 1.316561 & 2.3543936 & & & 2.5030219 \\
\hline \multirow[t]{2}{*}{ SW788.02 } & 15 & 15 & 0 & 15 & 18 & 8 & 0.879288 & 8.28418053 & 3 \\
\hline & & & 0.4841229 & & 1.544436 & 2.3367279 & & & 2.7047898 \\
\hline \multirow[t]{2}{*}{ SW788.04 } & 16 & 16 & 2 & 16.584 & 71 & 5 & 0.876364 & 8.08825908 & 6 \\
\hline & & & & & 0.953462 & 2.1119626 & & & \\
\hline \multirow[t]{2}{*}{ SW788.05 } & 11 & 11 & 0 & 11 & 59 & 7 & 0.844528 & 6.43202635 & 1.7290385 \\
\hline & & & 0.4909902 & 28.5219 & 1.802994 & 3.0172264 & & & 5.3470387 \\
\hline \multirow[t]{2}{*}{ SW788.06 } & 28 & 28 & 5 & 479 & 8 & 2 & 0.94003 & 16.6750042 & 8 \\
\hline & & & 0.2470058 & 42.3230 & 2.628861 & 3.5156234 & & & 8.8727322 \\
\hline \multirow[t]{2}{*}{ SW788.07 } & 42 & 42 & 8 & 794 & 97 & 3 & 0.96585 & 29.2825769 & 1 \\
\hline & & & 0.4894725 & 25.0864 & 1.486409 & 3.0453847 & & & 4.4238312 \\
\hline \multirow[t]{2}{*}{ SW788.10 } & 24 & 24 & 1 & 198 & 51 & 8 & 0.948544 & 19.4340796 & 1 \\
\hline & & & 25.114456 & 184.906 & 7.157030 & 4.3333098 & & & 40.732534 \\
\hline \multirow[t]{2}{*}{ SW789.01 } & 132 & 192.2 & 3 & 52 & 8 & 6 & 0.982354 & 56.6700669 & 1 \\
\hline & & & 0.0710705 & 100.188 & 4.850969 & 4.3972881 & & & 27.662922 \\
\hline \multirow[t]{2}{*}{ SW789.06 } & 100 & 100 & 3 & 378 & 97 & 8 & 0.985366 & 68.3340167 & 1 \\
\hline & & & 0.1236910 & 48.4451 & 2.997810 & 3.6571330 & & & 10.513519 \\
\hline \multirow[t]{2}{*}{ SW789.07 } & 48 & 48 & 6 & 802 & 7 & 2 & 0.970726 & 34.1600055 & 9 \\
\hline & & 370.131 & 18.441485 & 367.710 & 7.835813 & & & & 147.84082 \\
\hline \multirow[t]{2}{*}{ SW789.08 } & 303 & 148 & 8 & 768 & 9 & 5.4550575 & 0.994744 & 190.258752 & 4 \\
\hline & & & 13.212941 & 333.599 & 6.240322 & 5.4768672 & & & 141.15073 \\
\hline \multirow[t]{2}{*}{ SW790.01 } & 295 & 337.6 & 3 & 637 & 78 & 7 & 0.995088 & 203.583062 & 4 \\
\hline & & & 0.2461829 & 33.3284 & 2.406633 & 3.1917852 & & & 6.5554321 \\
\hline \multirow[t]{2}{*}{ SW790.03 } & 33 & 33 & 8 & 898 & 31 & 8 & 0.951062 & 20.4340186 & 1 \\
\hline & & & 1.8140507 & 47.5118 & 3.265108 & 3.4562311 & & & 9.9583175 \\
\hline \multirow[t]{2}{*}{ SW790.07 } & 46 & 47 & 6 & 713 & 18 & 9 & 0.962304 & 26.5280136 & 9 \\
\hline & & & & & 1.328422 & & & & 2.9096498 \\
\hline \multirow[t]{2}{*}{ SW793.02 } & 17 & 17 & 0 & 17 & 33 & 2.4908301 & 0.902418 & 10.2477916 & 3 \\
\hline & & & & & 2.366431 & 3.2884088 & & & 7.0549535 \\
\hline \multirow[t]{2}{*}{ SW793.03 } & 35 & 35 & 0 & 35 & 91 & 8 & 0.954492 & 21.9741584 & 3 \\
\hline & & & & & 1.581138 & 2.5854474 & & & 3.1175139 \\
\hline SW793.06 & 18 & 18 & 0 & 18 & 83 & 8 & 0.917158 & 12.0711716 & 4 \\
\hline & & & & & 0.974679 & 2.7854278 & & & 3.5419457 \\
\hline SW793.09 & 20 & 20 & 0 & 20 & 43 & 4 & 0.930386 & 14.3649266 & 8 \\
\hline & & & & & 0.948683 & 1.8878644 & & & 1.5445238 \\
\hline SW793.10 & 10 & 10 & 0 & 10 & 3 & 9 & 0.810434 & 5.27520758 & 2 \\
\hline & & & & & 1.609630 & 2.8108780 & & & \\
\hline SW795.04 & 22 & 22 & 0 & 22 & 11 & 9 & 0.930508 & 14.3901456 & 3.9775371 \\
\hline & & & 0.4931969 & 37.2942 & 2.167712 & 3.4277975 & & & 7.5634245 \\
\hline SW795.07 & 37 & 37 & 6 & 31 & 65 & 1 & 0.96396 & 27.7469478 & 5 \\
\hline & & & & & 0.960768 & & & & 2.1091676 \\
\hline SW795.09 & 13 & 13 & 0 & 13 & 92 & 2.3976174 & 0.898864 & 9.887676 & 9 \\
\hline & & & & & 1.561249 & & & & 2.7047898 \\
\hline SW795.10 & 16 & 16 & 0 & 16 & 5 & 2.4102199 & 0.896332 & 9.64617818 & 6 \\
\hline & & & 0.2425356 & 17.8308 & 1.774503 & 2.5228005 & & & 2.9096498 \\
\hline SW796.03 & 17 & 17 & 3 & 148 & 65 & 2 & 0.909696 & 11.0737066 & 3 \\
\hline
\end{tabular}




\begin{tabular}{|c|c|c|c|c|c|c|c|c|c|}
\hline & & & & & 1.358732 & 3.1038568 & & & 4.8804419 \\
\hline \multirow[t]{2}{*}{ SW796.04 } & 26 & 26 & 0 & 26 & 44 & 8 & 0.95008 & 20.0320513 & 6 \\
\hline & & 149.555 & 4.9829943 & 149.631 & 5.390597 & 4.6730675 & & & 45.215037 \\
\hline \multirow[t]{2}{*}{ SW796.05 } & 142 & 556 & 8 & 339 & 72 & 8 & 0.988782 & 89.1424496 & 5 \\
\hline & & & & & 2.070196 & & & & 7.0549535 \\
\hline \multirow[t]{2}{*}{ SW796.06 } & 35 & 35 & 0 & 35 & 68 & 3.3809776 & 0.96205 & 26.3504611 & 3 \\
\hline & & & & & 3.125290 & 3.4371735 & & & 9.1409943 \\
\hline \multirow[t]{2}{*}{ SW796.10 } & 43 & 43 & 0 & 43 & 68 & 4 & 0.959992 & 24.995001 & 4 \\
\hline & & & & & 1.620185 & 2.9123211 & & & 4.4238312 \\
\hline \multirow[t]{2}{*}{ SW797.01 } & 24 & 24 & 0 & 24 & 18 & 6 & 0.93673 & 15.805279 & 1 \\
\hline & & & & & 3.603117 & 3.8380698 & & & 13.111649 \\
\hline \multirow[t]{2}{*}{ SW797.02 } & 57 & 57 & 0 & 57 & 56 & 1 & 0.974412 & 39.0808191 & 3 \\
\hline & & & & & 1.596871 & 2.6838457 & & & 3.5419457 \\
\hline \multirow[t]{2}{*}{ SW797.04 } & 20 & 20 & 0 & 20 & 94 & 1 & 0.919916 & 12.4868888 & 8 \\
\hline & & & & & 0.963624 & 2.2614517 & & & 2.3044443 \\
\hline \multirow[t]{2}{*}{ SW797.06 } & 14 & 14 & 0 & 14 & 11 & 6 & 0.870718 & 7.73502885 & 1 \\
\hline & & 563.082 & 27.427164 & 578.552 & 12.38594 & 5.8351822 & & & 279.25447 \\
\hline \multirow[t]{2}{*}{ SW797.09 } & 425 & 569 & 4 & 045 & 97 & 9 & 0.996424 & 279.642058 & 9 \\
\hline & & & & & 3.195741 & 3.5668079 & & & 10.234894 \\
\hline \multirow[t]{2}{*}{ SW798.05 } & 47 & 47 & 0 & 47 & 85 & 6 & 0.965328 & 28.8417167 & 7 \\
\hline & & & & & 0.982607 & 3.2202277 & & & 5.5839911 \\
\hline \multirow[t]{2}{*}{ SW798.06 } & 29 & 29 & 0 & 29 & 37 & 5 & 0.955364 & 22.4034412 & 2 \\
\hline & & 110.571 & 2.5150130 & 112.088 & 5.114972 & 4.3651484 & & & 30.750531 \\
\hline \multirow[t]{2}{*}{ SW798.09 } & 108 & 429 & 3 & 235 & 26 & 8 & 0.984544 & 64.699793 & 5 \\
\hline & & & 0.2457980 & 30.4786 & 2.053989 & 3.2099464 & & & 5.8233357 \\
\hline \multirow[t]{2}{*}{ SW798.10 } & 30 & 30 & 2 & 994 & 87 & 8 & 0.955386 & 22.4144887 & 9 \\
\hline & & & & & 1.333333 & 2.7259285 & & & 3.1175139 \\
\hline \multirow[t]{2}{*}{ SW799.03 } & 18 & 18 & 0 & 18 & 33 & 1 & 0.928784 & 14.0417884 & 4 \\
\hline & & & & & 1.866513 & & & & \\
\hline \multirow[t]{2}{*}{ SW799.05 } & 31 & 31 & 0 & 31 & 05 & 3.2578298 & 0.957222 & 23.3765019 & 6.0650427 \\
\hline & & 55.3333 & 0.9243672 & 55.5916 & 3.449167 & 3.7821489 & & & 12.520377 \\
\hline \multirow[t]{2}{*}{ SW799.07 } & 55 & 333 & 7 & 843 & 61 & 8 & 0.974084 & 38.5862016 & 3 \\
\hline & & & 16.813203 & 209.034 & 6.798887 & 4.7630813 & & & 60.363131 \\
\hline \multirow[t]{2}{*}{ SW799.09 } & 173 & 216.125 & 6 & 524 & 43 & 8 & 0.989052 & 91.3408842 & 1 \\
\hline & & 195.791 & 11.029161 & 192.486 & 6.073507 & & & & 59.327189 \\
\hline \multirow[t]{2}{*}{ SW799.10 } & 171 & 667 & 9 & 382 & 98 & 4.7611125 & 0.988738 & 88.7941751 & 1 \\
\hline & & & 0.1647618 & 44.3347 & 2.854134 & 3.5303744 & & & 9.4113548 \\
\hline SW802.04 & 44 & 44 & 4 & 037 & 42 & 6 & 0.96553 & 29.010734 & 7 \\
\hline & & & & & 3.174901 & 3.7404316 & & & 11.076870 \\
\hline SW803.03 & 50 & 50 & 0 & 50 & 57 & 7 & 0.972994 & 37.0288084 & 8 \\
\hline & & & 0.4909902 & 28.4176 & 1.767283 & 3.1044229 & & & 5.3470387 \\
\hline SW803.04 & 28 & 28 & 5 & 955 & 31 & 3 & 0.948632 & 19.4673727 & 8 \\
\hline & & & & & 1.341640 & 2.7913704 & & & 3.5419457 \\
\hline SW803.05 & 20 & 20 & 0 & 20 & 79 & 2 & 0.931386 & 14.5742851 & 8 \\
\hline & & 51.3333 & & 51.7428 & 3.216859 & 3.6694280 & & & \\
\hline SW803.06 & 51 & 333 & 0.9242168 & 336 & 98 & 1 & 0.969834 & 33.1499039 & 11.361576 \\
\hline & & & 12.108790 & 186.530 & 5.539810 & 4.8045816 & & & 58.812315 \\
\hline SW803.07 & 170 & 196.4 & 1 & 556 & 24 & 8 & 0.989402 & 94.3574259 & 3 \\
\hline & & & & & 1.648863 & 3.3003673 & & & 6.3090836 \\
\hline SW803.08 & 32 & 32 & 0 & 32 & 25 & 9 & 0.958406 & 24.0419291 & 3 \\
\hline & & & & & 1.888800 & 3.4276346 & & & 7.5634245 \\
\hline SW803.09 & 37 & 37 & 0 & 37 & 56 & 8 & 0.96211 & 26.3921879 & 5 \\
\hline
\end{tabular}




\begin{tabular}{|c|c|c|c|c|c|c|c|c|c|}
\hline & & & & & 1.646109 & 3.2577012 & & & \\
\hline \multirow[t]{2}{*}{ SW805.01 } & 31 & 31 & 0 & 31 & 78 & 4 & 0.95692 & 23.2126277 & 6.0650427 \\
\hline & & & 0.2480694 & 65.2219 & 3.869117 & 3.9193552 & & & 15.554577 \\
\hline \multirow[t]{2}{*}{ SW805.02 } & 65 & 65 & 7 & 077 & 21 & 5 & 0.976268 & 42.1371987 & 7 \\
\hline & & & 0.2477168 & 55.2919 & 3.052005 & 3.8404970 & & & 12.520377 \\
\hline \multirow[t]{2}{*}{ SW805.03 } & 55 & 55 & 5 & 282 & 22 & 2 & 0.975504 & 40.8229915 & 3 \\
\hline & & 407.118 & 17.846479 & 404.106 & 7.986731 & 5.5998246 & & & 179.55857 \\
\hline \multirow[t]{2}{*}{ SW805.04 } & 338 & 421 & 7 & 58 & 12 & 1 & 0.99555 & 224.719101 & 6 \\
\hline & & & & & 0.974679 & 2.8595438 & & & 3.5419457 \\
\hline \multirow[t]{2}{*}{ SW805.05 } & 20 & 20 & 0 & 20 & 43 & 6 & 0.937284 & 15.9448944 & 8 \\
\hline & & 195.387 & 2.6507250 & 197.021 & 4.033269 & 5.0639293 & & & 70.623828 \\
\hline \multirow[t]{2}{*}{ SW805.06 } & 192 & 097 & 9 & 517 & 06 & 9 & 0.99266 & 136.239782 & 2 \\
\hline & & & & & 1.653872 & 3.3595380 & & & 6.8040632 \\
\hline \multirow[t]{2}{*}{ SW805.07 } & 34 & 34 & 0 & 34 & 46 & 4 & 0.9603 & 25.1889169 & 3 \\
\hline & & & 1.8401708 & 97.7915 & 4.795703 & 4.3725341 & & & 26.535662 \\
\hline \multirow[t]{2}{*}{ SW805.08 } & 97 & 98.2 & 9 & 191 & 85 & 2 & 0.984734 & 65.5050439 & 1 \\
\hline & & 295.489 & 14.789478 & 296.018 & 6.956748 & & & & 106.29379 \\
\hline \multirow[t]{2}{*}{ SW806.01 } & 249 & 796 & 3 & 045 & 49 & 5.2054738 & 0.99304 & 143.678161 & 2 \\
\hline & & & 4.6273642 & 58.0724 & 3.499970 & 3.8171965 & & & 13.111649 \\
\hline \multirow[t]{2}{*}{ SW806.02 } & 57 & 60 & 6 & 869 & 53 & 7 & 0.97427 & 38.865138 & 3 \\
\hline & & & & & 1.833030 & 2.9655511 & & & 4.6508688 \\
\hline \multirow[t]{2}{*}{ SW806.03 } & 25 & 25 & 0 & 25 & 28 & 9 & 0.94062 & 16.8406871 & 2 \\
\hline & & & 0.4873397 & 21.1111 & 1.212469 & 2.8358486 & & & 3.5419457 \\
\hline \multirow[t]{2}{*}{ SW806.04 } & 20 & 20 & 2 & 111 & 61 & 1 & 0.93648 & 15.7430731 & 8 \\
\hline & & & 2.3175348 & & 1.928104 & 3.1881191 & & & 5.8233357 \\
\hline \multirow[t]{2}{*}{ SW806.05 } & 30 & 31 & 4 & 32.12 & 02 & 5 & 0.953784 & 21.6375281 & 9 \\
\hline & & & 0.4923659 & 33.2941 & 1.999130 & 3.3099720 & & & 6.5554321 \\
\hline \multirow[t]{2}{*}{ SW806.06 } & 33 & 33 & 6 & 9 & 2 & 1 & 0.959222 & 24.5230271 & 1 \\
\hline & & & 5.8565645 & 175.825 & 4.707394 & 4.9275278 & & & 58.812315 \\
\hline \multirow[t]{2}{*}{ SW806.08 } & 170 & 179.5 & 5 & 824 & 14 & 9 & 0.991544 & 118.259224 & 3 \\
\hline & & & 0.6202686 & 86.0507 & 4.598278 & 4.1318451 & & & 22.193839 \\
\hline \multirow[t]{2}{*}{ SW806.09 } & 85 & 85.25 & 3 & 291 & 97 & 9 & 0.980432 & 51.103843 & 2 \\
\hline & & & 11.998471 & 178.978 & 6.737979 & & & & 45.215037 \\
\hline \multirow[t]{2}{*}{ SW808.01 } & 142 & 170.12 & 5 & 261 & 83 & 4.4453889 & 0.984218 & 63.3633253 & 5 \\
\hline & & & 2.8816147 & 59.6076 & 3.647304 & 3.7775234 & & & 13.410226 \\
\hline \multirow[t]{2}{*}{ SW808.02 } & 58 & 60 & 7 & 403 & 05 & 4 & 0.973232 & 37.3580395 & 7 \\
\hline & & & 0.1237684 & 51.3347 & 3.156760 & 3.7051349 & & & \\
\hline SW808.03 & 51 & 51 & 4 & 152 & 34 & 5 & 0.972308 & 36.1115124 & 11.361576 \\
\hline & & & & & 1.866513 & 3.2341032 & & & \\
\hline SW808.04 & 31 & 31 & 0 & 31 & 05 & 9 & 0.95598 & 22.7169468 & 6.0650427 \\
\hline & & & 0.2429563 & & 1.362106 & & & & 3.1175139 \\
\hline SW808.05 & 18 & 18 & 3 & 18.6 & 71 & 2.570515 & 0.912676 & 11.4516055 & 4 \\
\hline & & 216.562 & 11.718162 & 217.109 & 6.422373 & 4.8525849 & & & 67.849120 \\
\hline SW808.06 & 187 & 5 & 8 & 214 & 53 & 3 & 0.989662 & 96.7305088 & 5 \\
\hline & & 407.246 & 22.131121 & 408.480 & 9.021575 & 5.4834924 & & & 162.73204 \\
\hline SW808.07 & 320 & 154 & 7 & 747 & 09 & 8 & 0.99469 & 188.323917 & 9 \\
\hline & & & & 194.946 & 5.639601 & 4.8970522 & & & \\
\hline SW809.01 & 178 & 204.4 & 12.108828 & 914 & 04 & 1 & 0.99097 & 110.741971 & 62.989346 \\
\hline & & & 0.4935481 & 39.3469 & 2.351994 & 3.4342916 & & & \\
\hline SW809.02 & 39 & 39 & 2 & 388 & 6 & 7 & 0.962318 & 26.5378695 & 8.0806827 \\
\hline & & & 1.2941636 & 45.1479 & 2.681644 & 3.5009398 & & & 9.4113548 \\
\hline SW809.03 & 44 & 44.5 & 5 & 562 & 41 & 2 & 0.963256 & 27.2153277 & 7 \\
\hline
\end{tabular}




\begin{tabular}{|c|c|c|c|c|c|c|c|c|c|}
\hline & & 227.714 & 22.863570 & 213.805 & 7.162040 & 4.6610082 & & & 57.279981 \\
\hline \multirow[t]{2}{*}{ SW809.04 } & 167 & 286 & 5 & 3 & 01 & 8 & 0.98754 & 80.2568218 & 7 \\
\hline & & 304.615 & 28.805505 & 272.532 & 7.484375 & 5.0031086 & & & 85.327629 \\
\hline \multirow[t]{2}{*}{ SW809.05 } & 217 & 385 & 6 & 498 & 64 & 9 & 0.991174 & 113.301609 & 4 \\
\hline & & & & 41.3100 & 2.484734 & 3.4734062 & & & 8.6065827 \\
\hline \multirow[t]{2}{*}{ SW809.06 } & 41 & 41 & 0.4938648 & 306 & 86 & 4 & 0.96344 & 27.3522976 & 4 \\
\hline & & & 0.4850712 & 18.1111 & 1.201914 & 2.5543183 & & & 2.9096498 \\
\hline \multirow[t]{2}{*}{ SW809.07 } & 17 & 17 & 5 & 111 & 86 & 6 & 0.908938 & 10.9815291 & 3 \\
\hline & & & & 41.2538 & 2.373659 & 3.5205353 & & & 8.6065827 \\
\hline \multirow[t]{2}{*}{ SWG32.02 } & 41 & 41 & 0.4938648 & 84 & 21 & 5 & 0.965334 & 28.8467086 & 4 \\
\hline & & 101.333 & 15.071557 & 90.1604 & 4.694679 & 4.1069418 & & & 21.496200 \\
\hline \multirow[t]{2}{*}{ SWG32.03 } & 83 & 333 & 8 & 386 & 9 & 9 & 0.980706 & 51.8295843 & 3 \\
\hline & & & 9.2962342 & 163.648 & 5.377482 & & & & 50.850983 \\
\hline \multirow[t]{2}{*}{ SWG32.04 } & 154 & 170.5 & 9 & 136 & 33 & 4.7879969 & 0.990256 & 102.627258 & 5 \\
\hline & & 317.285 & 8.8111908 & 322.004 & 5.593233 & 5.4785320 & & & \\
\hline \multirow[t]{2}{*}{ SWG32.05 } & 292 & 714 & 6 & 987 & 27 & 2 & 0.995124 & 205.086136 & 138.69251 \\
\hline & & 353.137 & 14.792722 & 345.239 & 6.557215 & 5.5101147 & & & 148.69107 \\
\hline \multirow[t]{2}{*}{ SWG32.08 } & 304 & 931 & 3 & 587 & 13 & 1 & 0.995228 & 209.555742 & 3 \\
\hline & & & & & 0.966091 & 2.4866551 & & & 2.5030219 \\
\hline \multirow[t]{2}{*}{ SWG39.01 } & 15 & 15 & 0 & 15 & 78 & 2 & 0.904668 & 10.4896572 & 3 \\
\hline & & 528.135 & 22.387572 & 526.681 & 10.84031 & 5.8614962 & & & 275.22571 \\
\hline \multirow[t]{2}{*}{ SWG39.02 } & 422 & 135 & 9 & 273 & 27 & 3 & 0.996624 & 296.208531 & 7 \\
\hline & & 249.807 & 15.468139 & 235.861 & 6.028905 & 5.0531145 & & & 81.068072 \\
\hline \multirow[t]{2}{*}{ SWG39.05 } & 210 & 692 & 5 & 084 & 78 & 8 & 0.992116 & 126.839168 & 8 \\
\hline & & 546.722 & 26.836037 & 545.455 & 11.21525 & 5.8283957 & & & 267.31096 \\
\hline \multirow[t]{2}{*}{ SWG39.06 } & 416 & 772 & 2 & 834 & 23 & 3 & 0.99649 & 284.900285 & 5 \\
\hline & & & 13.789171 & 246.842 & 6.033289 & & & & \\
\hline \multirow[t]{2}{*}{ SWG39.07 } & 215 & 252.5 & 4 & 409 & 66 & 5.0622552 & 0.992004 & 125.062531 & 84.09905 \\
\hline & & & & & 1.870828 & 3.2234867 & & & 6.3090836 \\
\hline \multirow[t]{2}{*}{ Timber.04 } & 32 & 32 & 0 & 32 & 69 & 1 & 0.951664 & 20.6885137 & 3 \\
\hline & & & & & 0.963624 & 2.3617307 & & & 2.3044443 \\
\hline \multirow[t]{2}{*}{ Timber.06 } & 14 & 14 & 0 & 14 & 11 & 5 & 0.89116 & 9.1877986 & 1 \\
\hline & & & 10.091014 & 206.560 & 5.448567 & 4.9804185 & & & 69.507464 \\
\hline \multirow[t]{2}{*}{ Timber.07 } & 190 & 212 & 5 & 338 & 22 & 1 & 0.991758 & 121.329774 & 7 \\
\hline & & 891.149 & 54.734200 & 954.593 & 19.35277 & 6.0832006 & & & 474.51298 \\
\hline \multirow[t]{2}{*}{ WS4U.02 } & 538 & 606 & 7 & 369 & 81 & 9 & 0.997136 & 349.162011 & 6 \\
\hline & & & 19.937958 & 341.111 & 7.778163 & 5.3394405 & & & 129.90842 \\
\hline WS4U.03 & 281 & 351 & 3 & 39 & 45 & 1 & 0.99381 & 161.550889 & 7 \\
\hline & & 613.032 & & 605.653 & 12.90464 & 5.8068552 & & & 277.90619 \\
\hline WS4U.05 & 424 & 609 & 36.62875 & 172 & 5 & 4 & 0.996194 & 262.743037 & 9 \\
\hline & & & 138.55759 & 1951.51 & 16.95901 & 6.5255707 & & & 1387.0462 \\
\hline WS4U.06 & 753 & 1887 & 6 & 607 & 04 & 8 & 0.998336 & 600.961539 & 8 \\
\hline & & 619.205 & 35.894854 & 641.760 & 13.53377 & 5.7890665 & & & 283.33186 \\
\hline WS4U.07 & 428 & 882 & 9 & 819 & 11 & 3 & 0.995836 & 240.153698 & 7 \\
\hline & & 1088.04 & 66.696762 & 1137.36 & 18.48859 & & & & 667.10792 \\
\hline WS4U.08 & 611 & 082 & 7 & 841 & 39 & 6.2573398 & 0.997706 & 435.919791 & 1 \\
\hline & & & & & 2.738612 & 3.0383803 & & & 6.3090836 \\
\hline WS98SB.01 & 32 & 32 & 0 & 32 & 79 & 7 & 0.938828 & 16.3473485 & 3 \\
\hline & & 2426.93 & 197.63015 & 2484.73 & 15.80698 & 6.6025057 & & & 1844.5148 \\
\hline WS98SB.02 & 799 & 651 & 8 & 584 & 47 & 6 & 0.998486 & 660.501982 & 3 \\
\hline & & 1114.49 & 71.024387 & 1119.28 & 17.63597 & 6.2590029 & & & 663.95241 \\
\hline WS98SB.04 & 610 & 64 & 9 & 408 & 84 & 8 & 0.997732 & 440.917108 & 1 \\
\hline
\end{tabular}




\begin{tabular}{|c|c|c|c|c|c|c|c|c|c|}
\hline & & 793.105 & 45.941701 & 795.717 & 15.66741 & 6.0524142 & & & 422.68149 \\
\hline \multirow[t]{2}{*}{ WS98SB.05 } & 513 & 691 & 3 & 803 & 56 & 2 & 0.997164 & 352.609309 & 6 \\
\hline & & 603.319 & 25.719927 & 643.275 & 13.57448 & 5.9470239 & & & 337.92165 \\
\hline \multirow[t]{2}{*}{ WS98SB.06 } & 465 & 149 & 7 & 296 & 65 & 6 & 0.996834 & 315.85597 & 5 \\
\hline & & & & 86.3404 & 4.601967 & 4.1681999 & & & 22.193839 \\
\hline \multirow[t]{2}{*}{ WS98SB.07 } & 85 & 86 & 1.5802193 & 574 & 23 & 5 & 0.981536 & 54.1594454 & 2 \\
\hline & & & & & 2.070196 & 3.3413749 & & & 7.0549535 \\
\hline \multirow[t]{2}{*}{ WS98SB.09 } & 35 & 35 & 0 & 35 & 68 & 1 & 0.959136 & 24.4714174 & 3 \\
\hline & & 148.687 & 6.5399460 & 147.014 & 5.396665 & & & & 43.398891 \\
\hline WS98SB.10 & 138 & 5 & 5 & 608 & 83 & 4.5484329 & 0.985916 & 71.0025561 & 2 \\
\hline
\end{tabular}

Supplemental Table 1:

830 Alpha Diversity Metrics: Results from the Alpha Diversity analysis for 365 switchgrass genotypes.

831

\begin{tabular}{|c|c|c|c|c|c|c|c|}
\hline family & snps & & h2 & se & $>0.9$ & $>0.1$ & $\begin{array}{l}>0.1 \\
\text { (outliers) }\end{array}$ \\
\hline Xanthobacteraceae & & 5 & 0.45489741 & 0.15006082 & TRUE & TRUE & TRUE \\
\hline Sphingomonadaceae & & 31 & 0.25080413 & 0.13608337 & TRUE & TRUE & TRUE \\
\hline Micrococcaceae & & 89 & 0.26493375 & 0.1376574 & FALSE & TRUE & TRUE \\
\hline Chitinophagaceae & NA & & 0.25752125 & 0.13692033 & FALSE & TRUE & TRUE \\
\hline Koribacteraceae & & 6 & 0.14298423 & 0.11619551 & FALSE & TRUE & TRUE \\
\hline Mycobacteriaceae & & 15 & 0.06959644 & 0.08384037 & FALSE & TRUE & TRUE \\
\hline Pyrinomonadaceae & & 8 & 0.0688696 & 0.08341623 & FALSE & TRUE & TRUE \\
\hline Pirellulaceae & NA & & 0.00794786 & 0.13035936 & FALSE & TRUE & TRUE \\
\hline Myxococcaceae & NA & & 0 & 0.17460424 & FALSE & TRUE & TRUE \\
\hline Polyangiaceae & NA & & 0 & 0.1601444 & FALSE & TRUE & TRUE \\
\hline Reyranellaceae & & 18 & 0 & 0.13129499 & FALSE & TRUE & TRUE \\
\hline Bacillaceae & & 12 & 0 & 0.11080426 & FALSE & TRUE & TRUE \\
\hline Chthoniobacteraceae & & 7 & 0 & 0.08612535 & FALSE & TRUE & TRUE \\
\hline Nitrosomonadaceae & & 1 & 0 & 0.0821527 & FALSE & TRUE & TRUE \\
\hline$A 21 b$ & & 2 & 0 & 0.06449511 & FALSE & TRUE & TRUE \\
\hline Haliangiaceae & & 80 & 0 & 0.05771382 & FALSE & TRUE & TRUE \\
\hline Rhodanobacteraceae & & 11 & 0 & 0.05728122 & FALSE & TRUE & TRUE \\
\hline Nitrospiraceae & NA & & 0 & 0.05377501 & FALSE & TRUE & TRUE \\
\hline Solibacteraceae & NA & & 0 & 0.04764666 & FALSE & TRUE & TRUE \\
\hline Comamonadaceae & & 5 & 0 & 0.04073533 & FALSE & TRUE & TRUE \\
\hline Pedosphaeraceae & NA & & 0 & 0.04072739 & FALSE & TRUE & TRUE \\
\hline Gaiellaceae & & 1 & 0 & 0.03478031 & FALSE & TRUE & TRUE \\
\hline Bryobacteraceae & & 4 & 0 & 0.03154768 & FALSE & TRUE & TRUE \\
\hline Gemmatimonadaceae & & 3 & 0 & 0.0254416 & FALSE & TRUE & TRUE \\
\hline Steroidobacteraceae & NA & & 0 & 0.01622218 & FALSE & TRUE & TRUE \\
\hline Acidothermaceae & & 3 & -0.0067312 & 0.00802897 & FALSE & TRUE & TRUE \\
\hline SC-I-84 & NA & & NA & NA & FALSE & TRUE & TRUE \\
\hline Unknown Family_4 & NA & & NA & NA & FALSE & TRUE & \\
\hline
\end{tabular}




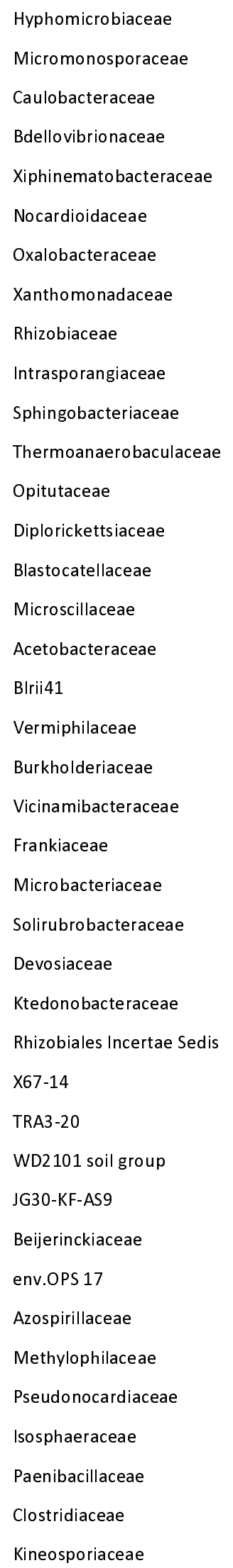

NA

\begin{tabular}{rrllll} 
& \multicolumn{1}{l}{ NA } & NA & FALSE & TRUE & TRU \\
8 & 0.32336921 & 0.14287441 & FALSE & TRUE & TRU \\
2 & 0.2011677 & 0.15233479 & FALSE & TRUE & TRU \\
12 & 0.19268472 & 0.12781354 & FALSE & TRUE & FALS \\
4 & 0.16183436 & 0.12038463 & FALSE & TRUE & TRU
\end{tabular}

$\begin{array}{lllll}1 & 0.12583433 & 0.1099005 & \text { FALSE } & \text { TRUE }\end{array}$

$\begin{array}{llllll}22 & 0.10620934 & 0.10302864 & \text { FALSE } & \text { TRUE } & \text { TRUE }\end{array}$

$\begin{array}{llllll}16 & 0.08703035 & 0.09431779 & \text { FALSE } & \text { TRUE }\end{array}$

$\begin{array}{llllll}1 & 0.08088047 & 0.16039007 & \text { FALSE } & \text { TRUE } & \text { TRUE }\end{array}$

$\begin{array}{llllll}91 & 0.07681519 & 0.08921872 & \text { FALSE } & \text { TRUE } & \text { TRUE }\end{array}$

NA

NA

NA

NA

NA

NA

NA

31

20

2

42

2

3

20

NA

NA

NA

NA

NA

NA

NA

NA

$0.06792159 \quad 0.08320344$

$\begin{array}{lll}11 & 0.05084146 & 0.10051362\end{array}$

FALSE

FALSE

FALSE

FALSE

$\begin{array}{lll}2 & 0.00896882 & 0.03285347\end{array}$

$0 \quad 0.63004088$

FALSE

$0 \quad 0.35296219$

FALSE

$0 \quad 0.22778964$

FALSE

$\begin{array}{ll}0 & 0.08574337\end{array}$

FALSE

$\begin{array}{ll}0 & 0.08323864\end{array}$

FALSE

$\begin{array}{ll}0 & 0.06809019\end{array}$

FALSE

$\begin{array}{ll}0 & 0.0513239\end{array}$

$0 \quad 0.03337879$

FALSE

FALSE

$0 \quad 0.02255735$

FALSE

$0 \quad 0.02232189$

FALSE

$\begin{array}{ll}0 & 0.02229932\end{array}$

FALSE

$0 \quad 0.01184748$

FALSE

FALSE

FALSE

FALSE

FALSE

FALSE

FALSE

FALSE

FALSE

FALSE

FALSE

$\begin{array}{llllll}24 & 0.2535165 & 0.13616372 & \text { FALSE } & \text { TRUE } & \text { TRUE }\end{array}$

$\begin{array}{llllll}11 & 0.23699145 & 0.13424919 & \text { FALSE } & \text { TRUE } & \text { FALSE }\end{array}$

$\begin{array}{llllll}309 & 0.18235269 & 0.12480892 & \text { FALSE } & \text { TRUE } & \text { TRUE }\end{array}$

$\begin{array}{llllll}64 & 0.17626353 & 0.12688325 & \text { FALSE } & \text { TRUE } & \text { TRUE }\end{array}$

TRUE TRUE

TRUE TRUE

TRUE TRUE

TRUE TRUE

TRUE TRUE

TRUE TRUE

TRUE TRUE

TRUE TRUE

TRUE TRUE

TRUE TRUE

TRUE TRUE

TRUE TRUE

TRUE TRUE

TRUE TRUE

TRUE TRUE

TRUE TRUE

TRUE TRUE

TRUE $\quad$ FALSE

TRUE TRUE

TRUE TRUE

TRUE TRUE

TRUE TRUE

TRUE $\quad$ FALSE

TRUE TRUE

TRUE TRUE

TRUE TRUE 


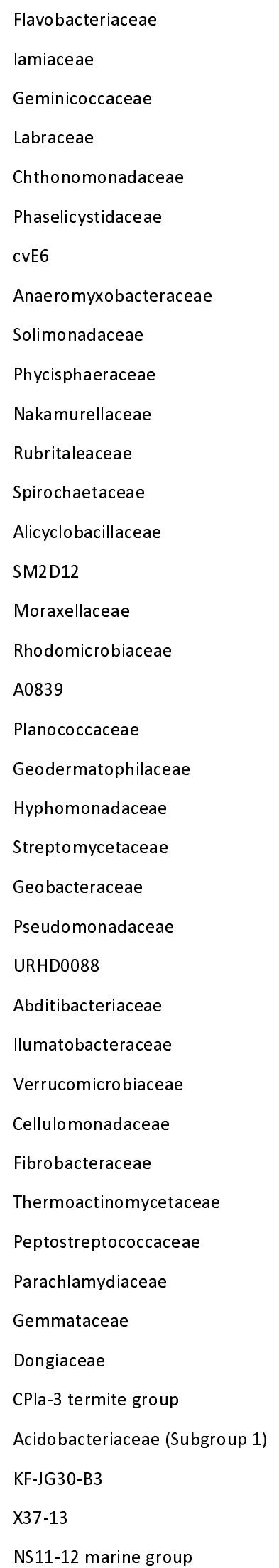

\begin{tabular}{|c|c|c|c|c|c|c|}
\hline & 211 & 0.1756527 & 0.12278504 & FALSE & TRUE & FALSE \\
\hline & 25 & 0.138249 & 0.11405764 & FALSE & TRUE & FALSE \\
\hline & 50 & 0.12800102 & 0.11102073 & FALSE & TRUE & TRUE \\
\hline & 7 & 0.11543509 & 0.13795443 & FALSE & TRUE & TRUE \\
\hline & 33 & 0.06042788 & 0.08631568 & FALSE & TRUE & FALSE \\
\hline NA & & 0.04328935 & 0.04395835 & FALSE & TRUE & TRUE \\
\hline & 14 & 0.01969061 & 0.06606464 & FALSE & TRUE & FALSE \\
\hline NA & & 0.01845726 & 0.02758436 & FALSE & TRUE & TRUE \\
\hline & 25 & 0.01797846 & 0.04217796 & FALSE & TRUE & FALSE \\
\hline & 11 & 0.01003618 & 0.07399336 & FALSE & TRUE & FALSE \\
\hline & 56 & 0.00733123 & 0.0313196 & FALSE & TRUE & TRUE \\
\hline & 2 & 0.00299102 & 0.02880787 & FALSE & TRUE & FALSE \\
\hline & 3 & 0.00111513 & 0.0238385 & FALSE & TRUE & FALSE \\
\hline & 8 & $5.04 \mathrm{E}-05$ & 0.03636558 & FALSE & TRUE & TRUE \\
\hline & 60 & 0 & 0.21567637 & FALSE & TRUE & FALSE \\
\hline & 2 & 0 & 0.07885071 & FALSE & TRUE & TRUE \\
\hline & 11 & 0 & 0.07551665 & FALSE & TRUE & FALSE \\
\hline & 1 & 0 & 0.05401663 & FALSE & TRUE & FALSE \\
\hline & 1 & 0 & 0.04551408 & FALSE & TRUE & FALSE \\
\hline NA & & 0 & 0.03953639 & FALSE & TRUE & TRUE \\
\hline & 6 & 0 & 0.02803625 & FALSE & TRUE & FALSE \\
\hline & 11 & 0 & 0.0244267 & FALSE & TRUE & TRUE \\
\hline & 28 & 0 & 0.02304121 & FALSE & TRUE & TRUE \\
\hline & 24 & 0 & 0.02231061 & FALSE & TRUE & TRUE \\
\hline & 81 & -0.0028494 & 0.01910465 & FALSE & TRUE & FALSE \\
\hline & 87 & -0.005207 & 0.01375589 & FALSE & TRUE & FALSE \\
\hline & 3 & -0.0054262 & 0.02290175 & FALSE & TRUE & FALSE \\
\hline & 1 & -1.8867917 & 79.8301507 & FALSE & TRUE & FALSE \\
\hline & 15 & -1.9632452 & 67.3985434 & FALSE & TRUE & TRUE \\
\hline NA & & -2.4936366 & 137.92784 & FALSE & TRUE & FALSE \\
\hline & 23 & -2.5751422 & 150.57728 & FALSE & TRUE & FALSE \\
\hline & 45 & -3.8013187 & 81.2594218 & FALSE & TRUE & FALSE \\
\hline & 14 & -4.6415211 & 71.2198938 & FALSE & TRUE & FALSE \\
\hline NA & & NA & NA & FALSE & TRUE & FALSE \\
\hline NA & & NA & NA & FALSE & TRUE & FALSE \\
\hline NA & & NA & NA & FALSE & TRUE & FALSE \\
\hline NA & & NA & NA & FALSE & TRUE & TRUE \\
\hline NA & & NA & NA & FALSE & TRUE & FALSE \\
\hline NA & & NA & NA & FALSE & TRUE & FALSE \\
\hline NA & & NA & NA & FALSE & TRUE & \\
\hline
\end{tabular}




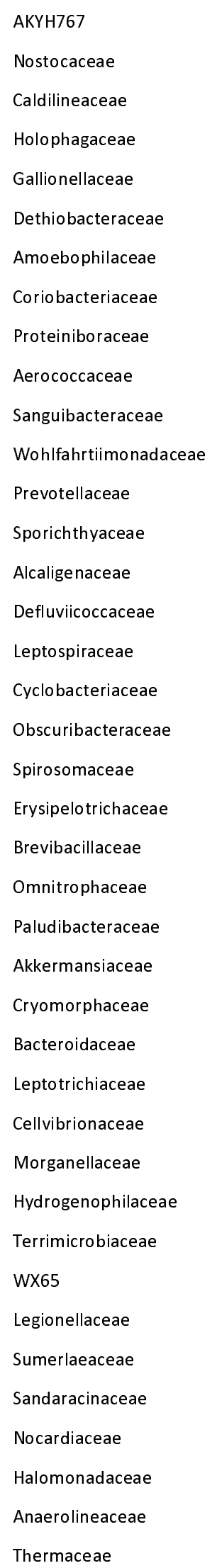

\begin{tabular}{|c|c|c|c|c|c|c|}
\hline NA & & NA & NA & FALSE & TRUE & TRUE \\
\hline NA & & NA & NA & FALSE & TRUE & FALSE \\
\hline & 88 & 0.76067873 & 0.15879238 & FALSE & FALSE & FALSE \\
\hline & 271 & 0.65671928 & 0.15669245 & FALSE & FALSE & FALSE \\
\hline & 339 & 0.65416872 & 0.15683858 & FALSE & FALSE & FALSE \\
\hline NA & & 0.62208092 & 0.1131101 & FALSE & FALSE & FALSE \\
\hline & 243 & 0.55321342 & 0.15365691 & FALSE & FALSE & FALSE \\
\hline & 483 & 0.48429688 & 0.15094295 & FALSE & FALSE & FALSE \\
\hline & 209 & 0.43875513 & 0.1493015 & FALSE & FALSE & FALSE \\
\hline & 231 & 0.42740944 & 0.1488965 & FALSE & FALSE & FALSE \\
\hline & 470 & 0.37437605 & 0.14575336 & FALSE & FALSE & FALSE \\
\hline & 397 & 0.35941743 & 0.14514329 & FALSE & FALSE & FALSE \\
\hline & 69 & 0.32828338 & 0.14307546 & FALSE & FALSE & FALSE \\
\hline & 197 & 0.28849102 & 0.14004792 & FALSE & FALSE & FALSE \\
\hline & 368 & 0.28154792 & 0.13934373 & FALSE & FALSE & FALSE \\
\hline & 315 & 0.2798717 & 0.13911257 & FALSE & FALSE & FALSE \\
\hline & 229 & 0.21808269 & 0.13091858 & FALSE & FALSE & FALSE \\
\hline & 521 & 0.20954394 & 0.13018992 & FALSE & FALSE & FALSE \\
\hline & 219 & 0.18240802 & 0.12479559 & FALSE & FALSE & FALSE \\
\hline & 411 & 0.17824146 & 0.12530481 & FALSE & FALSE & FALSE \\
\hline & 218 & 0.17748616 & 0.1232979 & FALSE & FALSE & FALSE \\
\hline & 162 & 0.17234433 & 0.12269324 & FALSE & FALSE & FALSE \\
\hline & 1 & 0.17212481 & 0.12300393 & FALSE & FALSE & FALSE \\
\hline & 221 & 0.16980054 & 0.1239147 & FALSE & FALSE & FALSE \\
\hline NA & & 0.16815901 & 0.12097812 & FALSE & FALSE & FALSE \\
\hline NA & & 0.16815901 & 0.12097812 & FALSE & FALSE & FALSE \\
\hline & 95 & 0.15706174 & 0.11871881 & FALSE & FALSE & FALSE \\
\hline & 411 & 0.14468155 & 0.11591839 & FALSE & FALSE & FALSE \\
\hline & 23 & $0.1389 / 261$ & 0.11354993 & FALSE & FALSE & FALSE \\
\hline NA & & 0.13096179 & 0.11149072 & FALSE & FALSE & FALSE \\
\hline & 418 & 0.12965953 & 0.11115586 & FALSE & FALSE & FALSE \\
\hline & 220 & 0.12007945 & 0.10722102 & FALSE & FALSE & FALSE \\
\hline & 60 & 0.11502143 & 0.10310093 & FALSE & FALSE & FALSE \\
\hline & 154 & 0.11389058 & 0.10533955 & FALSE & FALSE & FALSE \\
\hline & 158 & 0.10742225 & 0.10392821 & FALSE & FALSE & FALSE \\
\hline & 243 & 0.10576886 & 0.10177004 & FALSE & FALSE & FALSE \\
\hline & 35 & 0.10035008 & 0.09940176 & FALSE & FALSE & FALSE \\
\hline & 200 & 0.08853067 & 0.15415457 & FALSE & FALSE & FALSE \\
\hline & 360 & 0.08144329 & 0.09026023 & FALSE & FALSE & FALSE \\
\hline & 205 & 0.07620147 & 0.14974382 & FALSE & FALSE & \\
\hline
\end{tabular}




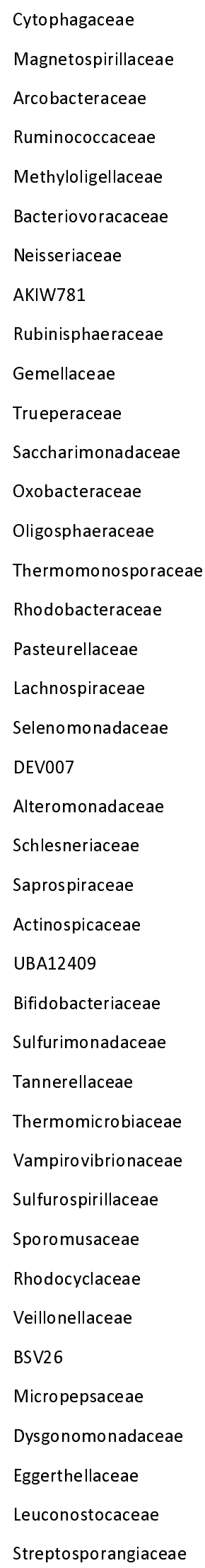

\begin{tabular}{|c|c|c|c|c|}
\hline 19 & 0.07041701 & 0.08371033 & FALSE & FALSE \\
\hline 308 & 0.06858003 & 0.09539432 & FALSE & FALSE \\
\hline 217 & 0.06132036 & 0.07754565 & FALSE & FALSE \\
\hline 4 & 0.05736914 & 0.07498634 & FALSE & FALSE \\
\hline 99 & 0.05513853 & 0.07494552 & FALSE & FALSE \\
\hline 58 & 0.04963317 & 0.07027572 & FALSE & FALSE \\
\hline 117 & 0.04484694 & 0.06957396 & FALSE & FALSE \\
\hline 65 & 0.04173726 & 0.06354817 & FALSE & FALSE \\
\hline 20 & 0.04112421 & 0.063642 & FALSE & FALSE \\
\hline 250 & 0.03846134 & 0.06204274 & FALSE & FALSE \\
\hline 250 & 0.03685005 & 0.06030392 & FALSE & FALSE \\
\hline 250 & 0.03685005 & 0.06030392 & FALSE & FALSE \\
\hline 250 & 0.03685005 & 0.06030392 & FALSE & FALSE \\
\hline 284 & 0.03302006 & 0.05765196 & FALSE & FALSE \\
\hline 119 & 0.0249567 & 0.0495929 & FALSE & FALSE \\
\hline 22 & 0.02005565 & 0.04473901 & FALSE & FALSE \\
\hline 302 & 0.01828478 & 0.04338533 & FALSE & FALSE \\
\hline 104 & 0.01781246 & 0.05359081 & FALSE & FALSE \\
\hline 302 & 0.01553585 & 0.04045114 & FALSE & FALSE \\
\hline 369 & 0.01132861 & 0.0358079 & FALSE & FALSE \\
\hline 64 & 0.0105716 & 0.04212393 & FALSE & FALSE \\
\hline 26 & 0.01026488 & 0.03455747 & FALSE & FALSE \\
\hline 199 & 0.00747033 & 0.03160117 & FALSE & FALSE \\
\hline 327 & 0.00683266 & 0.03874494 & FALSE & FALSE \\
\hline 56 & 0.00375163 & 0.02858096 & FALSE & FALSE \\
\hline 267 & 0.00373363 & 0.02719774 & FALSE & FALSE \\
\hline 222 & 0.00269238 & 0.02610891 & FALSE & FALSE \\
\hline 268 & 0.0022849 & 0.02572081 & FALSE & FALSE \\
\hline 221 & 0.00193853 & 0.02508234 & FALSE & FALSE \\
\hline 299 & 0.00166096 & 0.02470817 & FALSE & FALSE \\
\hline 512 & 0 & 1.41266348 & FALSE & FALSE \\
\hline 55 & 0 & 0.53576159 & FALSE & FALSE \\
\hline \multirow[t]{2}{*}{339} & 0 & 0.46270774 & FALSE & FALSE \\
\hline & 0 & 0.28029337 & FALSE & FALSE \\
\hline 26 & 0 & 0.1916218 & FALSE & FALSE \\
\hline 22 & 0 & 0.17047885 & FALSE & FALSE \\
\hline \multirow[t]{3}{*}{320} & 0 & 0.10911275 & FALSE & FALSE \\
\hline & 0 & 0.10837229 & FALSE & FALSE \\
\hline & 0 & 0.10837229 & FALSE & FALSE \\
\hline 267 & 0 & 0.09141077 & FALSE & FALSE \\
\hline
\end{tabular}




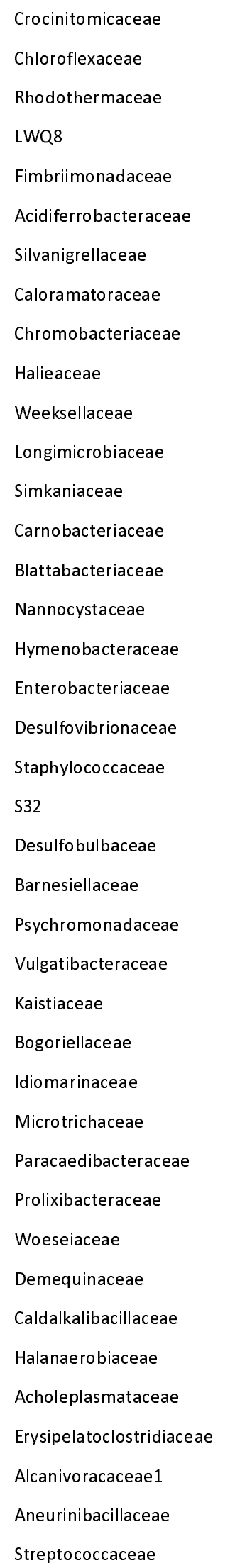

\begin{tabular}{|c|c|c|c|c|c|c|}
\hline & 7 & 0 & 0.08330471 & FALSE & FALSE & FALSE \\
\hline & 73 & 0 & 0.06733627 & FALSE & FALSE & FALSE \\
\hline \multirow[t]{12}{*}{ NA } & & 0 & 0.05466097 & FALSE & FALSE & FALSE \\
\hline & 240 & 0 & 0.03622526 & FALSE & FALSE & FALSE \\
\hline & 415 & 0 & 0.03347359 & FALSE & FALSE & FALSE \\
\hline & 67 & 0 & 0.02598065 & FALSE & FALSE & FALSE \\
\hline & 5 & 0 & 0.02305175 & FALSE & FALSE & FALSE \\
\hline & 416 & 0 & 0.02255735 & FALSE & FALSE & FALSE \\
\hline & 92 & 0 & 0.02255735 & FALSE & FALSE & FALSE \\
\hline & 272 & 0 & 0.02226287 & FALSE & FALSE & FALSE \\
\hline & 26 & 0 & 0.02212612 & FALSE & FALSE & FALSE \\
\hline & 57 & 0 & 0.0220318 & FALSE & FALSE & FALSE \\
\hline & 5 & 0 & 0.02027306 & FALSE & FALSE & FALSE \\
\hline & 538 & 0 & 0.0185994 & FALSE & FALSE & FALSE \\
\hline \multirow[t]{18}{*}{ NA } & & 0 & 0.0148498 & FALSE & FALSE & FALSE \\
\hline & 3 & 0 & 0.01281651 & FALSE & FALSE & FALSE \\
\hline & 96 & 0 & 0.01103008 & FALSE & FALSE & FALSE \\
\hline & 281 & -0.001057 & 0.02115837 & FALSE & FALSE & FALSE \\
\hline & 419 & -0.0016626 & 0.02045536 & FALSE & FALSE & FALSE \\
\hline & 22 & -0.0459734 & 0.15984776 & FALSE & FALSE & FALSE \\
\hline & 418 & -0.17952 & 4.0598948 & FALSE & FALSE & FALSE \\
\hline & 408 & -0.9083787 & 105.776702 & FALSE & FALSE & FALSE \\
\hline & 408 & -0.9083787 & 105.776702 & FALSE & FALSE & FALSE \\
\hline & 278 & -1.7288246 & 91.5697065 & FALSE & FALSE & FALSE \\
\hline & 84 & -1.7783036 & 1.20791225 & FALSE & FALSE & FALSE \\
\hline & 324 & -1.8310767 & 83.8592642 & FALSE & FALSE & FALSE \\
\hline & 280 & -1.8538133 & 80.2846575 & FALSE & FALSE & FALSE \\
\hline & 169 & -2.4796445 & 131.65033 & FALSE & FALSE & FALSE \\
\hline & 85 & -2.9002719 & 609.137226 & FALSE & FALSE & FALSE \\
\hline & 13 & -2.9232174 & 367.275503 & FALSE & FALSE & FALSE \\
\hline & 13 & -3.0826234 & 175.050572 & FALSE & FALSE & FALSE \\
\hline & 73 & -3.1008482 & 168.423304 & FALSE & FALSE & FALSE \\
\hline \multirow[t]{8}{*}{ NA } & & -3.2695624 & 121.800573 & FALSE & FALSE & FALSE \\
\hline & 20 & -3.3221406 & 114.828941 & FALSE & FALSE & FALSE \\
\hline & 75 & -3.5777428 & 90.7245235 & FALSE & FALSE & FALSE \\
\hline & 111 & -3.6316076 & 87.8364168 & FALSE & FALSE & FALSE \\
\hline & 96 & -3.7160219 & 84.1578126 & FALSE & FALSE & FALSE \\
\hline & 70 & -3.7730001 & 82.1393022 & FALSE & FALSE & FALSE \\
\hline & 84 & -3.8207342 & 80.6500404 & FALSE & FALSE & FALSE \\
\hline & 56 & -4.0198736 & 76.1528722 & FALSE & FALSE & FALSE \\
\hline
\end{tabular}




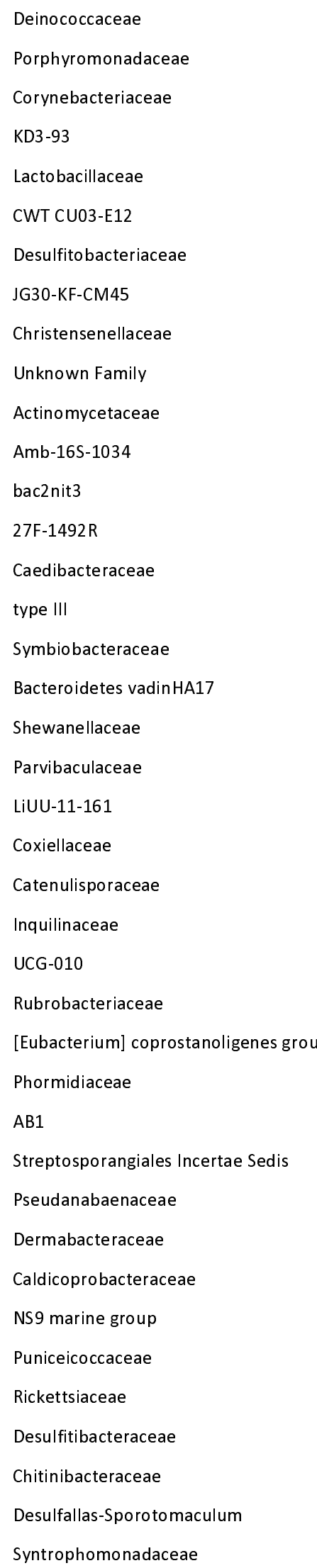

\begin{tabular}{|c|c|c|c|c|c|c|}
\hline & 60 & -4.0612542 & 75.4414778 & FALSE & FALSE & FALSE \\
\hline & 23 & -7.0024208 & 86.3138376 & FALSE & FALSE & FALSE \\
\hline & 42 & -14.232355 & 203.724539 & FALSE & FALSE & FALSE \\
\hline NA & & NA & NA & FALSE & FALSE & FALSE \\
\hline NA & & NA & NA & FALSE & FALSE & FALSE \\
\hline NA & & NA & NA & FALSE & FALSE & FALSE \\
\hline NA & & NA & NA & FALSE & FALSE & FALSE \\
\hline NA & & NA & NA & FALSE & FALSE & FALSE \\
\hline NA & & NA & NA & FALSE & FALSE & FALSE \\
\hline NA & & NA & NA & FALSE & FALSE & FALSE \\
\hline NA & & NA & NA & FALSE & FALSE & FALSE \\
\hline NA & & NA & NA & FALSE & FALSE & FALSE \\
\hline NA & & NA & NA & FALSE & FALSE & FALSE \\
\hline NA & & NA & NA & FALSE & FALSE & FALSE \\
\hline NA & & NA & NA & FALSE & FALSE & FALSE \\
\hline NA & & NA & NA & FALSE & FALSE & FALSE \\
\hline NA & & NA & NA & FALSE & FALSE & FALSE \\
\hline NA & & NA & NA & FALSE & FALSE & FALSE \\
\hline NA & & NA & NA & FALSE & FALSE & FALSE \\
\hline NA & & NA & NA & FALSE & FALSE & FALSE \\
\hline NA & & NA & NA & FALSE & FALSE & FALSE \\
\hline NA & & NA & NA & FALSE & FALSE & FALSE \\
\hline NA & & NA & NA & FALSE & FALSE & FALSE \\
\hline NA & & NA & NA & FALSE & FALSE & FALSE \\
\hline NA & & NA & NA & FALSE & FALSE & FALSE \\
\hline NA & & NA & NA & FALSE & FALSE & FALSE \\
\hline NA & & NA & NA & FALSE & FALSE & FALSE \\
\hline NA & & NA & NA & FALSE & FALSE & FALSE \\
\hline NA & & NA & NA & FALSE & FALSE & FALSE \\
\hline NA & & NA & NA & FALSE & FALSE & FALSE \\
\hline NA & & NA & NA & FALSE & FALSE & FALSE \\
\hline NA & & NA & NA & FALSE & FALSE & FALSE \\
\hline NA & & NA & NA & FALSE & FALSE & FALSE \\
\hline NA & & NA & NA & FALSE & FALSE & FALSE \\
\hline NA & & NA & NA & FALSE & FALSE & FALSE \\
\hline NA & & NA & NA & FALSE & FALSE & FALSE \\
\hline NA & & NA & NA & FALSE & FALSE & FALSE \\
\hline NA & & NA & NA & FALSE & FALSE & FALSE \\
\hline NA & & NA & NA & FALSE & FALSE & FALSE \\
\hline NA & & NA & NA & FALSE & FALSE & FALSE \\
\hline
\end{tabular}


832 Supplemental Table 2:

833 Bacterial Family Association Data: Data represents the number of significant SNPs associated with each family,

834 the heritability estimate and standard error, and an indicator for their presence above the occupancy thresholds 0.9

835 and 0.1 for the full ASV dataset and 0.1 for the outlier ASV dataset.

836

\begin{tabular}{|c|c|c|c|c|c|c|c|}
\hline $\begin{array}{l}\text { GO } \\
\text { term } \\
\text { GO:00 }\end{array}$ & $\begin{array}{l}\text { Ontol } \\
\text { ogy }\end{array}$ & Description & $\begin{array}{l}\text { Number in } \\
\text { input list }\end{array}$ & $\begin{array}{l}\text { Number in } \\
\text { BG/Ref }\end{array}$ & $\begin{array}{l}p- \\
\text { value }\end{array}$ & $\begin{array}{l}\text { FDR } \\
0.04\end{array}$ & $\begin{array}{l}\text { Family } \\
\text { Xanthobacte }\end{array}$ \\
\hline GO:00 & $\mathrm{F}$ & ATPase activity & 15 & 698 & 0.0044 & $\begin{array}{r}1 \\
0.02\end{array}$ & $\begin{array}{l}\text { raceae } \\
\text { Xanthobacte }\end{array}$ \\
\hline $\begin{array}{l}16817 \\
\text { GO:00 }\end{array}$ & $\mathrm{F}$ & $\begin{array}{l}\text { hydrolase activity, acting on acid anhydrides } \\
\text { hydrolase activity, acting on acid anhydrides, in }\end{array}$ & 26 & 1415 & 0.0019 & $\begin{array}{r}5 \\
0.02\end{array}$ & $\begin{array}{l}\text { raceae } \\
\text { Xanthobacte }\end{array}$ \\
\hline 16818 & $\mathrm{~F}$ & phosphorus-containing anhydrides & 26 & 1391 & 0.0015 & & raceae \\
\hline GO:00 & $\mathrm{F}$ & ligase activity & 16 & 600 & $\begin{array}{r}0.0003 \\
8\end{array}$ & $\begin{array}{r}0.02 \\
5\end{array}$ & $\begin{array}{l}\text { Xanthobacte } \\
\text { raceae }\end{array}$ \\
\hline GO:00 & & & & & & 0.04 & Xanthobacte \\
\hline 03774 & $\mathrm{~F}$ & motor activity & 6 & 152 & 0.0045 & 1 & raceae \\
\hline GO:00 & & & & & 0.0007 & 0.02 & Xanthobacte \\
\hline $\begin{array}{l}17111 \\
\text { GO:00 }\end{array}$ & $\mathrm{F}$ & nucleoside-triphosphatase activity & 26 & 1324 & 5 & $\begin{array}{r}5 \\
0.02\end{array}$ & $\begin{array}{l}\text { raceae } \\
\text { Xanthobacte }\end{array}$ \\
\hline $\begin{array}{l}16462 \\
\text { GO:00 }\end{array}$ & $\mathrm{F}$ & pyrophosphatase activity & 26 & 1357 & 0.0011 & $\begin{array}{r}5 \\
0.02\end{array}$ & $\begin{array}{l}\text { raceae } \\
\text { Xanthobacte }\end{array}$ \\
\hline $\begin{array}{l}19787 \\
\text { GO:00 }\end{array}$ & $\mathrm{F}$ & small conjugating protein ligase activity & 6 & 130 & 0.0021 & $\begin{array}{r}5 \\
0.02\end{array}$ & $\begin{array}{l}\text { raceae } \\
\text { Xanthobacte }\end{array}$ \\
\hline 04842 & $\mathrm{~F}$ & ubiquitin-protein ligase activity & 6 & 130 & 0.0021 & 5 & raceae \\
\hline GO:00 & & & & & & 0.03 & Sphingomon \\
\hline $\begin{array}{l}05623 \\
\text { GO:00 }\end{array}$ & C & cell & 103 & 8213 & 0.0085 & $\begin{array}{r}7 \\
0.03\end{array}$ & $\begin{array}{l}\text { adaceae } \\
\text { Sphingomon }\end{array}$ \\
\hline $\begin{array}{l}44464 \\
\text { GO:00 }\end{array}$ & $\mathrm{C}$ & cell part & 103 & 8213 & 0.0085 & $\begin{array}{r}7 \\
0.03\end{array}$ & $\begin{array}{l}\text { adaceae } \\
\text { Sphingomon }\end{array}$ \\
\hline $\begin{array}{l}\text { 16021 } \\
\text { GO:00 }\end{array}$ & $\mathrm{C}$ & integral to membrane & 27 & 1616 & 0.0083 & $\begin{array}{r}7 \\
0.03\end{array}$ & $\begin{array}{l}\text { adaceae } \\
\text { Sphingomon }\end{array}$ \\
\hline $\begin{array}{l}31224 \\
\text { GO:00 }\end{array}$ & C & intrinsic to membrane & 27 & 1651 & 0.011 & $\begin{array}{r}9 \\
0.03\end{array}$ & $\begin{array}{l}\text { adaceae } \\
\text { Sphingomon }\end{array}$ \\
\hline 16020 & C & membrane & 58 & 4123 & 0.0063 & 7 & adaceae \\
\hline GO:00 & & & & & 0.0005 & 0.01 & Sphingomon \\
\hline 44425 & C & membrane part & 37 & 2042 & 2 & 2 & adaceae \\
\hline GO:00 & & & & & & 0.02 & Sphingomon \\
\hline 04222 & $\mathrm{~F}$ & metalloendopeptidase activity & 6 & 100 & 0.0007 & 8 & adaceae \\
\hline GO:00 & & & & & 0.0000 & 0.00 & Sphingomon \\
\hline 08237 & $\mathrm{~F}$ & metallopeptidase activity & 8 & 119 & 44 & 35 & adaceae \\
\hline GO:00 & & & & & & 0.02 & Sphingomon \\
\hline 70727 & $\mathrm{P}$ & cellular macromolecule localization & 10 & 311 & 0.0016 & 6 & adaceae \\
\hline GO:00 & & & & & 0.0006 & 0.01 & Sphingomon \\
\hline 44237 & $\mathrm{P}$ & cellular metabolic process & 142 & 11155 & 9 & 6 & adaceae \\
\hline GO:00 & & & & & 0.0000 & 0.00 & Sphingomon \\
\hline $\begin{array}{l}09987 \\
\text { GO:00 }\end{array}$ & $P$ & cellular process & 190 & 14248 & 0079 & $\begin{array}{r}0091 \\
0.02\end{array}$ & $\begin{array}{l}\text { adaceae } \\
\text { Sphingomon }\end{array}$ \\
\hline 34613 & $\mathrm{P}$ & cellular protein localization & 10 & 311 & 0.0016 & 6 & adaceae \\
\hline GO:00 & & & & & 0.0001 & 0.00 & Sphingomon \\
\hline 09719 & $\mathrm{P}$ & response to endogenous stimulus & 5 & 48 & 9 & 54 & adaceae \\
\hline GO:00 & & & & & 0.0001 & 0.00 & Sphingomon \\
\hline 09725 & $\mathrm{P}$ & response to hormone stimulus & 5 & 48 & 9 & 54 & adaceae \\
\hline GO:00 & & & & & 0.0001 & 0.00 & Sphingomon \\
\hline 10033 & $\mathrm{P}$ & response to organic substance & 5 & 48 & 9 & 54 & adaceae \\
\hline GO:00 & & & & & & 0.04 & Micromonos \\
\hline 08026 & $\mathrm{~F}$ & ATP-dependent helicase activity & 5 & 232 & 0.0084 & 4 & poraceae \\
\hline GO:00 & & & & & & 0.00 & Micromonos \\
\hline 16887 & $\mathrm{~F}$ & ATPase activity & 12 & 698 & 0.0004 & 41 & poraceae \\
\hline GO:00 & & & & & 0.0004 & 0.00 & Micromonos \\
\hline 42623 & $\mathrm{~F}$ & ATPase activity, coupled & 9 & 422 & 8 & 42 & poraceae \\
\hline GO:00 & & & & & & 0.03 & Micromonos \\
\hline 04386 & $\mathrm{~F}$ & helicase activity & 8 & 477 & 0.0042 & 1 & poraceae \\
\hline GO:00 & & & & & & 0.04 & Micromonos \\
\hline $\begin{array}{l}16787 \\
\text { GO:00 }\end{array}$ & $\mathrm{F}$ & hydrolase activity & 43 & 5652 & 0.0075 & & poraceae \\
\hline $\begin{array}{l}\text { GO:00 } \\
16817\end{array}$ & $\mathrm{~F}$ & hydrolase activity, acting on ac & 19 & 1415 & $\begin{array}{r}0.0002 \\
1\end{array}$ & $\begin{array}{r}0.00 \\
27\end{array}$ & $\begin{array}{l}\text { Micromonos } \\
\text { poraceae }\end{array}$ \\
\hline GO:00 & & hydrolase activity, acting on acid anhydrides, in & & & 0.0001 & 0.00 & Micromonos \\
\hline 16818 & $\mathrm{~F}$ & phosphorus-containing anhydrides & 19 & 1391 & 7 & 27 & poraceae \\
\hline
\end{tabular}


GO:00

17111

GO:00

70035

GO:00

16462

GO:00

07242

GO:00

07264

837

Supplemental Table 3:

F nucleoside-triphosphatase activity

F purine NTP-dependent helicase activity

F pyrophosphatase activity

P intracellular signaling cascade

small GTPase mediated signal transduction

$\begin{array}{rrrrl}19 & 1324 & 0.0000 & 0.00 & \text { Micromonos } \\ & & 9 & 0.04 & \text { poraceae } \\ & & & \text { Micromonos } \\ 5 & 232 & 0.0084 & 4 & \text { poraceae } \\ & & 0.0001 & 0.00 & \text { Micromonos } \\ 19 & 1357 & 2 & 27 & \text { poraceae } \\ & & & 0.04 & \text { Micromonos } \\ 7 & 291 & 0.001 & 1 & \text { poraceae } \\ & & & 0.04 & \text { Micromonos } \\ 7 & 289 & 0.001 & 1 & \text { poraceae }\end{array}$

838 GO Term Data: Data represents the Ontologies, Descriptions, Number of genes in the input list and reference genome, p-value, and FDR for GO terms associated with Xanthobacteraceae, Sphingomonadaceae, and Micromonosporaceae abundances. 